\title{
IV. Soziale Probleme der Vertriebenen-Integration
}




\section{Marcel Boldorf \\ Fürsorgeunterstützung in Deutschland unter dem Einfluß der Zwangsmigrationen der Nachkriegszeit (1945-1952)}

Die Bewältigung der Krisensituation nach 1945 bietet für einen die Fürsorge betreffenden Vergleich beider deutschen Staaten ein günstiges Untersuchungsfeld, da sich die Problemlagen ähnelten. In der Langzeitperspektive änderte sich dies, weil die Fürsorge in der DDR aufgrund ihres schrumpfenden Umfangs ein an Gewicht verlierendes, im Westen hingegen seit den 1970 er Jahren ein wachsendes Problem darstellte. Der Schwerpunkt der folgenden Untersuchung liegt auf der SBZ/DDR, da hier auf Archivmaterial zurückgegriffen wurde. An mancher Stelle konnte der Vergleich mit Westdeutschland anhand der vorliegenden Forschungsergebnisse sowie der Auswertung gedruckter Quellen gezogen werden.

Die wesentliche Ursache für die Ausweitung des Fürsorgeempfangs in der Nachkriegszeit waren die Zwangsmigrationen von Millionen Menschen infolge des Zweiten Weltkrieges. Wie jede Bevölkerungsbewegung solchen Ausmaßes führte die Vertreibung der deutschstämmigen Bevölkerung zu einer sozialen Deklassierung der betroffenen Migranten. Besonders anschaulich zeigt dies der hohe Anteil der Flüchtlinge und Vertriebenen an den Fürsorgeempfängern. In Sachsen lag er 1946 und 1947 zwischen 31 und 39 Prozent ${ }^{1}$. Als sich die Zahl der Fürsorgeempfänger Ende 1948 im Zuge verschärfter Bedürftigkeitsprüfungen und der Einschränkung der Freistellungskriterien von Arbeitseinsatz für alleinerziehende Frauen ${ }^{2}$ entscheidend verminderte, stieg der Anteil der Umsiedler auf über 45 Prozent. Ein ähnliches Bild wiesen die Statistiken in Sachsen-Anhalt auf 3 . Nach dem Einschnitt in der Fürsorgestatistik zählten dort Ende 1948 sogar 63,2 Prozent der Unterstützten zu den Umsiedlern. Der Anteil verminderte sich auf 58,1 Prozent (Dezember 1949) und 51,9 Prozent (Dezember 1950). Es zeigt sich am Beispiel der beiden bevölkerungsreichsten Länder der SBZ, in denen durchschnittlich zwei Drittel aller Fürsorgeempfänger lebten, daß weitaus mehr Umsiedler Fürsorgeunterstützung erhielten, als es ihrem Gewicht an der Gesamtbevölkerung, rund 24 Prozent gegen Ende der Hauptzuwanderungsphase, ${ }^{4}$ entsprach.

1 MfAS Sachsen, Statistiken vom 30. 6. 1946 und 18.12. 1946, in: BAB, DQ 2/3785; Statistiken vom 24. 4. 1947 und 17. 7. 1947, in: BAB, DQ 2/3786; Statistik vom 6. 5. 1949, in: BAB, DQ 2/3775.

2 ZVOBl. 1948, S. 469. 2. Durchführungsverordnung zur Verordnung über Sozialfürsorge vom 21. 9. 1948. $\$ 2(5)$. Für alleinerziehende Fürsorgeempfängerinnen wurden die Altersgrenzen ihrer Kinder, die zur Freistellung berechtigten, von 15 auf 8 bei zwei Kindern und von 6 auf 3 Jahre bei cinem Kind gesenkt. Dies machte mit einem Schlag über 100000 Frauen arbeitseinsatzpflichtig.

${ }^{3}$ MfAS Sachsen-Anhalt, Bericht über den Stand der Sozialfürsorge in den Jahren 1948-1950, 14. 2. 1951, in: BAB, DQ 2/3755.

${ }^{4}$ Hoffmann / Wille / Meinicke, Flüchtlinge, S. 19. 
Nicht so deutlich schien dieser Zusammenhang in der Bundesrepublik hervorzutreten, wo im ersten Halbjahr 1950 von fast 1,4 Millionen Unterstützungsempfängern rund 28 Prozent als „Heimatvertriebene“ und über sechs Prozent als Evakuierte erfaßt waren 5 . Bei dieser Angabe gilt es allerdings zu beachten, daß die offene Fürsorge durch die Unterhaltshilfe des Soforthilfegesetzes, auf das später zurückzukommen sein wird, wesentlich entlastet wurde. Bis zum 1. Juni 1950 waren über 428000 Anträge bewilligt worden 6 . Diese Unterhaltshilfeempfänger waren mit Ausnahme einer unbestimmten Anzahl von Heimbewohnern zuvor in offener Fürsorge Unterstützte. Sie empfingen ihre Unterstützungen nun nicht mehr aus kommunalen Mitteln, sondern aus dem Bundeshaushalt und wurden daher in der Fürsorgestatistik nicht mehr erfaßt. Gleichwohl sind sie, zumal in der SBZ/DDR ein entsprechendes Versorgungssystem fehlte, zu den Unterstützungsfällen zu rechnen. Daher kann auch in der Bundesrepublik die Quote der Vertriebenen an der Gesamtzahl der Empfänger öffentlicher Unterstützungsleistungen auf mehr als 45 Prozent geschätzt werden - bei einem Anteil der Vertriebenen von ca. 16,5 Prozent an der Gesamtbevölkerung ${ }^{7}$ in den frühen 1950 er Jahren.

Die Entwurzelung von Millionen Menschen bildete den Kern des Unterstützungsproblems der Nachkriegszeit. Die Fürsorgeempfänger konnten in der allgemeinen Not der Nachkriegsjahre als die am härtesten betroffene Bevölkerungsschicht gelten. Die Handlungsspielräume, die in der SBZ während der drei unterscheidbaren Phasen der Flüchtlingsansiedlung bestanden, können nachgezeichnet werden. Da das Ergebnis der Ansiedlung demjenigen im Westen gleicht, wird hiernach für beide Teile Deutschlands untersucht, inwiefern sich die regionale Verteilung der Flüchtlinge mit der registrierten Armut in Zusammenhang bringen läßt. Ferner soll ein Vergleich des Niveaus der materiellen Unterstützung in Ost und West gezogen werden.

\section{Das Ergebnis der Flüchtlingslenkung}

In den bisherigen Forschungen zur SBZ wurde bislang nur an ausgewählten Zeitpunkten der Ist-Stand der aufgenommenen Umsiedler in den einzelnen Ländern und Provinzen erhoben ${ }^{8}$.Wenig Beachtung fanden hingegen die einzelnen Phasen, in denen sich die Bedingungen für die Aufnahme des Flüchtlingsstromes allmählich änderten. Die regional unterschiedliche Belastung der Aufnahmegebiete entsprang sozialen, wirtschaftlichen und politischen Determinanten, die in ihrem Wandel untersucht werden sollen. Hieran lassen sich mögliche Alternativen aufzeigen, die bei der Lenkung der Ansiedlung bestanden.

Nach Kriegsende herrschten völlig unklare Vorstellungen über das Ausmaß der Migrationsbewegungen. Im Juli 1945 ging eine irreale Schätzung der SBZ-Verwaltungsbehörden davon aus, daß 12 bis 12,5 Millionen Personen allein in der eigenen Besatzungszone aufzunehmen seien'. Angesichts solcher Prognosen entwickelte sich vielerorts eine Abwehrhaltung gegen die Flüchtlingsströme. Die sächsische Landesverwaltung glaubte, daß die bis zum Winter erwarteten zwei Millionen Umsiedler weder untergebracht noch ernährt werden könnten, weil durch ihren Zuzug die Versorgung der „eigene[n] Be-

${ }^{5}$ Wirtschaft und Statistik N. F. 3 (1951), S. 33.

${ }^{6}$ Ebenda, S. 36.

7 Stat. Jb. Bundesrepublik 1952, S. 30.

${ }^{8}$ Vgl. z. B. Hoffmann / Wille / Meinicke, Flüchtlinge, S. 19; Wille, Zentralverwaltung, S. 34; Meinicke, Probleme der Integration, S. 3.

9 Wille, Zentralverwaltung, S. 28; Hoffmann / Wille / Meinicke, Flüchtlinge, S. 14. 
völkerung Sachsens" ${ }^{10}$ gefährdet sei. Entsprechend verfügte man einen Aufnahmestopp, der bis März 1946 aufrecht erhalten wurde. Dasselbe galt für andere urban geprägte Gebiete Deutschlands, wie zum Beispiel für das Ruhrgebiet und Berlin. Die aufgenommenen Migranten sollten aus Sachsen in andere Gebiete der SBZ weitergeleitet werden, sofern sie nicht in einem geregelten Arbeitsverhältnis standen. Der vollständige Abtransport der zum Teil bereits seßhaft gewordenen Umsiedler war unmöglich. Dennoch hatte der Plan der sächsischen Landesverwaltung Auswirkungen, wie der Rückgang der registrierten Umsiedler, zu denen zum Teil allerdings Evakuierte gezählt wurden, von 686017 Personen im November $1945^{11}$ auf 544799 am 1. Juni 1946 zeigte. Aufgrund der Abwehrhaltung der urbanen Regionen erfolgte die Ansiedlung in ländlichen Gebieten.

Erst durch Kontrollratsentscheid im November 1945 wurden Quoten beschlossen, nach denen eine „angemessene Verteilung“ der Flüchtlingsbevölkerung auf die Besatzungszonen erfolgen sollte ${ }^{12}$. Für eine Lenkung nach einem langfristigen Plan fehlten nach wie vor die Voraussetzungen. Auf Kontrollratsebene beschränkte sich die Behandlung des Flüchtlingsproblems auf Fragen des Transports ${ }^{13}$. Die Alliierten hielten an der Ansiedlung in Gebieten mit geringer Bevölkerungsdichte fest, da in den agrarisch strukturierten Regionen das Ernährungs- und das Wohnraumproblem am leichtesten zu lösen waren. Gesichtspunkte der langfristigen wirtschaftlichen Trag- und Entwicklungsfähigkeit spielten keine Rolle.

Während die Aufnahme der Massentransporte in der US-amerikanischen Besatzungszone (USBZ) im Januar 1946 begann, ${ }^{14}$ sprach man in der SBZ ab Mitte 1946 von „planmäßigen Aktionen“, nach denen die Lenkung der Wanderung erfolgte. Bis zu diesem Zeitpunkt waren bereits, wie in Tabelle $1 \mathrm{zu}$ sehen, über drei Millionen Flüchtlinge und

Tabelle 1: Lenkung der Umsiedler in der SBZ während der Hauptzuwanderungsphase (1946-1948)

\begin{tabular}{|l|r|r|r|r|r|r|}
\hline Zeitraum & Sachsen & $\begin{array}{c}\text { Sachsen- } \\
\text { Anhalt }\end{array}$ & $\begin{array}{c}\text { Thürin- } \\
\text { gen }\end{array}$ & $\begin{array}{c}\text { Branden- } \\
\text { burg }\end{array}$ & $\begin{array}{c}\text { Mecklen- } \\
\text { burg }\end{array}$ & SBZ \\
\hline bis 1.6.46 & 544799 & 680933 & 488456 & 590649 & 837901 & 3142738 \\
1.6 bis 31.12.46 & 271943 & 330993 & 162638 & 86244 & 231791 & 1083609 \\
1947 & 268251 & 190026 & 134000 & 57511 & 22087 & 671875 \\
1948 & 92673 & 25448 & 30403 & 15328 & 1119 & 164971 \\
\hline Summe & 1177666 & 1227400 & 815497 & 749732 & 1092898 & 5063193 \\
\hline Registrierte am 1.1.49 & 997798 & 1051024 & 685913 & 655466 & 922088 & 4312289 \\
\hline
\end{tabular}

${ }^{10}$ Auch zum Folgenden: Rundverfügung der sächsischen Landesverwaltung, Abt. Inneres und Volksbildung, 10. 8. 1945, in : BAB, DQ-1/5548.

11 Wille, Zentralverwaltung, S. 34.

${ }^{12}$ Müller/Simon, Aufnahme, S. 315.

${ }^{13}$ Schraut, Flüchtlingsaufnahme, S. 41. Zur Genese des Verteilungsplanes im Kontrollrat unter besonderer Berücksichtigung der US-amerikanischen Haltung: Ebenda, S. 40-48.

14 Ebenda, S. 47.

15 DVdI, HA Umsiedler, Gesamtzahl der in die SBZ gekommenen Umsiedler nach Aufnahmeländern, 19.4. 1949, in: BAB, DO 1/10/19. Evakuierte sind hier nicht ausgewiesen, wie der Vergleich mit Meinicke, Probleme der Integration, S. 3, zeigt. Die Differenz von 750904 Umsiedlern zwischen der "Summe“ und den „Registrierten am 1.1.49" erfaßt die Zahl derer, die sich nur kurzzeitig in der SBZ niederließen und bis Ende 1948 in die Westzonen weiterzogen. Da die im ersten Halbjahr 1946 Abgewanderten nicht erfaßt sind, stimmt diese Angabe in der Größenordnung mit derjeinigen bei Heidemeyer, Flucht und Zuwanderung, S. 42-43, auf der Grundlage westdeutscher Volkszählung überein (844000 Flüchtlinge von 1946 bis 1948). 
Vertriebene ungeregelt in die SBZ eingeströmt. In der Statistik wurde für die Migration des Jahres 1945 und des ersten Halbjahres 1946 die Ist-Zahl am 1. Juni 1946 eingesetzt $^{16}$. Erst nach diesem Stichtag konnte die Zahl der aufgenommenen Umsiedler genau erfaßt werden.

Die beiden ersten sogenannten „planmäßigen Aktionen“ betrafen rund „600000 Umsiedler" aus der CSR und 405401 vertriebene Deutschstämmige aus den Gebieten östlich von Oder und Neiße. Die Planungen zur Aufnahme der Umsiedler aus dem Sudetenland begannen im April 1946. Die sowjetischen Besatzungsorgane legten einen Aufteilungsschlüssel fest, an dem sich die Zentralverwaltung für deutsche Umsiedler (ZVU) zu orientieren hatte ${ }^{17}$. Sachsen war als Aufnahmegebiet überhaupt nicht vorgesehen. An diese Vorgabe hielt sich die ZVU bei ihren Ausarbeitungen zum konkreten Ablauf, versuchte allerdings eine geringere Belastung Mecklenburgs zu erwirken. Die SMAD lehnte dies ab. Die Transporte aus der CSR wurden durch Sachsen geschleust und zu 37,7 Prozent in Mecklenburg und zu 35,5 Prozent in der Provinz Sachsen angesiedelt. Nur 1450 Sudetendeutsche ließen sich in Sachsen nieder, wie aus der folgenden Tabelle hervorgeht, die die Flüchtlingszuweisung in den beiden ersten "planmäßigen Aktionen“ zeigt.

Tabelle 2: Verteilung der Umsiedler auf die Länder der SBZ im zweiten Halbjahr $1946^{18}$

\begin{tabular}{|c|c|c|c|c|c|}
\hline & Sachsen & $\begin{array}{l}\text { Provinz } \\
\text { Sachsen }\end{array}$ & Thüringen & $\begin{array}{l}\text { Branden- } \\
\text { burg }\end{array}$ & $\begin{array}{l}\text { Mecklen- } \\
\text { burg }\end{array}$ \\
\hline CSR & 1450 & 205518 & 116458 & 41585 & 221028 \\
\hline $\begin{array}{l}\text { Gebiete östl. von } \\
\text { Oder und Neiße }\end{array}$ & 259582 & 87246 & 28211 & 30362 & - \\
\hline Gesamtzahl & 261032 & 292764 & 144669 & 71947 & 221028 \\
\hline
\end{tabular}

Bei den Transporten aus den polnischen Gebieten wurde ähnlich verfahren. Sie wurden zu 64 Prozent nach Sachsen gelenkt, in Mecklenburg ließ sich kein einziger dieser Umsiedler nieder. Es ist anzunehmen, daß diese Vorgehensweise der Tendenz entgegenwirken sollte, in den Gebieten, die an die ehemaligen Wohngegenden grenzten, zu siedeln ${ }^{19}$. Vielfach bestand die Hoffnung auf eine Rückkehr in die Heimat, die nach Möglichkeit im Keim erstickt werden sollte. Die Lenkung der Ansiedlung schien im zweiten Halbjahr 1946 eher von politischen als von wirtschaftlichen Zielsetzungen geleitet zu sein, denn die Erfordernisse des Arbeitsmarktes hätten nach einem anderen Verteilungsschlüssel verlangt.

Zu dieser Einsicht gelangte auch die Deutsche Verwaltung für Arbeit und Sozialfürsorge (DVAS). Von deren Seite wurde eine berufsbezogene Lenkung verlangt, welche die ankommenden Transporte in einen der Wirtschaftsstruktur ihres Herkunftsgebietes entsprechenden Kreis führen sollte ${ }^{20}$. Zum Beispiel ersuchte die Deutsche Verwaltung für

16 DVdI, HA Umsiedler, Bericht über die Gesamtzahl der in die SBZ gekommenen Umsiedler, 19. 4. 1949, in: BAB, DO 1/10/19.

${ }^{17}$ Bethke, Der Weg der Deutschen, S. 16-18.

18 ZVU, Verteilung der „600000 Umsiedler“ aus der CSR (Juni-Oktober 1946); Übernahme von rund 400000 Umsiedlern aus den Gebieten östlich von Oder und Neiße (Juli-Dezember 1946), 1. 1. 1947 , in: BAB, DO 1/10/13.

19 Vgl. Seraphim, Heimatvertriebene, S. 12.

20 Bethke, Weg, S. 20. 
Brennstoffindustrie die Zuteilung von Bergarbeitern für die Bergbauregion im Süden der SBZ. Die verlangte Auswahl von Fachkräften konnte nur in Ausnahmefällen vorgenommen werden. In der Regel wurden die Transporte schematisch in die zur Aufnahme bestimmten Gebiete geleitet.

Im November 1946 erließen die DVAS und die ZVU eine gemeinsame Anweisung, die eine arbeitsmarktorientierte Lenkung der Umsiedler vorsah ${ }^{21}$. Die Landesarbeitsämter sollten den Arbeitskräftebedarf, insbesondere denjenigen an Fachkräften, feststellen. Daraufhin war das Aufnahmeland von der DVAS im Einvernehmen mit der ZVU zu bestimmen. Die Festlegung des Vorrangs der Arbeitsvermittlung erfolgte aber erst zu einem Zeitpunkt, als sich bereits der größte Teil der Umsiedler in der SBZ niedergelassen hatte. Die neue Verfahrensweise führte dazu, daß 1947 fast 40 Prozent und 1948 über 56 Prozent der insgesamt registrierten Umsiedler in Sachsen eingebürgert wurden (vgl. Tabelle 1). Dieses Land besaß als eigentliches Industrieland der SBZ die besten Möglichkeiten für eine Arbeitsintegration gemäß den wirtschaftlichen Zielsetzungen in der Mitte der vierziger Jahre. Gleichwohl hatten die Modalitäten der Zuweisung, gemessen an den langfristigen Erfordernissen des Arbeitsmarktes, zu Disproportionen geführt, woran auch der Kurswechsel 1947 nichts mehr ändern konnte. Mecklenburg als reines Agrargebiet nahm im Verhältnis zur Gesamtbevölkerung die meisten Flüchtlinge und Vertriebenen aller deutschen Länder auf. Im April 1949 betrug deren Anteil an der gesamten Landesbevölkerung 43,3 Prozent ${ }^{22}$.

Eine Korrektur der Ergebnisse der Umsiedlerlenkung erreichte die überbezirkliche Arbeitskräftelenkung der Behörden nur in geringem Maße. Es wurde zwar die Umsetzung von einigen Zehntausend Textil-, Glas- und anderen Facharbeitern nach Thüringen oder Sachsen aktenkundig ${ }^{23}$, doch quantitativ gesehen fiel dies, gemessen an der hohen Gesamtzahl der Fehlzuweisungen bis Ende 1946, kaum ins Gewicht. Die Hauptverwaltung für Arbeit und Sozialfürsorge (HVAS) der Deutschen Wirtschaftskommission bezeichnete die Ende der vierziger Jahre einsetzende Wanderung vom Land in die Stadt als „sehr positive[n] Vorgang“. Dieser war aber „nicht etwa die Folge einer planmässigen Lenkung dieser Arbeitskräfte durch die Arbeitsämter [...], sondern tatsächlich mehr oder weniger der eigenen Initiative der Umsiedler “24 zuzuschreiben. Die Löhne, die im gewerblichen Sektor bezahlt wurden, lagen über dem niedrigen Niveau in der Landwirtschaft, so daß ein Anreiz zum Wohnortwechsel bestand. Angesichts der wenig erfolgreichen Bemühungen um eine Behebung der Disproportionen zwischen Qualifikation und Arbeitsunterbringung mußte die HVAS im Jahr 1949 - gemessen an den Erfordernissen des Arbeitsmarktes - eine weitgehende Fehlleitung der Umsiedler feststellen ${ }^{25}$. Statt der erwünschten langfristigen Arbeitsplatzeingliederung im Sekundärsektor lag eine Überbesetzung der Agrarregionen vor, die 1949 in der SBZ auf eine halbe Million Menschen ge-

${ }^{21}$ Anwcisung der DVAS (Brack) und der ZVU (Engel) an die Landes- und Provinzialbehörden für Arbeit und Sozialfürsorge sowie die Landesämter für Umsiedler, 7. 11. 1946, in: BAB, DO 1/10/ 13.

${ }^{22}$ Hoffmann / Wille / Meinicke, Flüchtlinge, S. 19.

${ }^{23}$ HVAS, Wandel der Bevölkerungsstruktur in Beziehung zum Zweijahresplan, 5. 3. 1949, in: BAB, DQ 2/3727; Wille, Zentralverwaltung, S. 22, beziffert die Zahl der Arbeitskräfte, die 1946 innerhalb der SBZ umgesiedelt wurden, auf 16970.

${ }^{24}$ HVAS, Wandel der Bevölkerungsstruktur in Beziehung zum Zweijahresplan, 5. 3. 1949, in: BAB, DQ 2/3727.

${ }^{25}$ Ebenda. 
schätzt wurde ${ }^{26}$. Das Ministerium für Arbeit und Sozialwesen in Sachsen-Anhalt mußte Anfang 1951 feststellen, daß die „nochmalige Umsiedlung in die Schwerpunktgebiete des Landes" noch nicht erfolgt sei ${ }^{27}$.

Das Ergebnis der Zuweisungspolitik in den Westzonen, d. h. vor allem der britischen und amerikanischen Besatzungszone, weil die französische Besatzungszone so gut wie nicht belastet war, unterschied sich kaum von der Lage in der SBZ. Eine wichtige Determinante der amerikanischen Politik war zum Beispiel, die räumliche Ballung der Flüchtlinge zu verhindern, wodurch der regionalen Streuung der Ansiedlung mehr Gewicht als der Arbeitsmarktintegration beigemessen wurde ${ }^{28}$. Insofern konstatierten auch dort bereits zeitgenössische Untersuchungen eine Fehlverteilung der Vertriebenen ${ }^{29}$. Mit wenig Erfolg bemühten sich die westzonalen Verwaltungen seit 1947 um eine Korrektur der festzustellenden Fehlallokationen. Im November 1949 wurde, allerdings auf freiwilliger Basis, eine Binnenumsiedlung von 300000 Vertriebenen, die sich zur Hälfte in Schleswig-Holstein und zu je einem Viertel in Bayern und Niedersachsen angesiedelt hatten, gesetzlich angeordnet ${ }^{30}$. Weitere Umsiedlungsprogramme folgten in den fünfziger Jahren. Auf die Wirkungen im hier untersuchten Zeitraum wird zurückzukommen sein. Es läßt sich für Gesamtdeutschland feststellen, daß die Maßgaben der Zuweisung in die Aufnahmegebiete zur einleitend konstatierten hohen Unterstütztenquote innerhalb der Flüchtlingsbevölkerung führten.

Als zusätzliche Ursache für den vermehrten Unterstützungsempfang ist eine niedrigere Arbeitsfähigenquote denkbar, d. h. der Anteil der arbeitsfähigen Meldepflichtigen an der Gesamtzahl der Umsiedler. Angesichts der weitgehenden Arbeitseinsatzpflicht in der SBZ konnte man davon ausgehen, daß nahezu alle Arbeitsfähigen von den Arbeitsämtern registriert waren. Der Anteil der Selbständigen, die nicht der Meldepflicht unterlagen, lag wie in den Westzonen sehr niedrig ${ }^{31}$. Als der Zuwanderungsstrom abebbte, waren zonenweit 49,8 Prozent der 4,3 Millionen registrierten Umsiedler meldepflichtig. Vergleicht man diesen Wert mit dem von Zank geschätzten Anteil der Arbeitsfähigen an der Gesamtbevölkerung, der zwischen 60,1 Prozent (1946) und 61,9 Prozent (1950) lag, ${ }^{32}$ erkennt man, daß die geringere Arbeitsfähigkeit ebenfalls einen Beitrag zur Erklärung des hohen Umsiedleranteils an den Fürsorgeempfängern zu leisten vermag.

Ganz anders sahen die Erhebungen zur Bundesrepublik aus. Zwar ließ sich 1950 eine niedrigere Erwerbsquote unter den Flüchtlingen feststellen, die sich auf 42,6 Prozent gegenüber 47,1 Prozent bei der übrigen Bevölkerung belief ${ }^{33}$. Diese Werte wurden auf eine mangelhafte Registrierung der Flüchtlinge bei den Arbeitsvermittlungsbehörden zurückgeführt $^{34}$. Im Gegensatz zur SBZ/DDR lag der Anteil der als erwerbsfähig geltenden

${ }^{26}$ FDGB, Bundesvorstand, Bericht über die Kommissionssitzung betr. Neubearbeitung des Umsiedlerproblems im ZS der SED am 3. 3. 1949, in: SAPMO, FDGB A 152.

27 MfAS Sachsen-Anhalt, Abt. Sozialwesen, Bericht über den Stand der Sozialfürsorge in den Jahren 1948, 1949 und 1950 im Lande Sachsen-Anhalt, 14. 2. 1951, in: BAB, DQ 2/3755; vgl. auch: Mehlhase, Bestrebungen, S. 350.

${ }^{28}$ Schraut, Flüchtlingsaufnahme, S. 45 und 332.

${ }^{29}$ Nimptsch, Heimatvertriebene, S. 468.

${ }^{30} \mathrm{Vgl}$. Bundesministerium des Inneren, Eingliederung, S. 76-84.

${ }^{31}$ Hoffmann / Wille / Meinicke, Flüchtlinge, S. 23; vgl. auch die Angaben bei Schraut, Flüchtlingsaufnahme, S. 383.

${ }^{32}$ Zank, Wirtschaft, S. 33.

33 Edding, Bevölkerung, S. 9.

${ }^{34}$ Bundesministerium für Vertriebene, Eingliederung, S. 20. 
Jahrgänge innerhalb der Flüchtlingsbevölkerung höher als derjenige der einheimischen Bevölkerung ${ }^{35}$. Hiermit korrespondiert die Feststellung, daß vor allem jüngere, ledige Männer die SBZ verließen und in die Westzonen weiterzogen ${ }^{36}$. In der Bundesrepublik waren 1950 die beiden gewichtigsten Gründe für den vermehrten Unterstützungsempfang bei Flüchtlingen und Vertriebenen: 1.) die längeren Zeiten der Arbeitslosigkeit, ${ }^{37}$ die zum Verlust der Leistungsberechtigung in der Arbeitslosenversicherung führten, 2.) die kurzzeitige, meist berufsfremde Beschäftigung, so daß die Erfüllung der Anwartschaftszeiten nicht gegeben war. Dies unterstrich die 1950 erhobene Arbeitslosenquote von 12,5 Prozent in dieser Bevölkerungsgruppe, die wesentlich höher als beim Rest der Bevölkerung (4,9 Prozent) lag. Jeder dritte Arbeitslose war Vertriebener ${ }^{38}$. Wie weiter unten zu zeigen ist, bezogen diese zwar größtenteils Leistungen aus der Arbeitslosenversicherung, doch fiel auch eine große Anzahl der Fürsorge zur Last.

\section{Die Aussagekraft der Unterstütztenquote im Hinblick auf die Verteilung der Armut}

$\mathrm{Da}$ die Flüchtlingsbevölkerung hauptsächlich in ländlichen Gebieten siedelte und den größten Teil der Unterstützungsempfänger ausmachte, liegt die Annahme nahe, daß auf dem Land auch die höchsten Unterstütztenquoten anzutreffen waren. Die folgende Tabelle gibt den Anteil der Unterstützungsempfänger an der Gesamtbevölkerung der einzelnen Länder der SBZ wieder. Um eine Vergleichsbasis herzustellen, wurden die Anga-

Tabelle 3: Unterstütztenzahlen und -quoten (kursiv) in den Ländern der SBZ/DDR (1946-1952) ${ }^{39}$

\begin{tabular}{|l|r|r|r|}
\hline & Dezember 1946 & Dezember 1948 & $\begin{array}{c}\text { Dezember 1952 } \\
\text { [Näherungswerte] }\end{array}$ \\
\hline Sachsen & 467051 & 142659 & 148422 \\
Sachsen-Anhalt & $8,3 \%$ & $2,4 \%$ & $2,5 \%$ \\
Thüringen & 272448 & 157419 & 97814 \\
& $6,4 \%$ & $3,7 \%$ & $2,7 \%$ \\
Brandenburg & 155664 & 75245 & 51420 \\
& $5,2 \%$ & $2,5 \%$ & $1,9 \%$ \\
Mecklenburg & 90496 & 79766 & 51383 \\
& $3,6 \%$ & $3,0 \%$ & $1,9 \%$ \\
SBZ/DDR & 84986 & 65429 & 84825 \\
(ohne Berlin) & $4,0 \%$ & $3,0 \%$ & $3,8 \%$ \\
& 1070645 & 520518 & 433864 \\
& $6,1 \%$ & $2,9 \%$ & $2,5 \%$ \\
\hline
\end{tabular}

${ }^{35}$ Ebenda und Nimptsch, Heimatvertriebene, S. 467.

${ }^{36}$ Von Plato / Meinicke, Heimat, S. 91.

37 Die arbeitslosen Vertriebenen im Bundesgebiet nach Alter und Dauer der Arbeitslosigkeit, in: Bundesarbeitsblatt 1 (1950), S. 256.

${ }^{38}$ Stat. Jb. Bundesrepublik 1952, S. 91.

39 DVAS (Rühl), Kostenvoranschlag für die SBZ bei der Einführung der Unterstützungsrichtsätze [Dez. 1946], 16. 2. 1947, in: BAB, DQ 2/3716; HVAS, Statistik der Fürsorgeempfänger. Stand: 1. Dezember 1948, in: BAB, DQ 2/3738; Bericht zur Begründung des Beschlusses des Präsidiums des Ministerrates der DDR „über Einführung des Sparsamkeitsprinzips in der Sozialfürsorge“, 12.3. 1953 , in: $\mathrm{BAB}, \mathrm{DQ} 2 / 780$. 
ben zu den im Sommer 1952 gebildeten Bezirken gemäß der früheren Zugehörigkeit der Bezirkshauptstadt auf die ehemaligen Landesgebiete umgerechnet. Hieraus ergeben sich Ungenauigkeiten bei den genannten absoluten Zahlen, weil die Grenzen der Bezirke nicht mit denjenigen der ehemaligen Länder übereinstimmten. Mitunter wurden sogar Kreise auf zwei Bezirke aufgeteilt. Die Fehler bei den Näherungswerten im Dezember 1952 werden durch die Berechnung der Unterstütztenquote relativiert.

Der vermutete Zusammenhang läßt sich im Dezember 1946 nicht herstellen. In Mecklenburg, das am stärksten von Flüchtlingen belastet war, lag die Unterstütztenquote relativ niedrig. Zur Zahl von knapp 85000 Unterstützungsempfängern bemerkte die DVAS, daß es sich nur um die wirklich Unterstützten handelte, der Kreis derer, die als unterstützungsbedürftig gelten könnten, weitaus größer $\operatorname{se}^{40}$. Dies weist auf eine wesentliche Eigenart der Armutsstatistik hin. Die Zahl der unterstützten Personen variierte in der Fürsorgegeschichte nicht nur mit der tatsächlich vorhandenen Armut, sondern spiegelte stets auch die Bewilligungspraxis des verpflichteten Fürsorgeträgers wider ${ }^{4}$.

Als wesentliche Prämisse für den Unterstützungsempfang galt das Lohnabstandsgebot, demzufolge der Unterstützungssatz stets unter dem ortsüblichen Mindestlohn des ungelernten Arbeiters liegen mußte. Im Agrarsektor wurden ausgesprochen niedrige Löhne bezahlt, die oftmals unter dem tarifvertraglich vereinbarten Stundenlohn von 50 Pfennigen $^{42}$ lagen. Die durch die Sozialfürsorge seit September 1947 garantierten Richtsätze, die sich am Bedarfsprinzip orientierten, gerieten mit den Niedriglöhnen in Kollision. Durch Einführung einer starren „Auffanggrenze“, die im Oktober 1948 Höchstsätze unter Einhaltung des Lohnabstandsgebotes festsetzte, wurde diesem Umstand Rechnung getragen. Da die Auffanggrenze wie auch die Niedriglöhne unter dem Niveau der Fürsorgerichtsätze lagen, entstand das Phänomen der labouring poor, die ihren Lebensbedarf trotz Arbeitstätigkeit mit ihrem Einkommen nicht decken konnten. Demnach konnten weitaus mehr Personen als hilfsbedürftig gelten, als die amtliche Statistik erfaßte.

Ferner wirkte sich die ökonomische Leistungsfähigkeit des verpflichteten Fürsorgeträgers aus. Als in der SBZ im September 1947 einheitliche Richtsätze eingeführt wurden, bedeutete dies vielerorts eine erhebliche Erhöhung der bislang lokal unterschiedlichen Unterstützungssätze. Angesichts der geplanten Mehrausgaben kürzte die SMA Mecklenburg die im Landesetat für Fürsorgezwecke vorgesehenen Mittel im vierten Quartal 1947 von 14,1 auf 10,5 Millionen Mark, was erst verspätet durch Intervention der DVAS bei der SMAD in Karlshorst geändert werden konnte ${ }^{43}$. Solche Finanzierungslücken hatten ein Sparsamkeitsregime der Fürsorgebehörden auf Gemeinde- und Kreisebene zur Folge, was sich sowohl auf die Höhe der Unterstützungsleistungen als auch auf die Größe des Empfängerkreises auswirkte. Infolge dessen waren die höchsten Unterstütztenquoten in den urbanen, industriell geprägten Gebieten anzutreffen. Dort wurden einerseits höhere Löhne gezahlt und andererseits standen verhältnismäßig größere Summen für Fürsorgezwecke zur Verfügung.

to DVAS (Rühl), Kostenvoranschlag für die SBZ bei der Einführung der Unterstützungsrichtsätze, 16. 2. 1947 , in: BAB, DQ 2/3716.

${ }^{41}$ Vgl. Sachße / Tennstedt, Geschichte, Bd. 2, S. 170.

${ }^{42}$ Gries-Schwerin, Sozialversicherungsbeiträge, S. 320-322.

${ }^{43}$ DVAS (Rühl), Besprechung bei der SMAD, Abt. Finanzkraft (Moschkin), 16. 2. 1948, in: BAB, DQ 2/3753. 
Die Armutsziffern änderten sich: Im Dezember 1948, als sich die Gesamtzahl der Fürsorgeempfänger zonenweit halbiert hatte, schwankte die Unterstütztenquote aller SBZLänder um drei Prozent. Sachsen hatte seine herausragende Stellung des Jahres 1946 nicht nur verloren, sondern wies nun sogar die niedrigste Unterstütztenquote auf. Daß die registrierten Unterstütztenzahlen die existierende Landarmut nicht widerspiegelten, zeigt auch eine Differenzierung nach Stadt- und Landkreisen, die für das Jahresende 1948 vorlag. In den urbanen Gebieten, d. h. den Stadtkreisen, lag die Unterstütztenquote bei 3,4 Prozent, in den ländlichen Gebieten, d. h. der überwiegenden Zahl der Landkreise, aber lediglich bei 2,8 Prozent ${ }^{44}$. Die Erfolge beim Abbau der Unterstütztenzahlen wurden vor allem durch Integration in den Arbeitsprozeß erzielt, wobei die Aufnahme in die Landarbeit unter den oben beschriebenen Bedingungen eine herausragende Rolle spielte.

Die Entlastung der Sozialfürsorge durch andere Systeme der sozialen Versorgung muß in der SBZ/DDR als gering eingestuft werden. Aufgrund kurzzeitiger Beschäftigung erreichten viele Arbeitslose nicht die Anwartschaftszeit der Arbeitslosenversicherung. Auch als diese einer flexiblen Handhabung unterworfen wurde, ${ }^{45}$ leistete die Arbeitslosenversicherung nur einen geringen Beitrag zur Entlastung der Fürsorge, weil die gezahlten Sätze aufgrund der meist zugrunde liegenden Niedrigöhne nicht den Stand der Fürsorgerichtsätze erreichten ${ }^{46}$. Somit empfing die Mehrzahl der Arbeitslosen gleichzeitig Unterstützungsleistungen aus der Sozialfürsorge, tauchte also auch in der Fürsorgestatistik auf. Dasselbe galt für Kriegsbeschädigte und deren Hinterbliebene. Die seit Juli 1948 bezahlten Renten erreichten das Niveau der Richtsätze meist nicht ${ }^{47}$.

An den statistischen Angaben zum Dezember 1952 fällt auf, daß in den früheren mecklenburgischen Gebieten entgegen der Tendenz in den anderen ehemaligen Ländern eine Steigerung der Unterstütztenquote festzustellen war. Die absolute Zahl der Unterstützungsempfänger in den drei Bezirken des Nordens der DDR lag auf dem Stand des Dezembers 1946. Dies läßt sich dadurch erklären, daß das Bedarfsprinzip konsequenter angewandt wurde, so daß nun alle Bedürftigen auch tatsächlich unterstützt wurden. Angesichts eines verbesserten Systems des Finanzausgleichs vermochten die überlasteten Budgets einzelner Kommunen leichter ausgeglichen zu werden. Insgesamt zeigt die regionale Entwicklung der Unterstütztenquote in der DDR einen Trend zur Nivellierung auf sinkendem Niveau.

Es soll ein Vergleich mit dem Vereinigten Wirtschaftsgebiet bzw. der Bundesrepublik Deutschland vorgenommen werden. Dort lag für die Jahre 1949/50 eine entsprechende Erhebung vor.

Markant ist, daß sich die bundesweit erfaßte Unterstütztenquote innerhalb eines Jahres halbierte, so daß sie im Juni 1950 auf einem ebenso niedrigen Niveau wie in der SBZ bereits Ende 1948 lag. Anders als dort beruhte die Entwicklung des Unterstützungsempfangs in den Westzonen/Bundesrepublik auf den veränderten sozialpolitischen Weichen-

${ }_{44}$ HVAS, Statistik der Fürsorgeempfänger, Stand 1. Dezember 1948, in: BAB, DQ 2/3738.

${ }^{45}$ ZVOBl. 1948, S. 62; entsprechende Änderung in der 2. Durchführungsverordnung zur Verordnung über die Pflichtversicherung gegen Arbeitslosigkeit vom 27. 12. 1947.

${ }^{46}$ Frerich / Frey, Handbuch, Bd. 2, S. 37 und 172; MfA, HR Sozialfürsorge, Exposé über die Gestaltung der Sozialfürsorge entsprechend der ökonomischen Entwicklung, 16. 9. 1952, in: BAB, DQ $2 / 780$.

47 HVAS (Hartung), Bericht über die Entwicklung der Sozialfürsorge aufgrund der Fürsorgestatistik im November 1948, 10. 1. 1949, in: BAB, DQ 2/3728. 
Tabelle 4: Unterstütztenzahlen und -quoten (kursiv) in den Ländern und Landesteilen der Westzonen/Bundesrepublik (1949-1950) ${ }^{48}$

\begin{tabular}{|l|r|r|}
\hline & März 1949 & Juni 1950 \\
\hline Nordrhein-Westfalen & 692270 & 388238 \\
Bayern & $5,4 \%$ & $2,9 \%$ \\
Niedersachsen & 617197 & 289718 \\
& $6,6 \%$ & $3,1 \%$ \\
Hessen & 473719 & 194098 \\
Württemberg-Baden & $6,9 \%$ & $2,8 \%$ \\
Schleswig-Holstein & 260869 & 133334 \\
& $6,1 \%$ & $3,1 \%$ \\
Hamburg & 199354 & 97282 \\
& $5,1 \%$ & $2,5 \%$ \\
Bremen & 251065 & 94797 \\
& $9,2 \%$ & $3,6 \%$ \\
Rheinland-Pfalz & 54237 & 38910 \\
Baden & $3,6 \%$ & $2,4 \%$ \\
Württemberg-Hohenzollern & 29344 & 25999 \\
Vereinigtes Wirtschaftsgebiet/ & $5,5 \%$ & $4,6 \%$ \\
Bundesrepublik & - & 59091 \\
& & $2,0 \%$ \\
& & 28697 \\
& & $2,2 \%$ \\
& & 21632 \\
& & $1,8 \%$ \\
& & 1371746 \\
& & $2,8 \%$ \\
\hline
\end{tabular}

stellungen der Nachkriegsjahre. Der Erlaß des Soforthilfegesetzes (SHG) vom 8. August $1949,{ }^{49}$ das zeitlich zwischen den Erhebungszeitpunkten der obigen Statistik angesiedelt war, führte zu einer erheblichen Entlastung der kommunalen Fürsorge. Wie erwähnt, wurden bis 1. Juni 1950 rund 428000 Anträge bewilligt, so daß die Antragsteller nun aus Bundesmitteln unterstützt wurden. Aus systematischen Gründen tauchten diese Leistungsempfänger nicht mehr in der Fürsorgestatistik auf. Die Sonderbestimmungen, nach denen die Empfänger von Unterhaltshilfe versorgt wurden, werden im folgenden Abschnitt untersucht.

Ferner spielte in dem hier interessierenden Zusammenhang das SozialversicherungsAnpassungsgesetz (SVAG) vom 17. Juni 1949 eine entscheidende Rolle. Betrug die durchschnittliche Altersrente eines Arbeiters Anfang 1949 noch monatlich 42,80 DM und eine entsprechende Witwenrente 25,10 DM, führte das Gesetz nun Mindestrentensätze von $50 \mathrm{DM}$ bzw. $40 \mathrm{DM}$ ein $^{50}$. Die bis Mitte 1949 gezahlten niedrigen Renten hat-

48 Wirtschaft und Statistik N. F. 1 (1949/50), S. 88; ebenda, N. F. 2 (1950), S. 272.

49 Gesetzblatt der Verwaltung des Vereinigten Wirtschaftsgebietes 1949, S. $205 \mathrm{ff}$.

${ }^{50}$ Hockerts, Entscheidungen, S. 88 und 91; Frerich / Frey, Handbuch, Bd. 3, S. 6-7. 
ten eine zusätzliche Unterstützung durch die Fürsorge verlangt, die nach Inkrafttreten des SVAG kaum noch erforderlich war ${ }^{51}$.

Wie in der SBZ/DDR war auch im Westen ein Doppelbezug von Leistungen aus der Fürsorge und der Arbeitslosenversicherung denkbar. Das Arbeitslosenversicherungsrecht der Weimarer Zeit wurde im Grundsatz in der amerikanischen und britischen Zone am 1. Oktober 1947 wieder in Kraft gesetzt und bei einigen länderspezifischen Abweichungen $^{52}$ auch in der Bundesrepublik übernommen ${ }^{53} .1950$ erhielten von den 1,8 Millionen registrierten Arbeitslosen 70,3 Prozent Leistungen aus der Arbeitslosenversicherung, ${ }^{54}$ wodurch die Fürsorge erheblich entlastet wurde. Die durch die Reichsversicherungsanstalt gezahlten Sätze lagen - im Gegensatz zur DDR - über den in der Fürsorge üblichen Richtsätzen, was das nach der Aufhebung des Lohnstopps im November 1948 höhere Lohnniveau widerspiegelte. Andernfalls hätte die Zahl der zusätzlich durch die Fürsorge unterstützten Leistungsempfänger sehr viel höher liegen müssen. Einerseits war das System der Arbeitslosenversicherung im Westen in höherem Maße als im Osten funktionsfähig, weil in der SBZ/DDR so gut wie alle Empfänger von Arbeitslosenunterstützung zusätzlich von der Sozialfürsorge unterstützt wurden, mithin auch in der Fürsorgestatistik auftraten. Andererseits läßt sich feststellen, daß die Belastung der öffentlichen Sozialhaushalte bedeutend blieb, da das Sinken der Unterstütztenzahlen nicht, wie in der SBZ/DDR, über Arbeitsmarktintegration, sondern im wesentlichen über eine Verschiebung in andere Leistungsbereiche erfolgte. Erst während der 1950 er Jahre gelang es, die hohen Arbeitslosenzahlen zu senken.

Eine denkbare Entlastung der Fürsorge durch eine Binnenumsiedlung der Flüchtlinge und Vertriebenen erfolgte kaum. Die gelenkte Wanderung setzte 1949/50 ein, spielte aber quantitativ insgesamt eine ungeordnete Rolle im Rahmen der Wanderung innerhalb der Bundesrepublik ${ }^{55}$. Generell überwogen bei den registrierten Umsiedlungstransporten die jüngeren, arbeitsfähigen Jahrgänge bei weitem ${ }^{56}$. Als Indiz für die geringe Bedeutung in Bezug auf die Fürsorge kann auf eine Einzelbestimmung des Änderungsgesetzes vom 23. September $1952 \mathrm{im}$ Zuge des zweiten Umsiedlungsprogramms verwiesen werden. Angesichts eines ständig wachsenden Sozialaufwandes der Abgabeländer wurde explizit herausgestellt, daß das Gesetz „auch erstmals die Einbeziehung von 30000 Rentnern, Pensionären und Fürsorgeempfängern in die Umsiedlung ${ }^{47}$ brachte. Hieraus läßt sich ableiten, daß nur ausnahmsweise eine geplante Umsetzung von Fürsorgeunterstützten stattfand und die Binnenumsiedlung vor allem von den wirtschaftlichen Bedürfnissen der Aufnahmeländer geleitet war.

Für einen länderorientierten Vergleich mit der SBZ/DDR eignet sich die Unterstütztenstatistik des Vereinigten Wirtschaftsgebietes vom März 1949 besonders, weil die Unterstütztenquote aufgrund der ausstehenden Gesetzesreformen im Sozialwesen eine ähnliche Aussagekraft wie in der SBZ hatte. Zu diesem Zeitpunkt erfaßte sie noch fast alle Empfänger staatlicher Sozialleistungen, was sich erst durch den Erlaß des SHG und

${ }^{51} \mathrm{Zu}$ den Auswirkungen des Erlasses des SVAG auf die Fürsorgedebatte vgl. Heisig, Armenpolitik, S. $136 \mathrm{ff}$.

52 Vgl. Trode, Grundriß, S. 41 f.

${ }^{53}$ Frerich / Frey, Handbuch, Bd. 3, S. 8.

${ }^{54}$ Ebenda, S. 83.

55 Marschalck, Bevölkerungsgeschichte, S. 89.

${ }^{56}$ Stat. Jb. Bundesrepublik 1952, S. 51.

57 Bundesministerium des Inneren, Eingliederung, S. 80. 
SVAG änderte, in deren Folge das Unterstützungsproblem teilweise in andere Bereiche des Sozialleistungssystems verlagert wurde. Die Unterstütztenquote lag im März 1949 noch auf einem ähnlich hohen Stand wie in der SBZ während der Hauptzuwanderungsphase. Daraus läßt sich folgern, daß die für den Abbau der Fürsorgeempfängerzahlen wesentliche Arbeitsvermittlung bis zu diesem Zeitpunkt in der SBZ viel erfolgreicher als in den Westzonen arbeitete ${ }^{58}$. Eine Übereinstimmung zwischen Vertriebenenaufnahme und Unterstützungsempfang läßt sich in einzelnen Ländern der Bizone deutlicher als in der SBZ herausstellen. Hierfür sprach die hohe Unterstütztenquote von 9,2 Prozent in Schleswig-Holstein, die weit über derjenigen aller anderen deutschen Länder lag. Am Beispiel der nördlichen Gebiete Badens und Württembergs läßt sich zeigen, daß die Fürsorgelasten mit steigender Entfernung zur Industrie wuchsen ${ }^{59}$. Dem könnte eine strengere Durchsetzung des Bedarfsprinzips als in der SBZ zugrunde liegen, wo ja die Landkreise tendenziell niedrigere Unterstütztenquoten aufwiesen. Eine an der Entwicklung der Unterstütztenzahlen erkennbare, längerfristige Landarmut entstand im Westen offenbar nicht, weil sich die Quoten der agrarisch strukturierten Länder im Juni 1950 denjenigen der industriell und urban geprägten Gebiete allmählich anglichen. Im Westen wurden offenbar gerade die ländlichen Gebiete von der Einführung einer Mindestrente durch das SVAG entlastet, weil dort die Altersrenten besonders niedrig gewesen waren ${ }^{60}$. Im Osten zeichneten rigorose Konzepte der Eingliederung in den Arbeitsmarkt für die vor allem nach 1952 rapide sinkenden Unterstütztenzahlen verantwortlich ${ }^{61}$.

\section{Materielles Unterstützungsniveau und besondere Fürsorgeleistungen}

Die Entstehung von Sonderfürsorgebereichen geht auf die Zeit nach dem Ersten Weltkrieg zurück. 1924 wurden mit der "gehobenen Fürsorge“ spezielle Unterstützungsbedingungen für verschiedene Gruppen von Unterstützungsempfängern, nämlich für Kriegshinterbliebene und -beschädigte sowie für Klein- und Sozialrentner, eingeführt ${ }^{62}$. Diese Sonderfürsorge unterschied sich von der allgemeinen Fürsorge durch höhere materielle Unterstützungsleistungen und ein gesteigertes Sozialprestige. Sowohl in der SBZ als auch den Westzonen ${ }^{63}$ konnte das System der Gruppenfürsorge wegen seiner Einbindung in die rassistische Auslese während des Nationalsozialismus ${ }^{64}$ als diskreditiert gelten. In der SBZ, wo vor allem der FDGB auf die Abschaffung drängte, ${ }^{65}$ wurde dies ideologisch dadurch begründet, daß man den Kriegsteilnehmern, denen man mitunter pauschalisierend Militarismus vorwarf, keine begünstigte Stellung in der Fürsorge einräumen

${ }^{58}$ Vgl. auch Zank, Wirtschaft, S. 174.

${ }^{59}$ Schraut, Flüchtlingsaufnahme, S. 388.

${ }^{60}$ Ende 1948 lag in den ländlichen Gebieten über die Hälfte der Renten unter 35 Mark, vgl. Hockerts, Entscheidungen, S. 91.

${ }^{61}$ MfA, HR Sozialfürsorge, Exposé über die Gestaltung der Sozialfürsorge entsprechend der ökonomischen Entwicklung, 16. 9. 1952, in: BAB, DQ 2/780; Anweisung über dic Anwendung der gesetzlichen Bestimmungen der Sozialfürsorge (Arbeitsrichtlinien für alle Mitarbeiter der Sozialfürsorge), 20. 12. 1952, in: ebenda.

${ }^{62}$ Sachße/ Tennstedt, Geschichte, Bd. 2, S. 88.

${ }^{63}$ Heisig, Armenpolitik, S. $135 \mathrm{ff}$.

${ }^{64} \mathrm{Vgl}$. Sachße / Tennstedt, Geschichte, Bd. 3, S. 183-187.

${ }^{65}$ FDGB, Bundesvorstand, Stellungnahme zum DVAS-Verordnungsentwurf vom 19.2. 1946, o. D. [nach 19.2., vor 26.5.1946], in: SAPMO, FDGB 5/3/1479. 
wollte. Auch den Umsiedlern, die in Folge von Flucht und Vertreibung in soziale Notlagen geraten waren, gestand man keinen Sonderstatus zu.

In Westdeutschland knüpfte man in gewisser Hinsicht an die gehobene Fürsorge an, obgleich eine Abkehr vom Prinzip der Gruppenfürsorge von den Alliierten verfügt ${ }^{66}$ und von den sozialpolitisch relevanten Kräften auch gewollt war ${ }^{67}$. Zwar wurden keine Sonderfürsorgebereiche eingeführt, aber das SHG schuf durch Einführung einer Unterhaltshilfe eine begünstigte Stellung für gewisse Bevölkerungsgruppen, die von den Zwangsmigrationen betroffen waren. Die Kriterien zum Leistungsempfang waren Bedürftigkeit der betreffenden Person sowie das Über- bzw. Unterschreiten (bei Waisen) der Grenzen der Arbeitsfähigkeit. Im einzelnen umfaßte der Empfängerkreis Personen im Rentenalter (Männer über 65, Frauen über $60 \mathrm{Jahre}$ ), Invalide, alleinstehende Frauen mit mindestens drei Kindern und Vollwaisen. Die monatlich gezahlten Beträge lagen für einzelne Anspruchsberechtigte bei $70 \mathrm{DM}$ und für mitunterstützte Familienangehörige bei $30 \mathrm{DM}$ (Ehefrau) bzw. 20 DM (Kinder). Vollwaisen erhielten 35 DM. Auf Grund der Finanzierung aus Bundesmitteln wurden den genannten Personengruppen einheitliche Sätze gewährt, während die Unterstützungssätze der öffentlichen Fürsorge im Bundesgebiet im lokalen Maßstab ansonsten erheblich voneinander abwichen.

Eine entsprechende Begünstigung für nicht arbeitsfähige Umsiedler existierte in der SBZ/DDR nicht. Das sehr disparate Richtsatzgefüge nach dem Krieg wurde in den „Richtlinien für die Bemessung der Barleistungen für den Lebensunterhalt eines Hilfsbedürftigen “68 im September 1947 zonenweit vereinheitlicht. Die Richtsätze, die nach dem Bedarf errechnet wurden, lagen für Hauptunterstützungsempfänger bei 30 Mark; für erwachsene Mitunterstützte gab es einen Zuschlag von 20 Mark und pro Kind 17,50 Mark. Diese Sätze wurden im Oktober 1948 durch Einführung der Auffanggrenze ${ }^{69}$ auf 90 Mark monatlich beschränkt, was kinderreiche Familien besonders empfindlich traf. Für diese Fälle wurde die strenge Limitierung im Laufe des Jahres 1949 teilweise zurückgenommen. Als die Regierung der DDR die Richtsätze - mit Ausnahme derjenigen der erwachsenen Mitunterstützten - nach der Staatsgründung um fünf Mark erhöhte, wurde dies nur zum Teil wirksam, weil die Auffanggrenze erhalten blieb $^{70}$.

Die seit Erlaß des SHG einheitlich gezahlte Unterhaltshilfe lag für einen alleinstehenden, nicht arbeitsfähigen Unterstützten somit rund doppelt so hoch wie in Ostdeutschland, die Sätze der Mitunterstützten waren allerdings auf gleichem Niveau. Dieser Vergleich kann sich in der DDR nur auf die Fürsorgeempfänger beziehen, für die die gleichen Kriterien wie die Empfänger von Unterhaltshilfe galten, d. h. die sowohl Umsiedler waren, als auch die entsprechenden Altersgrenzen, die denjenigen in den Bundesrepublik entsprachen, überschritten hatten. Nach dem Stand vom Februar 1950 war dies rund ein Zehntel der zu diesem Zeitpunkt erfaßten 571000 Unterstützungsempfänger ${ }^{71}$.

${ }^{66}$ Tennstedt, Geschichte, S. 108.

67 Heisig, Armenpolitik, S. 119.

68 ZVOBl. 1947, S. 224-225, Anhang zur 1. Durchführungsverordnung, 2. 9. 1947.

${ }^{69}$ Eine solche starre Obergrenze gab es im Westen in einzelnen Ländern, z. B. Bayern und Baden, vgl. Heisig, Armenpolitik, S. 78.

70 Verordnung über Erhöhung für die Sozialversicherten und Kriegsinvaliden sowie der Richtsätze für Sozialuntersützungsempfänger vom 3. November 1949, in: Gbl. der DDR 1949, S. 36.

${ }^{71}$ Fürsorgestatistik [Januar-März 1950], 17. 5. 1950, in: BAB, DQ 2/3737; die Statistik wies 118500 Unterstützungsempfänger im Rentenalter aus; es wird geschätzt, daß hiervon rund dic Hälfte Umsiedler waren. 
Für die unterstützten Vertriebenen in Westdeutschland, die nicht unter das SHG fielen, muß die materielle Unterstützungssituation gesondert untersucht werden. Angesichts der Fülle von lokal unterschiedlichen Richtsatzbestimmungen erfaßten die Statistiken des Bundes nur Durchschnittssätze auf Länderebene ${ }^{72}$. Diese wichen im ersten Halbjahr 1950 erheblich voneinander ab: In Rheinland-Pfalz belief sich der monatlich durchschnittlich gezahlte Unterstützungssatz je „Heimatvertriebenen“ auf wenig mehr als 16 $\mathrm{DM}$, in Württemberg-Baden waren es rund $19 \mathrm{DM}$. Diese in den südwestdeutschen Gebieten der ehemaligen Französischen Besatzungszone gezahlten Durchschnittssätze lagen zu jenem Zeitpunkt unter denjenigen, die in der DDR gezahlt wurden. Andere Länder, die eine erheblich höhere Flüchtlingsbelastung aufwiesen, zahlten erheblich höhere Sätze, z. B. Schleswig-Holstein mit einem Durchschnittssatz von 30,37 DM oder Niedersachsen mit 29,61 DM. Somit läßt sich feststellen, daß das SHG ab August 1949 nur den oben aufgelisteten, ausgewählten Bevölkerungsgruppen eine begünstigte Stellung einräumte. Dies war aber nicht mit einer allgemeinen gehobenen Sonderfürsorge, die sich auf alle unterstützten Vertriebenen erstreckte, gleichzusetzen.

Von den starken regionalen Unterschieden in der Bundesrepublik abgesehen, herrschte in West und Ost beim Unterstützungsniveau der allgemeinen, offenen Fürsorge für Vertriebene bzw. Umsiedler eine erstaunliche Übereinstimmung: Im ersten Halbjahr 1950 lag in der DDR die Auffanggrenze für eine Durchschnittsfamilie (Ehepaar mit zwei Kindern) bei 100 Mark, d. h. 25 Mark pro Person. Dieser Satz entsprach nahezu exakt dem im Bundesgebiet für Vertriebene angegebenen Schnitt von 25,06 DM pro unterstützter Person ${ }^{73}$.

Für Geringverdienende unterschieden sich 1950 die Minimalausgaben für die Güter des alltäglichen Bedarfs in West und Ost kaum voneinander, wie eine Berechnung des Deutschen Wirtschaftsinstituts ermittelte ${ }^{74}$. Wenn man sich auf das Allernotwendigste beschränkte, schnitt die DDR sogar etwas günstiger ab. Dies änderte sich jedoch, wenn man einen (gehobenen) Kulturbedarf einberechnete. Diese Waren konnten aber für alle Fürsorgeempfänger als weitgehend unerschwinglich gelten. Insofern kann in beiden Teilen Deutschlands für die untersten sozialen Schichten, die von Fürsorgeleistungen abhängig waren, in den frühen $1950 \mathrm{er}$ Jahren ein annähernd gleicher materieller Lebensstandard angenommen werden.

72 Wirtschaft und Statistik N. F. 3 (1951), S. 35.

${ }^{73}$ Ebenda.

74 DIW-Wochenbericht 17 (1950), S. 199-201. 


\title{
Michael Grottendieck
}

\section{Zwischen Integration und Abstoßung.}

\author{
Probleme der Eingliederung von Vertriebenen im \\ münsterländischen Greven sowie von „antifaschistischen Umsiedlern“ \\ im mecklenburgischen Ludwigslust im Vergleich.
}

\section{Konflikte im Kontext der Vertriebenenintegration in den beiden deutschen Nachkriegsgesellschaften}

Längst hatte tiefe Desillusionierung um sich gegriffen, und von den hohen Erwartungen war nichts mehr zu spüren. „Die Kisten konnten nicht ausgepackt werden“, klagten die 83 „antifaschistischen Umsiedler" über die unzulängliche Unterkunft in der Nähe von Ludwigslust, in der sie bereits knapp einen Monat zubrachten, „und es ist mit größter Sicherheit anzunehmen, daß in den Kleidern und in der Wäsche bereits Stockflecken sind. Und immer besteht noch keine Aussicht, von hier wegzukommen." ${ }^{1}$ Aller Hoffnungslosigkeit zum Trotz gingen die Bemühungen um vernünftige Wohnungen und um Arbeitsplätze weiter. Doch innerhalb dieser Zeit fielen die Ergebnisse mager aus: Lediglich ein Transportmitglied hatte in der benachbarten Gemeinde Wöbbelin eine Anstellung als Polizist und „unter großen Schwierigkeiten" auch eine Wohnung erhalten.

Auch im münsterländischem Greven wuchs die Unzufriedenheit der Vertriebenen. Ihre „tägliche Not" erschien ihnen zunehmend schwerer erträglich, je länger sie zusehen mußten, wie für einheimische Grevener Familien, die sich nahezu in einer ähnlichen Lage wie sie selber befanden, in großem Stil Hilfe mobilisiert wurde. Es waren Familien, die ihre Häuser im Frühsommer 1945 hatten räumen müssen, als ein Sammelzentrum für ehemalige Fremdarbeiter in dem Dorf an der Ems errichtet wurde; nun aber durften sie nach mehr als zwei Jahren in ihre stark demolierten Wohnungen zurückkehren. Bei aller Not dieser Familien, so erklärten die Vertriebenen, sei ihr eigenes Los „das härtere“, so daß man eine Benachteiligung bei den Hilfsmaßnahmen keineswegs verstehen könne ${ }^{2}$.

Verteilungskonflikte um Wohnraum, um Arbeitsplätze sowie um die Zuwendungen von Hilfsmaßnahmen gab es allenthalben in der deutschen Nachkriegsgesellschaft. Tief prägten sich der Mangel an Nahrung, Kleidung, alltäglichen Gebrauchsgegenständen und Wohnungen in die Alltagserfahrungen der ersten Jahre nach dem „Zusammenbruch“ ein. Mit den mannigfaltigen materiellen Nöten hatten in besonderem Maße die Vertriebenen zu

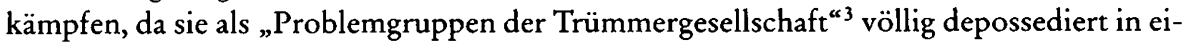
ner für sie fremden Umgebung häufig ohne die Hilfe der altbekannten sozialen Netzwerke

1 MLHA, Landesleitung SED Mecklenburg, IV/L/2/6/334, Bl. 3.

2 Flüchtlingsausschuß an das Amt Greven. „Kurzer Überblick über seine Tätigkeit“ vom 7. 12. 1947, StaG, 4-50-13.

3 Teppe, Trümmergesellschaft, S. 26. 
ein neues Leben beginnen mußten. Vergleicht man die Vertriebenen-Integration in den beiden deutschen Nachkriegsgesellschaften, was nach der Öffnung der Archive der ehemaligen DDR noch immer ein Forschungsdesiderat ist ${ }^{4}$, bieten die Verteilungskonflikte um knappen Wohnraum und um Arbeitsplätze durchaus einen wichtigen Ansatzpunkt. Dabei ist das Angebot etwa von Wohnungen je nach den Folgen kriegerischer Handlungen, massenhafter Migration oder Beschlagnahmungen durch die Besatzungsmächte für die unmittelbare Nachkriegszeit ein nicht zu unterschätzender, aber nicht allein entscheidender Faktor; zu berücksichtigen sind auch die Anrechte im Sinne von Ralf Dahrendorf, die sich bei diesem Beispiel auf die Menge von Zugangschancen auf eine Wohnung beziehen. Anrechte sind laut Dahrendorf weniger persönliche Fähigkeiten als „sozial definierte Zugangsmittel “5, die wie Eintrittskarten verschlossene Türen öffnen können; allerdings bleiben die Türen zugleich für diejenigen geschlossen, die über keine Eintrittskarten verfügen. „In diesem Sinne ziehen Anrechte Grenzen und schaffen Barrieren. " ${ }^{6}$ Um ihre Lebenschancen zu verbessern, bedurften die Vertriebenen beiderlei, der Angebote und und der Anrechte.

Grundsätzlich ist bei den Aufnahmebedingungen für beide deutschen Nachkriegsgesellschaften zu differenzieren zwischen Stadt und Land, zwischen industriell bzw. landwirtschaftlich strukturierten Regionen. Wie die Forschung zur Vertriebenenintegration in den westdeutschen Zonen gezeigt hat, bieten sich ländliche Regionen für die Untersuchung des Umgangs mit Konflikten insofern an, als die Konflikte zwischen Einheimischen und Neuankömmlingen signifikanter hervortraten ${ }^{7}$. Das hat natürlich etwas mit den Zahlen der aufzunehmenden Menschen zu tun, da die ländlichen Regionen in beiden deutschen Teilgesellschaften die Funktionen eines Auffangbeckens oder eines Puffers erfüllten ${ }^{8}$. Innerhalb der Forschung wurden die Konflikte vornehmlich im Lichte der Modernisierungstheorie als Ausdruck des Aufbrechens traditionaler sowie nicht selten konfessionell homogener Milieus thematisiert. Das Dorf wurde zu einem Schauplatz einer alltäglichen Konfliktgeschichte, „die bei der gemeinsamen Küchenbenutzung begann und bei der Besetzung lokaler Ämter endete“"

Ein Vergleich zweier landwirtschaftlich geprägter Regionen wie Mecklenburg-Vorpommern und Niedersachsen oder dem Münsterland ist aus erfahrungsgeschichtlicher Perspektive für einen Ost-West-Vergleich fruchtbar. In der Beschreibung ähnlich gelagerter materieller oder sozialer Notlagen darf er sich jedoch keineswegs erschöpfen ${ }^{10}$, da al-

${ }^{4}$ Eine erste vergleichende Sicht auf das gesellschaftspolitische Problem der Vertriebenenintegration bietet Schwartz, Vom ,Flüchtling' zum Neubürger; siehe auch die zeitnahe Arbeit von Beyer, Versuch einer Darstellung der Lage der deutschen Ostflüchtlinge in der SBZ, S. 320 ff.; lediglich nebeneinander gestellt sind die Integrationsprozesse in Ost und West in dem ansonsten überaus brauchbaren Überblick bei Steinert, Dic große Flucht, S. $557 \mathrm{ff}$.

${ }^{5}$ Dahrendorf, Der moderne soziale Konflikt, S. 28.

${ }^{6}$ Ebenda, S. 28 und 40.

7 Zuletzt Schulze, „Die Ansprüche kamen erst später“, S. 266 ff. mit breiten Literaturangaben.

${ }^{8}$ Plato/Mcinicke, S. 58; Kleßmann, Doppelte Staatsgründung, S. 41.

${ }_{9}^{9}$ Haerendel, Flüchtlinge und Vertriebene, S. 37.

${ }^{10}$ Es wäre verfehlt, bei einer Phänomenologie der gegebenen Probleme stehenzubleiben. Siehe auch den Hinweis bei Bechthold-Comforty, S. 147: „Hier [in Lokalstudien. M. G.] zeigt sich nämlich, daß zwischen 1945 und 1948 zwar fast überall die gleichen Probleme der Unterbringung und Versorgung der Flüchtlinge und Vertriebenen auftraten, dabei aber von Ort zu Ort durchaus individuelle Problemlösungen gefunden wurden." Methodisch weiterführend: Lehmann, Im Fremden ungewollt zuhaus, S. $30 \mathrm{ff}$., $48 \mathrm{ff}$., $68 \mathrm{ff}$.; zudem die Sammlung von alltäglichen Konfliktstoffen bei Frantzioch, Die Vertriebenen als Fremde. S. 171-183. 
lenfalls das Problem des Angebots, nicht aber das der Anrechte thematisiert würde. In den Blick zu nehmen sind vielmehr sozial-kulturelle Konflikte sowie Integrations- und Abstoßungsprozesse, die sich auf interpersonaler wie intergruppaler Ebene bei der Konfrontation der Etablierten mit den Hinzugezogenen und Fremden vollzogen. Zu ergründen wäre, welchen Einfluß gesellschaftliche Strukturen und soziale Kontexte auf die Form von Konflikten haben; in welchem Umfang soziale, kulturelle und politische Unterschiede Entstehung, Form und Verlauf von Konflikten zwischen Gruppen und Personen bestimmen; welche Strategien die involvierten Personen im Umgang mit derartigen Konfliktsituationen wählen.

Die Studie von Peter Exner in diesem Sammelband sowie die ältere Arbeit von Ilien und Jeggle ${ }^{11}$ zum dörflichen Alltag zeigen in der Zusammenschau zahlreiche Gemeinsamkeiten in beiden deutschen Nachkriegsgesellschaften bei der einseitigen Anpassungsleistung der Neuankömmlinge an die in Bewegung geratene Dorfgesellschaft. Es bedarf keiner weiteren Erläuterung, daß dieser für ländlich geprägte Regionen allgemein gültige Befund zur Skepsis gegenüber der weit verbreiteten Ansicht mahnt, in der SBZ/DDR seien Vertriebene zu einseitiger Anpassung gezwungen worden ${ }^{12}$, während in den westlichen Zonen eher von einem Zusammenwachsen und einer gegenseitigen Durchdringung auszugehen sei. Der Weg in die oft beschworene "Neue Zeit" war für Einheimische und Vertriebene unterschiedlich lang ${ }^{13}$. Ein "beträchtlich erhöhter Anpassungsdruck “14, dem die Vertriebenen in der SBZ/DDR im Vergleich zu den Westzonen gleichwohl ausgesetzt waren, wird auf einer anderen Ebene zu verorten sein. Signifikant für die sozialkulturellen Konflikte bei den Integrationsprozessen in der SBZ/DDR scheint es zu sein, daß die Versuche der Vertriebenen, die auf der Flucht und bei der Ausweisung erlittenen traumatischen Erlebnisse durch Zusammenschlüsse auf örtlicher Ebene zu verarbeiten, damit auch den Erfahrungen der Ausgrenzung und Abstoßung in der neuen Heimat zu entgehen und womöglich die eigenen Interessen im Überlebenskampf zu artikulieren, weder von der Besatzungsmacht noch von der KPD/SED geduldet wurden. Sie ließen die Flüchtlinge und Vertriebenen mit ihren Erlebnissen allein und offerierten ihnen allenfalls den Sozialismus als einzige Lebensperspektive bei gleichzeitiger „Verleugnung der eigenen Lebensgeschichte ${ }^{\star 15}$.

Unter dem Gesichtspunkt, einen Beitrag zur Sozialgeschichte von Herrschaft in der SBZ leisten zu wollen, erscheint die Einbeziehung politik- und strukturgeschichtlicher

${ }^{11}$ Ilien/Jeggle, Leben auf dem Dorf.

12 Grundsätzlich ist festzustellen, daß die Forderung, die Vertriebenen hätten sich ohne wenn und aber an die einheimische Gesellschaft zu assimilieren, keine Vorgabe der sowjetischen Besatzungsmacht und der KPD/SED allein war; eine verordnete Eingliederung war Konsens in der Flüchtlingspolitik der Alliierten Siegermächte. Siche Benz, Fremde in der Heimat, S. 382; ebenfalls: Schraut, Assimilationsdiktat, S. 81; Wiesemann/Kleinert, Flüchtlinge und Wiederaufbau, S. 300 .

${ }^{13}$ Vgl. dic treffenden Bemerkungen aus volkskundlicher Sicht bei Lehmann, Erinnern und Vergleichen. S. 21.

${ }^{14}$ Kleßmann, Doppelte Staatsgründung, S. 277; Storbeck, S. 229; Seraphim, S. 177; Christopeit, Verschwiegene vier Millionen, S. 228; ferner die instruktiven Ausführungen bei Plato/Meinicke, S. 80 .

15 Plato/Meinicke, S. 80. Kulturellen Wandel als Folge von Zuwanderung unter Kontrolle zu halten und „die Komposition neuer, ungewollter Identitäten zu verhindern“, betrachtet Wierlacher aus kulturwissenschaftlicher Sicht als ein Signum totalitärer Regime oder Diktaturen; vgl. Wierlacher, S. 97. 
Fragestellungen unerläßlich. Die Teilgesellschaft der SBZ war bekanntermaßen nicht nur eine „Zusammenbruchsgesellschaft“, sondern vor allem eine Übergangsgesellschaft zwischen zwei totalitären Diktaturen ${ }^{16}$. Mag man auch der bekannten These der Soziologin Sigrid Meuschel, die von einer "Entdifferenzierung der Gesellschaft ${ }^{\text {“17 }}$ spricht, einige Vorbehalte entgegenbringen, so wird man nicht leugnen, daß schon früh der Abbau von traditionellen Hierarchien, Systemautonomie und Interessenpluralismus von den neuen Machthabern in Angriff genommen wurde ${ }^{18}$.

Ein wesentlicher Faktor in diesem Prozeß war bei aller Ambivalenz die Eingliederung von etwa vier Millionen Vertriebenen und Flüchtlingen in die SBZ. Diejenigen Vertriebenen, die der Partei die geforderte Subalternität entgegenbrachten, erlebten recht bald einen sozialen Aufstieg und wurden zu einem Instrument, das diesen Prozeß der gesellschaftlichen Entdifferenzierung potentiell vorantreiben konnte. Zugleich aber erfuhren die ohnehin vorhandenen sozialen Notlagen in der Nachkriegsgesellschaft durch den Zustrom der Vertriebenen eine weitere Verschärfung - eine Verschärfung, die eine Integration der neu Hinzugekommenen wenn nicht vereitelte, so doch häufig sehr stark hemmte und verzögerte, niemals jedoch eine Eingliederung ohne schwerwiegende Konflikte erlaubte.

Diese Feststellung gilt freilich für die östliche wie für die westliche Teilgesellschaft. $\mathrm{Zu}$ fragen ist allerdings in diesem Kontext, wie KPD und SED mit den sozialkulturellen Konflikten umgegangen sind. Vor allem, wenn „die eigenen Leute“, die „antifaschistischen Umsiedler", von diesen Abstoßungsvorgängen betroffen waren wie in Ludwigslust. Der Anteil dieser Gruppe an der Gesamtzahl der Vertriebenen war gewiß recht gering, jedoch markierte "der spezielle politisch-moralische Status eine hohe Dringlichkeit der Problemlösungen "19. Die Frage nach dem Umgang und der Lösung derartiger Konflikte ist auch insofern von Interesse, als sie das Problem der sozialen Machtbasis der SED und damit die Grenzen der sich etablierenden Diktatur berührt ${ }^{20}$, zumal sich die Handlungsmöglichkeiten von Migranten in Aufnahmegesellschaften nachhaltig nur über diejenigen Personen und Gruppen verändern lassen, "die Zugang zu den Machtquellen“ haben ${ }^{21}$.

Durch einen umgrenzten, keineswegs systematisch angelegten Vergleich mit den Problemlagen in der münsterländischen Gemeinde Greven wird zu zeigen sein, daß Partei und Verwaltung in der SBZ die Eingliederung der Neuankömmlinge nicht mit dem Nachdruck betreiben konnten, wie es "von oben" gewünscht war, wollten sie nicht die eigene Macht in ihrer sozialen Umgebung aufs Spiel setzen. Dem intendierten problemzentrierten Vergleich kommt insofern ein vornehmlich heuristischer Wert zu, d. h. er soll helfen, Probleme der Vertriebenenintegration in der SBZ deutlicher benennen zu können.

Für den weiteren Aufbau des Aufsatzes ergibt sich daraus, daß in einem ersten Schritt auf der Basis bisher dargelegter Überlegungen die Versuche geschildert werden, die Probleme bei der Aufnahme "antifaschistischer Umsiedler“ in Ludwigslust zu lösen. Die

${ }^{16}$ Möller/Mehringer, S. 179.

17 Meuschel, Legitimation und Parteiherrschaft, S. 10f; Meuschel, Überlegungen, S. 5 f.

${ }^{18}$ Eingehend untersucht wird diese Fragestellung in einem größeren, von der Volkswagen-Stiftung geförderten Forschungsprojekt „Transformationspolitik und Stalinisierung in der sowjetischen Besatzungszone (SBZ) 1945-1948/49. Politische und soziostrukturelle Transformationsprozesse zwischen zwei Diktaturen." am Lehrstuhl von Prof. Dr. Hans-Ulrich Thamer in Münster.

${ }^{19}$ Schneider, Aussiedlung, S. 82.

${ }^{20}$ Bessel/Jessen, Grenzen der Diktatur, S. 13.

${ }^{21}$ Esser, Wanderungssoziologie, S. 217. 
Darstellung der spezifischen Probleme bei der Vertriebenenaufnahme im münsterländischen Greven wird sich anschließen, um sodann nochmals in Ludwigslust weitere Konfliktpunkte zu analysieren, die zu späteren Zeitpunkten auftraten und Aufschluß erlauben über die „Umsiedler“-Politik in der SBZ/DDR.

\section{Das Eintreffen "antifaschistischer Umsiedler" in Ludwigslust:}

Probleme, die gar nicht auftreten durften

Sechs Tage nach ihrer Ankunft in Ludwigslust hatte sich die Situation der kommunistischen Funktionäre, die mit dem Transport Nr. 4368 in die einstige mecklenburgische Residenzstadt gelangt waren, konfliktartig zugespitzt. Bei der Frage der wohnlichen Unterbringung war man noch keinen Schritt weitergekommen. Gemeinsam mit der Stadtverwaltung ${ }^{22}$ waren die Transportmitglieder durch die Straßen gezogen, um vergeblich nach Wohnungen zu suchen, die ihren Ansprüchen genügten. Das übrige tat aufkommender Dauerregen, der am 6. Januar 1946 die Stimmung endgültig auf den Nullpunkt sinken ließ. Die „antifaschistischen Umsiedler“ aus dem Sudetenland mußten nun tatenlos mitansehen, wie ihre Möbel weiterhin unter freiem Himmel standen und alsbald, völlig aufgeweicht durch zweitägigen Dauerregen, aus dem Leim gingen. Noch glücklich schätzen durften sich die Kommunisten ${ }^{23}$ aus dem Sudetenland, wenn sie und ihre Familien ein einigermaßen wetterfestes Dach über dem Kopf hatten.

Das Mobiliar stand weiterhin auf offener Straße und versperrte seit Tagen die Wege im provisorisch angelegten Umsiedlerlager am Ludwigsluster Bahnhof, nachdem es aus den Eisenbahnwaggons ausgeladen worden war $^{24}$. Die Bedeutung dieses Umzugsguts, das die kommunistischen Funktionäre mitnehmen durften, ist vor allem deshalb für die Neuankömmlinge so hoch gewesen, da sie somit in einer Umsiedlungsaktion erster Klasse in die Aufnahmegesellschaft gelangten ${ }^{25}$. In seinem materiellen Wert erschöpfte sich das Umzugsgut nicht: Die Neuankömmlinge kamen nicht als „Habenichtse“, was auch psy-

22 Vgl. den Brief des Bürgermeisters von Ludwigslust an den Präsidenten des Landes MecklenburgVorpommern am 9. 1. 1946; MLHA, MdI 146, ohne Paginierung. Detalliert werden die Ereignisse der ersten Tage geschildert in einem Bericht des Sondergesandten Raddatz vom 10. 1. 1946; vgl. MLHA, Landesleitung KPD Mecklenburg, I, 5. Bl. 180-183.

${ }^{23} \mathrm{BAB}, \mathrm{DO} 1 / 10 / 52, \mathrm{Bl} .57-60$. Wie Manfred Wille dargelegt hat, waren für die KPD lediglich die Kommunisten für die Besetzung von Schlüsselpositionen interessant. Dem Transfer von Sozialdemokraten der Zinner-Gruppe stimmte die KPD noch zu, während sie den Transfer von Jaksch-Leuten hintertrieb; vgl. Wille, Freiwillige Ausreise, S. 35. Die strategische Bedeutung, die Jan Foitzik, Transfer, S. 320, den sudetendeutschen Kommunisten ob ihrer Vertrautheit mit der Volksfront-Taktik zumaß, ist von Wille nachdrücklich bestritten, freilich aber noch nicht schlüssig widerlegt worden; vgl. Wille, Freiwillige Ausreise, S. 46f. Einen Überblick über die Transferaktion geben folgende Akten: BAB, DO 1/10/52, Bl. 45ff., 51; BAB, DO 1/10/52, Bl. 191-192; BAB, DO 1/10/93, Bl. 23.

${ }^{24}$ Eine Lösung war nicht in Sicht: Das Mobiliar, die Koffer voller Kleidung und die sonstige Habe hatte man auch in den Eisenbahnwaggons nicht länger zwischenlagern können; sie gehörten der tschechoslowakischen Regierung. Nur aufgrund von Koordinationsproblemen an der deutschtschechoslowakischen Grenze waren sie nicht ausgeladen worden, mußten aber nach der Ankunft in Ludwigslust unverzüglich auf die Heimreise geschickt werden. Vgl. BAB, DO 1/10/ $52, \mathrm{Bl} .58$.

${ }^{25}$ So wurden sie darüber hinaus vor Plünderern geschützt; auch war am 1.10. 1945 der Chef der Kommandanturdienstverwaltung der SMA in Deutschland von der ZVU darum gebeten worden, daß die Antifaschisten von der Besatzungsmacht „besser behandelt und transportiert werden“ sollten; vgl. $\mathrm{BAB}, \mathrm{DO} 1 / 10 / 86, \mathrm{Bl} .2$. 
chologisch wichtig war. Es war mithin das äußere Zeichen dafür, daß sie mit einer gültigen Eintrittskarte für die vollen Anrechte in der Sowjetischen Besatzungszone ausgestattet waren.

Diese Privilegierung hatte ihren Grund weniger in dem konkreten Verhalten der Funktionäre in der NS-Zeit, in die die neuen Machthaber beim Aufbau einer ,antifaschistischdemokratischen Ordnung" große Hoffnungen setzten. Es lag - insbesondere auf tschechoslowakischer Seite - vielmehr in der Logik des Begründungsmodells für die Vertreibung, daß komplementär zu den Deutschen, die für ihre Unterstützung des Hitlerschen Eroberungskrieges zu bestrafen waren, diejenigen davon weitgehend ausgenommen sein müßten, die sich aktiv gegen das verbrecherische Regime gestellt hatten ${ }^{26}$. So hatten die „antifaschistischen Umsiedler" zwar ihre Heimat und gewohnte Umgebung zu verlassen, durften sich jedoch geschlossen in der "neuen Heimat" ansiedeln und blieben vor allem vor einem Totalverlust ihres Eigentums verschont ${ }^{27}$. Deutlich wird dieses, wenn man sich vergegenwärtigt, daß in der ersten Phase des organisierten Transfers kommunistischer Kader in die SBZ, der im Oktober 1945 einsetzte, sich im Schnitt etwa drei bis vier Familien einen Eisenbahnwaggon teilten ${ }^{28}$.

Wiederum eine andere Frage ist es, inwiefern diese Privilegierung sowie die Etikettierung mit dem Gütesiegel, ein antifaschistischer Kämpfer gewesen zu sein, für die Neuankömmlinge relativierende Statuskonsequenzen aufwiesen. Oder anders gefragt: Wurde die Eintrittskarte, mit der sie von den kommunistischen Machthabern in der SBZ sowie von der Besatzungsmacht ausgestattet worden waren, von allen Teilen der Gesellschaft als Zugangsberechtigung zu den vollen Anrechten akzeptiert?

Als völlige „Habenichtse“ wie die Masse der depossedierten Flüchtlinge und Vertriebenen konnten sie durch die einheimische Bevölkerung nur schwerlich stigmatisiert werden. Aber Fremde blieben sie allemal, die im Gegensatz standen zum Eigenen, zum Gewohnten, Bekannten und Vertrauten. Daraus allein schon konnte Mißtrauen resultieren, da man die Fremden nicht durchschaute. Den „antifaschistischen Umsiedlern“ wurde von seiten der Einheimischen schon insofern erhöhtes Mißtrauen entgegengebracht, als sie in Machtpositionen der lokalen Gesellschaften implantiert werden sollten, zu denen Neuankömmlinge aufgrund des größeren Kohäsionspotentials der Alteingesessenen ${ }^{29}$

${ }^{26}$ Vgl. Hrabovec, Vertreibung und Abschub, S. 373. Die Kriterien dafür, als Antifaschist anerkannt zu werden, variierten nicht unerheblich. Mithin wurde die A-Legitimation bereits an Personen ausgehändigt, die lediglich aufweisen konnten, Brücken gesprengt oder SS-Männer erschossen zu haben. Bemerkenswert sind auch die Widersprüche zwischen den Definitionen, die vom Innenministerium einerseits und vom Landwirtschaftsministerium andererseits aufgestellt wurden; sie halfen aber, den Grund und Boden deutscher Personen schon einmal in tschechische und slowakische Hände zu überführen. Eine wichtige Voraussetzung, als Antifaschist anerkannt zu werden, hatte weniger mit der Vergangenheit als mit der Gegenwart zu tun: Unterstützung erhielten diejenigen Kommunisten und Sozialdemokraten, die bereit waren, den Vertreibungsgedanken zu unterstützen und dann selbst in die SBZ auszureisen. Schließlich galt es ein Fait accompli zu schaffen; vgl. dazu Hrabovec, Vertreibung und Abschub, S. 376 ff., 379, 392, 423.

27 Vergegenwärtigt man sich die Probleme, mit denen Vertriebene nach dem Zerreißen des gewohnten und gewachsenen Sozialverbandes sowie dem Totalverlust des Eigentums zu kämpfen hatten, werden diese Startvorteile der ,antifaschistischen Umsiedler“ augenfällig; vgl. Pfeil: Soziologische und psychologische Aspekte der Vertreibung, S. $40 \mathrm{ff}$.

${ }^{28}$ Hrabovec, Vertreibung und Abschub, S. 405.

${ }^{29}$ So nennen Elias und Scotson in ihrer instruktiven Studie über die Beziehungen zwischen Etablierten und Außenseitern einer Gesellschaft den größeren Zusammenhalt zwischen alteingesessenen Familien und Gruppen, die sich seit mehreren Generationen kennen. Kennzeichnend sind 
wohl kaum Zugang gewährt worden wäre. Bereits im April 1946 wurde in einem Bericht aus dem Kreis Güstrow eindringlich davor gewarnt, die wichtigsten Posten der Dorfgesellschaft wie etwa das Bürgermeisteramt durch Vertriebene und Flüchtlinge besetzen zu lassen: „Und darin liegt vielleicht einer der Kardinalfehler, die zu Beginn unseres Aufbaus gemacht worden sind, daß nämlich an manchen Stellen die einheimische Bevölkerung sich derart zurückgesetzt fühlte zugunsten der sog. ,Fremden', deren politische Herkunft niemand kannte, daß die Kluft nur noch vergrößert wurde. " 30 Während diese Probleme in einem späteren Stadium des Aufnahmeprozesses zu beobachten waren, kam es in Ludwigslust bereits in der ersten Phase zu eklatanten Schwierigkeiten. Ob die Gründe dafür womöglich in einer Abwehrreaktion gegenüber einer politischen Fremdherrschaft $\mathrm{zu}$ sehen sind oder ganz andere Ursachen zugrundeliegen, wird zu klären sein. Jedenfalls scheint es sinnvoll, dabei neueste sozialgeschichtliche Forschungen zum politischen Verhalten in der NS-Zeit heranzuziehen, die davor warnen, ein allzu „starre[s] Bild von Herrschaft versus Gesellschaft, von totalitärer Aggressivität versus milieugebundener Defensive“ zu zeichnen, und stattdessen „die Dominanz gesellschaftlicher Selbstbezogenheit sozialer Konflikte im NS-Staat " ${ }^{\text {31 }}$ betonen.

Zunächst einmal war es in der Tat ein gewaltiges logistisches Problem, das auf die zuständigen Behörden in Ludwigslust zukam, als ihnen am 31. Dezember 1945 um 16.45 Uhr telefonisch mitgeteilt wurde, ein Transport mit 297 sudetendeutschen Antifaschisten, fünf Personenwagen und 26 Güterwaggons im Schlepptau, müsse noch in der Silvesternacht entladen werden. Verteilt wurden sie auf Ludwigslust und die umliegenden Städte und Dörfer. Während in Neustadt-Glewe, Grabow, Dömitz, Eldena sowie im Dorf Groß Laasch die Unterbringung „reibungslos“ gelang, war es in Ludwigslust sechs Tage nach der Ankunft noch immer nicht möglich gewesen, für das zugewiesene Kontingent von 23 Familien mit 83 Personen adäquate Unterbringungen zu finden.

Im Umsiedlerlager am Ludwigsluster Bahnhof jedenfalls konnten sie nicht dauerhaft bleiben. Dafür war die strategische Bedeutung von Ludwigslust bei der Lenkung und Verteilung der Vertriebenentransporte zu groß. Die mecklenburgische Residenzstadt war neben Neustrelitz eine der beiden Durchgangsstationen für Flüchtlingstransporte mit dem Ziel Mecklenburg-Vorpommern. Bereits im Spätherbst 1945 hatte der damalige Präsident der Zentralverwaltung für deutsche Umsiedler, Josef Schlaffer (KPD), sich persönlich vor Ort für den Ausbau der Lagerkapazitäten eingesetzt ${ }^{32}$. Die Zentralverwaltung für deutsche Umsiedler (ZVU) war bestrebt, in einem Rhythmus von 48 Stunden 2000 Vertriebene und Flüchtlinge kurzfristig unterbringen, registrieren, verpflegen und entlassen zu können. Ludwigslust mit seinen guten Bahnverbindungen nach Berlin, Schwerin und Hamburg glich einem Umschlagsplatz und Verschiebebahnhof, auf dem man versuchte, das riesige Heer von Migranten, die sich in Mecklenburg-Vorpommern befanden, in geordnete Bahnen zu lenken.

eine kollektive Identifizierung und die Gemeinsamkeit der Werte; aktiviert wird das Kohäsionspotential durch soziale Kontrolle; vgl. Elias/Scotson, Etablierte und Außenseiter, S. $11 \mathrm{f}$; zur Ambiguität und Ambivalenz des Fremden siehe: Wieslacher, S. 35 ff.; Thamer, Fremde im Land, S. 5; Graumann, Fremde und Fremdes, S. 12 ff.; Landmann, S. $180 \mathrm{f}$.

${ }^{30}$ MLHA, MdI 73

${ }^{31}$ Schlögl/Schwartz/Thamer, Zwischen Loyalität und Resistenz, S. 29.

${ }^{32} \mathrm{Zu}$ Schlaffers Besuch vom 15. bis 18. 11. 1945 siehe BAB, DO 1/10/11, Bl. 46; BAB DO 1/10/40, Bl. 7 f.; BAB DO 1/10/45, Bl. 112. Siehe auch den Bericht einer Mitarbeiterbesprechung in Ludwigslust: MLHA, Landesleitung SED Mecklenburg, IV/L/2/6/331, Bl. 28-33, insb. Bl. 29. 
Obgleich der große Flüchtlingsstrom für Mecklenburg-Vorpommern angesichts der akuten Gefahr großflächiger Seuchenausbreitung im Dezember 1945 gestoppt worden war, hatte diese Anordnung der ZVU keine allzu weitreichenden Folgen für Ludwigslust. Zwar wurde die Zeit für eine Umstrukturierung des Lagers genutz ${ }^{33}$, aber auch weiterhin strömten Menschen in die nur dünn besiedelten Gebiete Mecklenburg-Vorpommerns, dessen Bevölkerungszahl sich bereits bis zum Jahreswechsel 1945/46 nahezu verdoppelt hatte. Für den 7. Januar erwartete der Sonderbeauftragte der ZVU, der mit den Ludwigsluster Verhältnissen gut vertraute Fritz Raddatz, die Ankunft von 1800 Flüchtlingen. Ein nächster Transport sollte am 10. Januar folgen, so daß Raddatz die Räumung des Lagers anordnete ${ }^{34}$. Tatsächlich trafen bereits am 6. Januar 1000 Vertriebene ein. Für die „antifaschistischen Umsiedler“ hieß dieses, daß die Zustände im Lager zunehmend unhaltbar wurden und eine anderweitige, wohnlichere Unterbringung notwendig erschien. Die drängenden, noch nicht gelösten Alltagsprobleme blieben nicht ohne Einfluß auf ihre Haltung gegenüber der Aufnahmegesellschaft. Hier trat ein entscheidender, freilich wenig überraschender Wandel ein: Sie sahen mittlerweile keine Perspektive mehr für den Aufbau einer neuen Existenz in Ludwigslust - einem Ort, in den sie überdies ursprünglich gar nicht hatten ziehen wollen und für den sie auch gar nicht bestimmt gewesen waren. Auf der Fahrt erst hatte sich entschieden, daß die „antifaschistischen Umsiedler" aus dem Bezirk Neudeck in Mecklenburg siedeln sollten. Damit wurden mit einem Federstrich die Ergebnisse monatelanger Verhandlungen verworfen, den überwiegend aus Metall- und Textilarbeitern bestehenden Transport nach Thüringen zu lenken, das in der Tat geeignetere Arbeitsmöglichkeiten als das industriearme Mecklenburg-Vorpommern geboten hätte ${ }^{35}$.

\subsection{Die Suche nach politischen Lösungsmöglichkeiten}

Auf einer eilends einberufenen Besprechung am Abend des 6. Januar mit den maßgeblichen politischen Kräften vor Ort sowie einem Vertreter des Landesumsiedleramtes Schwerin wurde der Beschluß gefaßt, alle Möglichkeiten zu sondieren, die 83 Personen in die ursprünglich vorgesehenen Aufnahmeorte Rudolstadt und Zwickau umzuleiten. Die kommunistischen Funktionäre aus der Tschechoslowakei hielten dabei ihre Verbitterung über ihre Aufnahme in Ludwigslust keineswegs zurück: „Da die Aussichten, Wohnungen und Beschäftigungen zu bekommen, äußerst gering sind und durch die bisherigen Ereignisse bewiesen war, daß es entweder tatsächlich nicht möglich ist oder von bestimmter Weise verhindert wird, haben wir alle nur noch den einen Wunsch, uns an den

${ }^{33}$ BAB, DO 1/10/45, Bl.120-125; auf die konzeptionellen Überlegungen der ZVU-Spitze um den neuen Präsidenten Engel im Januar 1946, die Kompetenzen der ZVU zu erweitern, kann hier nur verwiesen werden. Vgl. Schwartz, Zwischen Zusammenbruch und Stalinisierung, S. $48 \mathrm{f}$.

${ }^{34}$ MLHA, Kreistag/Rat des Kreises Ludwigslust, Nr. 385.

${ }^{35} \mathrm{BAB}, \mathrm{DO} 1 / 10 / 52$, Bl. 54-56. Siehe auch die strategischen Überlegungen der KPD im Dezember 1945: SAPMO, DY 30/I/2/5/41, Bl. 53. Die geringe Industrieansiedlung im Kreis Ludwigslust belegt ein Exposé, das offensichtlich vom Landrat als eine Art Rechenschaftsbericht im Vorfeld der Kreis- und Landtagswahlen im Herbst 1946 erstellt worden ist. MLHA, SED Bezirksleitung Schwerin, IV/4/05/401: Folgende Zahlen werden für das Kreisgebiet genannt: „18 Sägewerke, 9 Ziegeleien, 2 Dachpappenfabriken; 2 Lederfabriken; 5 Betriebe der Elektroindustrie; 3 pharmazeutische Betriebe; 3 holzverarbeitende und 2 eisenverarbeitende Betriebe. Zur Zeit 1293 Handwerksbetriebe, davon 253 in der Stadt Ludwigslust." 


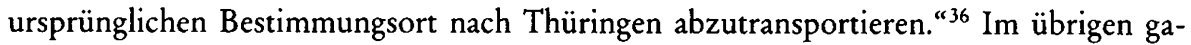
ben sie unmißverständlich zu verstehen, „daß sie keineswegs gewillt wären, sich eine derartige Behandlung, die Antifaschisten unwürdig wäre, gefallen zu lassen “37.

Dem Wunsch, in Thüringen zu siedeln, versuchten die verantwortlichen Dienst- und Parteistellen - selbst auf Landesebene - nachzukommen. Sie gaben das Versprechen, für den Fall des Weitertransports zehn Güterwagen und zwei Personenwagen bereitzustellen. Nur wenige Tage später jedoch wird man das Vorgehen von Behörden und Partei eher als Doppelstrategie charakterisieren müssen: Weiterhin wurden Kontakte nach Thüringen geknüpft, um den Abtransport der 83 Kommunisten in die Wege zu leiten; der Schwerpunkt lag aber auf den Bemühungen, Voraussetzungen für einen dauerhaften Verbleib der "antifaschistischen Umsiedler" in Ludwigslust zu schaffen ${ }^{38}$. Hier galt es vor allem die vordringliche Frage der wohnlichen Unterbringung zu lösen, zumal man erneut nicht über ein unzulängliches Provisorium hinausgekommen war. Die "antifaschistischen Umsiedler" waren mit Ausnahme des Transportführers, dem man eine feste Wohnung zugewiesen hatte, in den Baracken des ehemaligen Konzentrationslagers Wöbbelin untergebracht ${ }^{39}$.

Etwas salopp formuliert läßt sich feststellen, daß in Ludwigslust alles schiefgegangen war, was bei der Aufnahme schiefgehen kann. Das gilt insbesondere für Menschen, die nicht einfach flüchtig untergebracht, sondern dauerhaft angesiedelt werden sollten. Bei der Funktionärsgruppe hatte sich bereits nach wenigen Tagen der Eindruck verfestigt, völlig unerwünscht zu sein. Die Privilegien, die ihr noch beim ,Abschub' gewährt worden waren, schienen in der neuen Heimat wertlos zu sein. Wie entscheidend aber die Erfahrungen der ersten Tage nach der Ankunft für die Geschwindigkeit der weiteren Eingliederung sind, ist aus der Migrationsforschung hinreichend bekannt. Gerade die Kontakte in dieser ersten Aufenthaltsphase, die von starker Desorientierung und Unsicherheit geprägt ist, bestimmen beim Neuankommenden den Grad an Bereitschaft, sich künftig seiner neuen Umgebung anzupassen. Ein nicht zu unterschätzendes Gewicht kommt der Lösung besonders drängender Alltagsprobleme wie der Beschaffung von Wohnungen und Arbeitsmöglichkeiten $\mathrm{zu}^{40}$.

\subsection{Exkurs: Einsatz von „antifaschistischen Umsiedlern“} zur Behebung des Kadermangels

Stärker noch als bei der Aufnahme vermeintlich "normaler" Vertriebener prallten nach der Ankunft "antifaschistischer Umsiedler" das vor Ort und in der Praxis Machbare sowie das aus politischen Erwägungen Wünschbare aufeinander. Jan Foitzik hat bereits 1983 den Kadertransfer von Kommunisten in die SBZ in seiner Funktion eingehend be-

${ }^{36} \mathrm{BAB}, \mathrm{DO} 1 / 10 / 52, \mathrm{Bl} .58$.

37 MLHA, MdI 146.

${ }^{38} \mathrm{BAB}, \mathrm{DO} 1 / 10 / 52$, Bl. 57; zudem Bericht Otto Lechky vom 6. 2. 1946: MLHA, Landesleitung der SED Mecklenburg, IV/2/6/331, Bl. 41.

39 Treffend wurde in einem Brief an die ZVU angesichts der wiederum unzureichenden Unterbringung davon gesprochen, man sei "vom Regen in die Traufe gelangt“; BAB, DO 1/10/52, Bl. 59.

40 Esser, Wanderungssoziologie, S. 80, 93; Borrie, Cultural Integration, S. 94. Das gilt unabhängig davon, ob die Migranten freiwillig die Wanderung antreten oder ob dieses unter Zwang geschieht. Während bei Personen, die gegen ihren Willen zu Migranten werden, die Rückkehrabsichten wachsen, neigen Personen, die eher freiwillig und mit bestimmten Erwartungen gekommen sind, zu umso stärkeren Frustrationen. Vgl. Esser, Wanderungssoziologie, S. $88 \mathrm{f}$. 
schrieben. Das Ziel, den Kadermangel der mecklenburgischen KPD durch Genossen zu beheben, die in der Partei- und Verwaltungstätigkeit erfahren waren, gewann um die Jahreswende 1945/46 nicht zuletzt angesichts der nunmehr anvisierten Fusion mit der SPD an Aktualität. Insbesondere Franz Dahlem, Mitglied des Zentralkomitees der KPD, drängte auf einen verstärkten Kadereinsatz in Mecklenburg-Vorpommern, als er die politische Bedeutung dieser Migranten hervorhob. Er rückte somit von der bisherigen $\mathrm{Hal}-$ tung der Partei ab, die "antifaschistischen Umsiedler" vornehmlich entsprechend ihrer beruflichen Qualifikation einzusetzen. Trotz seiner Größe und seines offensichtlichen Kadermangels hatte Mecklenburg lediglich 1754 Kommunisten aus der Tschechoslowakei übernommen ${ }^{41}$. Das waren gerade einmal etwas mehr als zehn Prozent der „Antifaschisten" aus der Tschechoslowakei, die laut einer ZVU-Aufstellung bis zum 23. Dezember 1945 in die SBZ transferiert worden waren. Dabei ist zudem zu berücksichtigen, daß sich diese Zahl auf sämtliche Familienmitglieder und nicht auf die Funktionäre als solche bezieht.

Indem Dahlem in den kommunistischen Migranten vor allem ein „klassenbewußtes Proletariat" erkannte, schrieb er ihnen eine wichtige Funktion beim Ausbau der Machtstellung der Partei zu: "Jetzt haben wir die Gelegenheit, wirklich das ganze Land zu' durchziehen, das bisher keine Arbeiterkader, geschweige denn kommunistische Kräfte hatte [...]."42 Entsprechend erwartete die Partei die aktive Mitarbeit der „antifaschistischen Umsiedler “43. Da Dahlem zudem darauf verwies, daß unter den zumeist gewerkschaftlich oder genossenschaftlich organisierten Neuankömmlingen „alle Berufe, Handwerker, Lehrer usw." vertreten seien, unterstrich er gewissermaßen ihre universelle Verwendbarkeit. „So soll man das Problem sehen, dann wird auch das Interesse dafür da sein", erinnerte Dahlem an die ausgeschöpften Ressourcen fähigen Personals, das der Partei lediglich zur Verfügung stand. Anklang glaubte Dahlem mit seiner Argumentation „nicht nur oben“ in der Partei zu finden, „sondern auch bei den Orts- und Kreisleitungen ${ }^{\prime 4}$.

41 BAB, DO 1/10/52, Bl. 35. Für die Verteilung gab es eine einfache Faustregel, die sich an den Arbeitskräftebedürfnissen orientierte: Metallarbeiter kamen in die Provinz Sachsen; Glasarbeiter und Textilarbeiter nach Thüringen; vgl. BAB, DO 1/10/35, Bl. 76-80, 78. Siehe die programmatischen Festlegungen in einem Schreiben von Walter Ulbricht vor dem 1. 10. 1945 an die SMAD; SächsHStA, SED-Landesleitung A 25, ohne Paginierung.

42 SAPMO, DY 30/12/5/41, Bl. 59 .

${ }^{43}$ Das galt nicht nur für diese Gruppe, sondern für jedes Parteimitglied, gleichgültig, wohin es die Wirren des Krieges verschlagen hatten. So bekam ein Ostpreuße, der sich im niederbayerischen Vilshofen befand, vom ZK der KPD im Februar 1946 als Aufgabe gestellt: „Wer Antifaschist ist, muß überall dort arbeiten, wo er sich im gegenwärtigen Augenblick befindet, und sei es auch in Bayern." Die Fremdheit, die erst in der Nähe des Fremden spürbar wird, wie Georg Simmel gezeigt hat, sowie die eigentümliche Ambivalenz, die der Begegnung mit dem Fremden innewohnt und sich zwischen Faszination und Abstoßung bewegt, waren der KPD offensichtlich nicht bewußt. Unter Genossen durfte es zu keinen Abstoßungsprozessen kommen - angesichts der Größe der Aufgabe. So heißt es in dem zitierten Schreiben der Partei: „Bekanntlich ist gerade die Reaktion schr stark und Antifaschisten, die das Schicksal nach dort verschlagen hat, haben die große Aufgabe, mitzuhelfen und die Reaktion in Bayern auszurotten." SAPMO, RY1/I2/5/ 45a, Bl. 290.

${ }^{44}$ Zugleich hoffte Dahlem darauf, daß diesc „Antifaschisten“ die "großen undurchsichtigen, zum Teil faschistischen Massen bearbeiten“ und umerziehen könnten. Insofern sei es "kein Zufall, daß zuerst die Kommunisten kommen und dann die große Masse der Leute aus der Tschechei und dann die Millionen aus Polen“. Vgl. SAPMO, RY1/I2/5/45a, Bl. 290. Diese Idee verfolgte Dahlem offenbar seit mehreren Monaten; vgl. seinen Bericht über die Parteiorganisation der 
ZVU-Präsident Josef Schlaffer hatte dem politischen Wert der Kommunisten aus dem Sudetenland ebenfalls Priorität eingeräumt und im Dezember 1945 angeordnet, verstärkt kommunistische Familien nach Mecklenburg zu schicken ${ }^{45}$. Zugleich kam er damit Wünschen der Genossen vor Ort nach. Der Landrat von Ludwigslust und spätere ZVU-Mitarbeiter Hermann Schuldt hatte schon früh die Forderung nach zweitausend „antifaschistischen Umsiedlern“ für Mecklenburg-Vorpommern aufgestellt, zumal sich trotz der Bodenreform vielerorts in der Bevölkerung noch immer nicht die intendierte Loyalität gegenüber der KPD eingestellt hatte ${ }^{46}$.

Als die ZVU ein Jahr später Bilanz zog, war jegliche Euphorie verflogen. Berichte über Probleme mit den „antifaschistischen Umsiedlern“ aus allen Provinzen und Ländern häuften sich. Vor allem wurde beklagt, daß den Neuankömmlingen die Anerkennung verwehrt blieb. Es sei eine Tatsache, daß in Mecklenburg-Vorpommern ,in den unteren Organisationen bis zu den einzelnen Genossen der Landesvorstände der Wert dieser Funktionärskader verkannt wird “47. Der Leiter des Umsiedleramtes der Landesverwaltung in Schwerin hatte bereits einige Monate zuvor unumwunden von einem Fiasko gesprochen, das man bei der Aufnahme der „antifaschistischen Umsiedler“ erlebt habe ${ }^{48}$. Längst hatte sich gezeigt, daß sich dieser Problemkomplex nicht allein auf die zunächst zentrale Frage der Wohnungsunterbringung reduzieren ließ, wie dieses einige ZVU-Strategen allzu leichtfertig und voreilig taten ${ }^{49}$.

\subsection{Barrieren einer erfolgreichen Integration}

Für Ludwigslust erlaubt es die Quellenlage ${ }^{50}$, verschiedene Konfliktkonstellationen auf unterschiedlichen Ebenen sowie Reibereien zwischen Partei- und Verwaltungsstellen und parteipolitischen Streit zu rekonstruieren - allesamt Faktoren, die als Barrieren einer erfolgreichen Integration entgegenstanden.

KPD in der Sowjetzone, den er am 16.10. 1945 abgeschlossen hatte, SAPMO, NY4072/209, Bl. 9. Zum Kadermangel der KPD siehe: Geschichte der Landesparteiorganisation der SED Mecklenburg, S. 134.

${ }^{45} \mathrm{BAB}, \mathrm{DO} 1 / 10 / 35, \mathrm{Bl} .76-80$.

${ }^{46}$ Vgl. dazu den Bericht des Landrates von Ludwigslust, Hermann Schuldt, 28. bis 30. 12. 45, zur politischen Einstellung der Bevölkerung: „Bei den Flüchtlingen, die angesiedelt sind, herrscht folgende Stimmung: Warum anfangen zu wirtschaften, wenn wir bald wieder zurückkönnen auf die andere Seite der Oder. Bei den Ortsansässigen kommt folgende Stimmung zum Ausdruck: Die Engländer werden dieses Gebiet bald besetzen und die alten Zustände des Gutsbetriebes wieder herstellen. Auf Grund dieser politischen Einstellung und Beeinflussung durch die Nazipropaganda ist jede Aktivität zur Bearbeitung der neuen Arbeitsstellen gelähmt." SAPMO, RY1/IV2/7/245, Bl. 56-58, Bl. 57; MLHA, MdI 77, Bl. 521-522; siehe in diesem Zusammenhang auch Bauerkämper, Neubauern in der SBZ/DDR, S. 113. Zur Forderung nach den 2000 „antifaschistischen Umsiedlern": BAB, DO 1/10/29, Bl. 129-147, 146.

$47 \mathrm{BAB}$, DO 1/10/52, Bl. 191. Weitere Klagen: BAB, DO 1/10/41, Bl. 160 (Sachsen); BAB, DO $1 /$ 10/43, Bl. 47f. (Thüringen) oder BAB, DO 1/10/51, Bl. 203 (Provinz Sachsen).

48 Direktorenkonferenz der ZVU am 21. 5. 46. BAB, DO 1/10/30, B1. 134.

49 So etwa Georg Chwalczyk in seinem Bericht über die Arbeitskonferenz der Umsiedlerabteilung Schwerin vom 12. bis 14. April 1946; BAB, DO 1/10/34, Bl. 4-13, 10.

${ }^{50}$ Heranzuziehen sind Akten aus den ZVU-Beständen aus dem Bundesarchiv, Abteilungen Potsdam; vereinzelte Aussagen finden sich auch in Archivalien, die in der SAPMO gelagert sind; wichtige Quellenbestände sind im MLHA zu finden: Zu erwähnen ist das Parteiarchiv mit den Beständen der Landesleitung KPD Mecklenburg, Landesleitung SED Mecklenburg sowie der SED Bezirksleitung Schwerin; aus den staatlichen Aktenbeständen diejenigen des Rates und Kreistages Ludwigslust sowie des Ministeriums des Innern. 
So mangelte es erstens an einer festen Zuordnung der Zuständigkeiten. Zwischen der KPD und der Umsiedlerverwaltung, namentlich mit Fritz Raddatz als Sonderbeauftragtem der ZVU, kam es in dieser Frage zu handfesten Auseinandersetzungen. Raddatz beklagte sich, der Kreissekretär der KPD habe die Verteilung der ,antifaschistischen Umsiedler" zur Sache der Partei erklärt: „Dem Umsiedleramt wurde entgegen den sonst bei Transporten üblichen Obliegenheiten lediglich eine beratende Stimme zugestanden. ${ }^{\text {" } 1}$ In der Tat waren die Parteimitglieder im Dezember 1945 von der Landesleitung der KPD zu verstärkter Arbeit mit den „Umsiedlern“ aufgerufen worden. Die Vorgabe, die Umsiedler nicht nur menschenwürdig unterzubringen, die Distanz zu ihnen zu überbrücken „und sie in die antifaschistisch-demokratische Geistesrichtung zu lenken "52, nahm der Kreissekretär der KPD in Ludwigslust, Friedrich Fellenberg, offensichtlich sehr ernst. Das mag auch insofern verständlich sein, als die Parteileitung ihn zur Verantwortung hätte ziehen können. Auf das logistische Know-how des ZVU-Mitarbeiters konnte er freilich nicht verzichten. So mochte der KPD-Kreissekretär als Sündenbock nicht herhalten, als sich die Kritik an der verfahrenen Situation auf eine einzige Person konzentrierte: In dieser undankbaren Rolle fand sich der Sonderbeauftragte der ZVU wieder, der zwar ständig betonte, er sei für die Mißstände nicht verantwortlich, aber gerade deshalb bei den Neuankömmlingen in den Ruf kam, sich aus der Verantwortung stehlen zu wollen ${ }^{53}$. Wegen verschwiegener Angehörigkeit zur NSDAP wurde er Mitte Januar verhaftet ${ }^{54}$. Doch die Annahme, man habe den Kern des Übels erfaßt und nun werde alles normal funktionieren, erwies sich als Illusion. Die Dynamik der Konflikteskalation nahm eher noch $\mathrm{zu}^{55}$.

Sodann ist zweitens nicht von der Hand zu weisen, daß die unbestreitbar hohen Ansprüche der kommunistischen Funktionäre die Wohnungsunterbringung erschwerten. Wer seine gesamte persönliche Habe samt Mobiliar mitnehmen darf, hofft selbstverständlich, daß er nicht den überwiegenden Teil davon auf einem Speicher zu deponieren hat. Indem die Ludwigsluster Verwaltung unvermindert davon ausging, die Neuankömmlinge seien zu keinen Konzessionen bereit, mußte sie zu dem Ergebnis kommen, „daß es unmöglich sei, die Familien in Wohnungen unterzubringen ${ }^{456}$. In einem Klima wachsenden gegenseitigen Mißtrauens erwarteten die Konfliktparteien wenig Gutes voneinander. Zumal umgekehrt die kommunistischen Funktionäre die mangelnde Kooperationsbereitschaft der Verwaltungsstellen beklagten, die den Genossen einfach unterstellt hätten, jeder wolle „eine Küche und 3-4 Zimmer" haben - „was ja nicht der Fall ist“57. Bis die Erwartungshaltung der Neuankömmlinge auf massiven Druck der Ludwigsluster Kommunisten heruntergeschraubt wurde, war es für die bürgerlichen Parteien ein leichtes, daraus politisches Kapital geschlagen.

Hinzu kam drittens, daß die Wohnungssituation durch die Truppen der Besatzungsmacht erheblich verschärft wurde. Erschwerend wirkten neben dem ohnehin hohen Prozentsatz in Anspruch genommener Wohnungen die fortwährenden willkürlichen Be-

51 MLHA, Landesleitung KPD Mecklenburg, I/5, Bl. 180-183, 180.

${ }^{52}$ MLHA, Landesleitung KPD Mecklenburg, I/4, Bl. 171.

${ }^{53}$ BAB DO 1/10/52, Bl. 58.

${ }^{54}$ MLHA, MdI 843.

55 Glasl, Konfliktmanagement, S. $188 \mathrm{ff} ., 203 \mathrm{ff}$.

${ }^{56}$ MLHA, Landesleitung SED Mecklenburg, IV/L/2/6/331, Bl. 41.

57 Brief der Umsiedler an den Genossen Kurt Bürger am 31.1. 1946; MLHA, Landesleitung SED Mecklenburg, IV/L/2/6/334, Bl. 7. 
schlagnahmungen, vor denen die kommunistischen Funktionäre nicht verschont blieben. Beispielsweise hatten sie in Eigenarbeit eine Villa so weit hergerichtet, daß sie bewohnbar war, da wurde diese kurzerhand von sowjetischen Soldaten konfisziert. Obendrein erlebten die „antifaschistischen Umsiedler" die Rote Armee vollkommen anders, als diese ihnen aufgrund ihrer willfährigen Haltung in der Tschechoslowakei begegnet war. Nun bekamen sie von der Besatzungsmacht zu hören, „sie möchten sehen, daß sie fortkommen" 58 - am besten dorthin zurück, wo sie herkämen. Auch unter diesem Aspekt erlebten sie ihren eigenen Kulturschock, der das Gefühl der Fremdheit nochmals verstärkte ${ }^{59}$.

Viertens verschloß sich die KPD selbst den ankommenden Genossen aus der Tschechoslowakei. Nur allzu leicht wurden sie in die Ecke der Sektierer gestellt. „Sehr viele Genossen, die aus jenen Gebieten kommen, glauben, sie kommen in ein Stück SowjetDeutschland. “60 Zudem war gar nicht bekannt, daß sie ehemalige Funktionäre der KPC gewesen waren ${ }^{61}$. Aufgrund ihrer Privilegien beim Transfer wurden sie mit Neid betrachtet $^{62}$. Auch hatten sie sich des Verdachts zu erwehren, in ihre Reihen hätten sich „faschistische Elemente" eingeschlichen, wie dieses vereinzelt beobachtet wurde ${ }^{63}$. Mit sozialen Schließungsprozessen innerhalb der Partei hatten sie ebenso zu kämpfen, fürchteten doch die heimischen Genossen um ihre gerade erst eingenommenen Posten in Partei und Verwaltung ${ }^{64}$. Zu diesen Konkurrenzkonflikten um Status, Rang, Ansehen und Einfluß kamen kulturelle Konflikte um die Deutungsmonopole. Der Vorwurf des Sektierertums ist ein Ausdruck dafür. Derartige Ängste den Fremden gegenüber wurden in Ludwiglust zunächst noch nicht virulent, waren allenfalls latent vorhanden, da es primär noch um die Lösung grundlegender Probleme wie die Wohnungsunterbringung ging.

Politisch-kulturelle Unterschiede kamen fünftens allerdings zum Tragen, als mit der zunehmenden Komplexität der Probleme und der größer werdenden Spannung auf beiden Seiten die Neigung zur Simplifizierung sich breit machte, wie sie in Konfrontation mit einer als unbefriedigend empfundenen Situation nicht außergewöhnlich ist. Die Ankömmlinge nahmen Zuflucht zu radikalen Vereinfachungen in Form von Stereotypen. „Alles, was nicht ihren Wünschen entspricht, sehen sie als faschistisch an" ${ }^{\text {"65 }}$, bemerkte ein Mitarbeiter der Umsiedlerverwaltung in Thüringen treffend. In Mecklenburg-Vor-

${ }^{58}$ MLHA, Landesleitung SED Mecklenburg, IV/L/2/6/334, Bl. 7.

59 Allgemein ist das Phänomen des Kulturschocks bei der Ankunft der Vertriebenen in ihrer neuen Heimat häufig zu beobachten gewesen; siehe dazu Tolksdorf, Kulturelle Integration, S. 110; im größeren Zusammenhang zudem Bade, Homo Migrans, S. 44.

60 SAPMO, RY1/I2/5/41, Bl. 56.

${ }^{61}$ MLHA, Landesleitung KPD Mecklenburg, I/5, Bl. 240.

${ }^{62}$ Siehe für Ludwigslust: BAB, DO 1/10/52, Bl. 60 sowie MLHA, Landesleitung SED Mecklenburg, IV/L/2/6/331, Bl. 41; ferner etwa für den Kreis Schöneberg: MLHA, Landesleitung KPD Mecklenburg, I/5, Bl. 243.

${ }^{63}$ Vgl. Brief von ZVU-Präsident Engel vom 24. 1. 46 an die Landesregierungen. Betr. Lehrreiche Erfahrungen mit einem falschen Antifaschisten-Transport. BAB, DO 1/10/53, Bl. 133-134. Die produktive Rolle, die die Parteileitung den „Fremden“ zugeschrieben hatte, mußte nicht von allen Parteimitgliedern so wahrgenommen und eingeschätzt werden. Konkurrierende Interessen senken gemeinhin die Akzeptanz der Fremden; siehe hierzu mit weiteren Beispielen Thamer, Fremde im Land, S. 5.

${ }^{64}$ MLHA, Landesleitung KPD Mecklenburg, I/5, Bl. 334. Siehe auch weitere Beispiele bei Stößel, Positionen und Strömungen, S. 246.

${ }^{65}$ BAB DO 1/10/30, Bl. 134; siehe auch BAB DO 1/10/41, Bl. 161. Vom "fremden Blick“, der in der Regel größere Objektivität und Unbefangenheit verbürgt, kann somit keine Rede sein, als die „antifaschistischen Umsiedler“ ihre Felle schwimmen sahen. 
pommern, das den sudetendeutschen Familien mithin als „Ursprung des Faschismus" 66 galt, war diese Simplifizierung, die das Dilemma nur vergrößerte, überaus verbreitet. Sie wurden dadurch ,in ihrem Denken starrer, in ihrem Auftreten radikaler und in ihren Forderungen extremer ${ }^{467}$ - als es konkret um die sofortige Räumung von Wohnungen ging, die von vermeintlichen Faschisten bewohnt wurden.

\subsection{Wohnungsräumungen als Lösungsansatz?}

Zunächst versuchten die Ludwigsluster Kommunisten das Problem auf herkömmliche Weise zu lösen, indem sie sich auf eine Verordnung des Präsidenten des Landes Mecklenburg-Vorpommern vom 29. August 1945 zur „Inanspruchnahme von Wohnraum und Gebrauchsgegenständen durch die Gemeinden" beriefen. Ausdrücklich besagte die Verordnung, es sei die „Pflicht des gesamten Volkes, denen, die durch den Krieg und seine Folgen ihre Heimat, ihre Wohnungen und ihre Habe verloren haben, wieder zu einem -

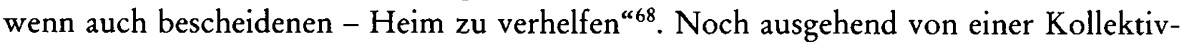
schuld des deutschen Volkes wurde betont, das "ganze deutsche Volk" sei heranzuziehen zur Wiedergutmachung der Schäden. Vor allem in den Blick nahm man dabei „die Mitglieder der früheren Nazi-Partei [. . . ] und unter diesen wieder die Aktivisten“. Von einer völligen Enteignung war allerdings keine Rede. Ausdrücklich wurde mißbilligt, „daß dem Einen alles genommen und dem Anderen alles gegeben werden soll“.

Als es am 24. Januar bei einer Sitzung des - aus KPD, SPD und CDU bestehenden Antifaschistischen Blocks zu einer intensiven Diskussion über das Wohnungsproblem der "antifaschistischen Umsiedler" kam, war von den einschränkenden Bestimmungen dieser Verordnung nur wenig zu spüren. Die Stadtverwaltung, vertreten durch ein Parteimitglied der Kommunisten, brachte den Vorschlag ein, die „Nazi-Familien“ aus Ludwigslust auszuweisen und sie im Wöbbeliner Konzentrationslager unterzubringen. Zur Begründung wurde angeführt, den sudetendeutschen Familien, von denen einige mehrere Jahre in Konzentrationslagern zugebracht hätten, sei es nicht länger zumutbar, in Wöbbelin zu verbleiben. Währenddessen seien „die Faschisten noch in ihren Wohnungen “69. Dem Einwand eines Vertreters der Sozialdemokraten, die zu hohen Ansprüche dieser Familien hätten bislang eine Unterbringung vereitelt, entgegnete der Kreissekretär der $\mathrm{KPD}$, diese Erwartungen seien bereits "auf ein bescheidenes Maß" heruntergeschraubt worden. Einstimmig wurde am Ende der Entschluß gefaßt, die Polizei solle in Abstimmung mit der Besatzungsmacht den „Faschisten“ die Räumung ihrer Wohnungen befehlen. Und nur für den Fall, daß sich diese nicht selbst neuen Wohnraum beschaffen könnten, würden sie in das Lager Wöbbelin eingewiesen.

\subsection{Lösungsansätze zur Wohnungsunterbringung als Gegenstand politischer Auseinandersetzungen}

Mit der politischen Einmütigkeit war es wenige Tage später bereits vorbei. Die rücksichtslose Vorgehensweise bei der Räumungsaktion hatte Zweifel an der Richtigkeit des Beschlusses genährt: Der Bürgermeister, ein Sozialdemokrat, sah sich jedenfalls gezwun-

${ }^{66}$ MLHA, Landesleitung KPD Mecklenburg, I/5, B1. 334.

67 Glasl, Konfliktmanagement, S. 199. Vgl. Brief der Umsiedler an den Genossen Kurt Bürger am 31. 1. 1946; MLHA, Landesleitung SED Mecklenburg, IV/L/2/6/334, Bl. 7.

${ }_{68}^{6}$ MLHA, MdI 604, Bl. 3 f.; ebenso die weiteren Zitate.

${ }_{69}$ MLHA, SED Bezirksleitung Schwerin, IV/4/04/411, Bl. 13. 
gen, am 30. Januar 1946 einen Richtlinien-Katalog zu formulieren, um den Auswüchsen Herr zu werden. So wurde festgelegt, lediglich die Wohnungen von ehemaligen NSDAP-Mitgliedern, die vor 1933 der Partei beigetreten seien, dürften geräumt werden. Auch sei ihnen „eine angemessene Frist zur Räumung“ zu geben, damit sie bei Freunden oder Verwandten unterkommen könnten. Die bisherige Vorgehensweise, ihnen eine Frist von 24 Stunden zu geben, bezeichnete der Bürgermeister „nicht als angemessen“. Ausdrücklich wies er abschließend darauf hin, daß die Familien aus der Tschechoslowakei „nicht besser untergebracht werden können als die eingesessene Ludwigsluster Bevölkerung“. Die nämlich bewohne „in der größten Mehrzahl noch höchstens 1 Zimmer und Küche“, so daß die Unterbringung „im allgemeinen auch nur in einem Zimmer geschehen" könne.

Auch von seiten der Parteien regte sich Widerstand gegen die gefaßten Beschlüsse. Am 31. Januar kam es zu einer außerordentlichen Sitzung des antifaschistischen Blocks in Ludwigslust. Das einzige Thema war die Unterbringung der „antifaschistischen Umsiedler". Die wiederum hatten sich inzwischen ebenfalls zu Wort gemeldet und Klage darüber geführt, daß die Liste der ehemaligen Nazis zwar 40 Namen umfasse, aber erst sechs Wohnungen geräumt worden seien ${ }^{70}$.

Zwei Stunden tagten die Mitglieder des antifaschistischen Blocks. Am Ende wurde festgehalten, „daß der gefaßte Beschluß vom 24. 1.46 bestehen bleibt und die Aktion weiter durchgeführt werden kann"71. Das bedeutete zunächst einmal, daß weitere Räumungen von den drei Parteien mitgetragen wurden. Allerdings weist die Kann-Bestimmung darauf hin, daß sich der antifaschistische Block auf eine weitere Vorgehensweise verständigt hatte. „Ferner wird je ein Vertreter der 3 Parteien am Montag morgen letztmalig beim Kommandanten vorstellig werden, um ihn zu ersuchen, Wohnräume freizugeben, da ein Teil des von der Roten Armee besetzten Wohnraumes nicht in der genügenden Weise ausgenutzt ist."

$\mathrm{Zu}$ werten ist der getroffene Beschluß als ein schwer umrungener Kompromiß, zumal die CDU für ein sofortiges Ende dieser Zwangsräumungen eingetreten sein dürfte. Das zumindest legt ein Brief an den Präsidenten des Landes Mecklenburg-Vorpommern vom 1. Februar nahe. Ihre Argumentation war dabei besonders geschickt angelegt, um nicht als revanchistisch und nazi-freundlich gegeißelt $\mathrm{zu}$ werden. Man verwies darauf, daß die ehemaligen NSDAP-Mitglieder lediglich ein oder zwei Zimmer ihrer früheren Wohnungen innehätten und ihren Wohnraum mit Flüchtlingen teilten. Müßten sie ihn nun räumen, hätten die Flüchtlinge ebenfalls auszuziehen, wobei wieder neue Wohnprobleme entstünden ${ }^{72}$. Als zweites Argument führten sie an, auch sogenannte Mitläufer hätten Wohnungen räumen müssen - ein Aspekt, auf den noch zurückzukommen sein wird.

Das Modell, auf das die neuen Machthaber in der SBZ seit dem Sommer 1945 nur allzu gern zurückgriffen, nämlich Probleme auf Kosten der ehemaligen Nationalsozialisten zu lösen, erwies sich als unzureichend und politisch höchst umstritten. Die Zwangsräumungen wurden zwar noch fortgeführt. Der Schwerpunkt des weiteren Vorgehens lag aber nun darauf, bei der russischen Militärverwaltung die Freigabe von nicht benötigtem Wohnraum zu erreichen. Die Festlegung, jeweils ein Vertreter der Parteien werde beim

\footnotetext{
70 MLHA, Landesleitung SED Mecklenburg, IV/L/2/6/331, Bl. 41.

71 MLHA, SED Bezirksleitung Schwerin, IV/4/05/411, Bl. 18.

72 MLHA, MdI 214, ohne Paginierung.
} 
Kommandanten vorstellig, hieß zugleich, daß auch die KPD mit in die Pflicht genommen wurde. Wenige Tage später dürfte die CDU einen weiteren Erfolg verbucht haben: Nachdem sie sich an den Präsidenten des Landes Mecklenburg-Vorpommern mit dem Hinweis gewandt hatte, daß auch die Wohnungen nomineller Nationalsozialisten geräumt worden seien, erging von der Landesverwaltung die Aufforderung, in diesen Fällen die Räumungen wieder rückgängig zu machen. Dabei dürfte Ludwigslust kein Einzelfall gewesen sein, zumal sich der Leiter des Schweriner Landesumsiedleramtes im Frühjahr 1946 zu diesem Problem äußerte: „Ein Teil der Antifa. hat bereits Wohnungen bekommen. Teilweise waren Wohnungen vorgesehen, diese wurden aber dann den kleinen Pg's wieder eingeräumt - die Landesverwaltung nimmt den kleinen Pg's nicht die Wohnungen. ${ }^{\text {"73 }}$ Der Interessenkonflikt, wie er im Vorfeld des Wahlkampfes 1946 zwischen den „Opfern des Faschismus" sowie den Verfechtern einer sanfteren Politik gegenüber den "kleinen Parteigenossen“ der ehemaligen NSDAP innerhalb der SED entbrann$\mathrm{te}^{74}$, zeichnete sich bereits zu diesem Zeitpunkt ab.

\subsection{Abwehrreaktion gegenüber einer KPD-Dominanz?}

Aufzugreifen ist die Frage, ob die Ludwigsluster Ereignisse als Abwehrrekation gegenüber einer KPD-Dominanz zu werten sind, die quasi von außen bzw. oben forciert wurden und somit einer politischen Fremdherrschaft nahekommen könnten. Für die Funktionäre und ihre Familien aus der Tschechoslowakei war diese Frage nach einigen Wochen des Gezerres bei der Wohnungsunterbringung eindeutig zu beantworten: „Mit einem Wort, man will keinen stärkeren Einfluß der KPD in Ludwigslust und den Faschisten nicht zu nahe treten. ${ }^{475}$ Dieser verbitterten Beobachtung ist zugleich der Hinweis zu entnehmen, wie die normale Lokalpolitik mit ihren Ränken und Rivalitäten, ihren Streitigkeiten und sozialen Zwängen trotz des Zusammenbruchs weiterzuleben und sich wieder neu zu entfalten schien. Bestätigt wird dieser Eindruck, wenn man den politischen Streit unter den Ludwigsluster Parteien betrachtet, der im Spätherbst 1945 bei der Neubesetzung des stellvertretenden Landratsamtes entbrannte ${ }^{76}$. Auch hier sollte ein Kandidat, der den alteingesessenen Ludwigslustern fremd war, auf diesen herausgehobenen Posten gehievt werden. Allerdings war der Kandidat nicht ein Mann der Kommunisten, sondern der Christdemokraten, die nach ihrem verspäteten Start in Ludwigslust den mittlerweile gewachsenen Einfluß auch bei der personellen Besetzung wichtiger Machtpositionen berücksichtigt wissen wollten. Als die CDU nicht in der Lage war, binnen eines Monats ein Leumundszeugnis durch ihren Landesvorstand vorzulegen, war der Kandidat im Antifaschistischen Block nicht mehr konsensfähig. SPD und KPD stimmten allerdings der Besetzung des Postens mit einem Christdemokraten zu, der in Ludwigslust allgemein bekannt war. Das Mißtrauen gegenüber allen Fremden saß offenbar tief. Insofern wäre es auch wenig zutreffend, die Probleme bei der Aufnahme kommunistischer Funktionäre aus der Tschechoslowakei als Ausdruck von Resistenz oder gar als Widerstand gegen eine sich formierende KPD-Dominanz zu verstehen.

73 BAB, DO 1/10/30, Bl. 134.

${ }^{74} \mathrm{Ke}$ ler/Peter, Antifaschisten, S. $630 \mathrm{ff}$.

${ }_{75}$ MLHA, Landesleitung SED Mecklenburg, IV/L/2/6/334, Bl. 7.

76 Siche zum folgenden die Sitzungsprotokolle des Antifaschistischen Blocks vom 1.11. 1945, 30.11. 1945 sowie vom 13.12. 1945; MLHA, SED Bezirksleitung Schwerin, IV/4/05/410, Bl. 22 f., 38 f., 43. 


\section{Opferkonkurrenz in Greven zwischen den „evakuierten" Alteingesessenen und den Vertriebenen}

Das Konzert mit Yehudi Menuhin am 27. Juli 1945 war zweifellos der Höhepunkt einer Kulturwoche im "Grevener Ausländerlager", wie es die Einheimischen nannten. Der Künstler wollte unmittelbar nach Kriegsende für Displaced Persons - insbesondere Überlebende der Konzentrationslager - spielen. Die britischen Behörden erlaubten Menuhin eine Konzertreise, und so machte dieser auch in Greven im Displaced Persons Assembly Centre Station ${ }^{77}$. In dem kleinen, etwa 8500 Einwohner zählenden Dorf, knapp 20 Kilometer nördlich von Münster, direkt an der Ems gelegen, hatten die Briten einen zentralen Sammelpunkt für ehemalige Fremdarbeiter und Kriegsgefangene eingerichtet. War die Gemeinde von Kriegsschäden weitgehend verschont geblieben, bekam sie nach dem Ende der kriegerischen Handlungen die verschiedenen Migrationswellen umso stärker zu spüren. Bis zu 9000 DP's hielten sich zeitweise in Greven auf. Die letzten von ihnen verließen den Ort erst im Jahre 1950.

Untergebracht waren sie allerdings nicht in irgendeinem Lager oder einer Zeltstadt. Für die ehemaligen Zwangsarbeiter hatten zahlreiche Grevener ihre Häuser zur Verfügung stellen müssen ${ }^{78}$. Im Nordviertel von Greven-Dorf wurden insgesamt 375 Häuser beschlagnahmt, das entsprach einem Anteil von $32,7 \%$ des gesamten Häuserbestandes. $35,6 \%$ der Bevölkerung waren auf den restlichen Teil des Ortes zu verteilen ${ }^{79}$. Diese „Evakuierten“ kamen in der Regel bei jenen Dorfbewohnern unter, die von den Hausbeschlagnahmungen verschont geblieben waren. Hinzu kam, daß im benachbarten Reckenfeld, das ebenfalls zum Amtsbezirk Greven gehörte, die Einschnitte für die deutsche Bevölkerung noch gravierender waren. Hier wurden zwei der vier Ortsteile komplett für das DP-Lager beschlagnahmt. Und schließlich kamen die evakuierten Personen aus anderen Städten, so daß das Leben in Greven bereits gehörig durcheinandergeraten war, bevor die ersten Vertriebenen und Flüchtlinge überhaupt der Emsstadt zugewiesen wurden. Die Konflikte, die bei der Aufnahme der Vertriebenen auftraten, wären ohne diesen Hintergrund kaum zu verstehen. Die lokalen Besonderheiten haben die Darstellung und Analyse dieser Konflikte ebenso zu berücksichtigen wie die Konkretisierung allgemeiner Probleme der Vertriebenenaufnahme in ländlichen Regionen der westlichen Zonen.

Eben weil die Belastungen durch das DP-Camp so groß waren, blieb Greven bei den Vertriebenenzuweisungen ausgespart, die im Rahmen der "Aktion Schwalbe“ in den Landkreis Münster kamen. Während im künftigen Bundesland Nordrhein-Westfalen das Rheinland sowie das Ruhrgebiet für Vertriebenentransporte abgeschottet waren, hat-

77 Dreßler/Galen/Spieker, Greven 1918-1950, Bd. 2, S. 236.

${ }^{78}$ Die Gründe für diese außergewöhnliche Praxis, DP-Lager zu errichten, sind noch nicht erforscht. Vgl. auch die leider sehr kursorisch bleibenden Ausführungen bei Jacobmeyer, „Displaced Persons“, S. 135. Im übrigen ist es unzutreffend, daß die Besitzer enteignet wurden, wie Jacobmeyer behauptet; zu den Beschlagnahmungen und zu den gezahlten Entschädigungen siehe umfassend Dreßler/Galen/Spieker, Greven 1918-1950, Bd. 2, S. 240.

79 Dreßler/Galen/Spieker, Greven 1918-1950, Bd.2, S.222. Siehe auch die Beobachtungen des schon erwähnten Yehudi Menuhin, der Greven als „kleines, sauberes Städtchen“ in Erinnerung behalten hat, das gerade „von den Polen“ übernommen worden war: „Die früheren deutschen Einwohner hatte man aus den Häusern vertrieben, wenn man ihnen auch offensichtlich erlaubte, tagsüber in der Stadt weiter ihren Tätigkeiten als Arzt, Hausmädchen usw. im Dienste der Polen nachzugehen." Zitiert nach Dreßler/Galen/Spieker, Greven 1918-1950, Bd. 2, S. 236. 
ten die ländlichen Regionen Westfalens in erheblichem Maße Vertriebene und Flüchtlinge aufzunehmen ${ }^{80}$. Noch bevor die "Aktion Schwalbe“ angelaufen war, klagten die Vertreter zahlreicher Ämter und Gemeinden des Landkreises Münster bei der konstituierenden Sitzung des Flüchtlingsausschusses am 25. Januar 1946, es sei ihnen unmöglich, weitere Evakuierte, Vertriebene und Flüchtlinge aufzunehmen ${ }^{81}$. Im Unterschied zu anderen Gemeinden brauchte man sich in Greven nicht zweifelhafter Argumentationen zu bedienen, die eine fremdenfeindliche Einstellung nur unzureichend verschleiern mochten; der Amtsbürgermeister Grevens konnte auf 537 für das DP-Lager beschlagnahmte Wohnhäuser mit etwa eintausend Wohnungen verweisen sowie auf Schäden in weiteren 575 Häusern durch ein Jahrhunderthochwasser im Winter 1945/46: „Die Beschädigungen sind umso größer, als die Bewohner aus dem geräumten Nordviertel des Dorfes mit ihrem Hab und Gut, soweit sie es mitnehmen durften, in den Süden des Dorfes gezogen und dort vom Hochwasser überrascht worden sind. Aus vorstehenden Gründen bitte ich nochmals dringend von der Überweisung von Ostflüchtlingen nach Greven Abstand zu nehmen." ${ }^{\text {"82 }}$

Bereits im Juni 1946 war das erste Kontingent an Vertriebenen aufzunehmen, obgleich wenige Tage zuvor noch festgestellt worden war, daß im Ort für „über 200 Familien noch Wohnraum beschafft ${ }^{\prime 83}$ werden müßte. Nennenswerte Zahlen wurden erst im Jahre 1947 erreicht - zu einem Zeitpunkt, als andernorts die Aufnahme größerer Vertriebenentransporte bereits abgeschlossen war. Bedeutsam für den weiteren Verlauf der Vertriebenenaufnahme in Greven ist die etwa zeitgleich einsetzende Rückkehr eines ersten Teils der alteingesessenen Grevener, die ihre Wohnungen hatten räumen müssen. Nach mehr als zwei Jahren kehrten sie in ihre Häuser zurück, da ein Teil des DP-Lagers im Sommer 1947 aufgelöst worden war. Vor diesem Hintergrund erweckte das Schicksal der Vertriebenen nur allzu wenig Aufmerksamkeit, obgleich die Lebensumstände der Grevener „evakuierten“ Familien geradezu frappierend der Situation von Vertriebenen nahekamen: „Die Bewohner, welche jetzt wieder einziehen wollen, stehen teilweise vor dem Nichts. Zusammengepfercht haben sie nun 2 Jahre lang bei anderen Familien in deren Hausgemeinschaft - teilweise bis zu 9 Personen in einem Raum - wohnen müssen und dort das Mobiliar dieser Familie benutzt. Jetzt, wo sie wieder einziehen, fehlen ihnen die notwendigsten Hilfsmittel wie Betten, Eßgeschirr usw. ${ }^{\text {"84 }}$

${ }^{80}$ Schulze-Westen, Das Flüchtlingsproblem, passim.

${ }^{81}$ Frie, Eingliederung, S. 125; vgl. auch Schwarze, Politische Entwicklung, S. 216-228; Muncke, Nachkriegsjahre, S. 111-123.

82 Vgl. Brief vom 23. 2. 46 des Amtsbürgermeisters von Greven an den Landrat, Kreis-Ernährungsamt. StaG, 4-50-10. Unterdessen wehrten sich Vertreter anderer Gemeinden im Münsterland mit fadenscheinigen Argumenten gegen eine fortwährende Zuweisung: „Es scheint bedenklich, sie [die Flüchtlinge] hier anzusiedeln, und sei es nur behelfsmäßig. Sie sind ein auf Dauer unerträglicher Fremdkörper im Münsterland, die Verhältnisse im Ruhrgebiet haben dies bewiesen." Zitiert nach Muncke, Nachkriegsjahre, S. 118. Plastisch geschildert wurde die Abwehrhaltung der Bevölkerung in münsterländischen Gemeinden in der Sitzung des Kreis-Flüchtlingsausschusses am 25. 1. 46, als das Versagen überörtlicher Kommissionen beklagt wurde: „Die Einwohner, insbesondere die Bauern wollen keine Ostflüchtlinge aufnehmen. Sobald die überörtliche Kommission da gewesen ist und den Leute gesagt hat, welche Räume für Ostflüchtlinge beschlagnahmt würden, vermieten diese die Räume möglichst bald an Evakuierte aus der Stadt Münster und würden geradezu darum betteln, daß diese Leute bei ihnen wohnen bleiben sollten, selbst wenn sie inzwischen in Münster ein Unterkommen finden würden. "StaM, Kreis E 398.

${ }^{83}$ Sitzung des Flüchtlingsausschusses vom 26. 6. 46; vgl. StaG, 4-50-10.

${ }^{84}$ Schreiben vom 21. 8. 1947 an des Kreistag des Landkreises Münster; StaM, C 11 106/328 
Es bedarf keiner besonderen Erläuterung, daß alsbald eine veritable Opferkonkurrenz zwischen diesen beiden Gruppen entbrannte, auch wenn sie freilich zunächst noch hinter den Kulissen und nicht in der Öffentlichkeit ausgetragen wurde. Aber mit der Lage der „evakuierten" Grevener und insbesondere den Hilfsmaßnahmen, die ergriffen wurden, um deren Not zu beheben, verglichen die Vertriebenen zunehmend diejenige Hilfe, die ihnen als besitzlosen „Fremden“ von seiten der zuständigen Verwaltungsstellen zuteil wurde. Denn Appelle an die freiwillige Hilfsbereitschaft der Bevölkerung, für die Neuankömmlinge zu spenden, waren schon deshalb wenig erfolgversprechend, da die Einheimischen "durch Räumung, Hochwasserschaden und den bereits mehrfach erfolgten hohen Abgaben von Bekleidung zum überwiegenden Teil selbst als äußerst notdürftig bezeichnet ${ }^{\text {"85 }}$ werden müßten, wie das Grevener Wohlfahrtsamt bereits frühzeitig feststellte. Mochte sich auch die Pfarrcaritas um diese Menschen kümmern, die Hilfe blieb im fürsorgerischen Bereich und nahm bei weitem nicht den Umfang der Solidaritätsmaßnahmen an, die von den Bürgern selbst im Rahmen einer Hilfsgemeinschaft für die evakuierten Alteingesessenen ins Leben gerufen wurde.

\subsection{Welle der Hilfsbereitschaft für die „evakuierten“ Familien}

Als im Sommer 1947 die ersten 125 der 375 beschlagnahmten Gebäude in Greven-Dorf den Besitzern zurückgegeben wurden, nutzte ein mittlerweile ins Leben gerufener Hilfsausschuß die Gunst der Stunde, eine Welle der Solidarität und Hilfsbereitschaft auszulösen. Zum entscheidenden Impuls, möglichst alle Kräfte zu mobilisieren, wurde die Schockwirkung, die von dem Anblick der Häuser ausging. Die kursierenden Gerüchte, die Displaced Persons hätten im kalten Winter 1946/47 alles zum Heizen gebraucht, was sie an Holz hätten finden können ${ }^{86}$, erwiesen sich als bittere Wahrheit. So berichteten am 13. August 1947 die „Westfälischen Nachrichten“ über eine Ortsbesichtigung des Kreisausschusses, der sich selbst ein Bild von den Zerstörungen verschaffen wollte: „Man stellte fest, daß die einstmals so schmucken Arbeiterhäuschen zum großen Teil abgewrackt sind, um Brennmaterial zu gewinnen. Während an sämtlichen Häusern die Türen und Fenster fehlen, sind aus diesen damals geräumten Häusern nicht nur auch die Treppen und Fußböden entfernt, sondern sogar die Dachtragbalken, teilweise auch die Dachbalken und selbst die Dachsparren. Man ist sogar soweit gegangen, daß man in einigen Fällen aus dem Mauerwerk die Fachwerkbalken loslöste. ${ }^{\text {"87 }}$ Schnell wurde deutlich, daß selbst die Leistungskraft des dörflichen Netzwerks gegenseitiger Hilfe überfordert sein würde, um die Schäden zu beseitigen. Auch die Kreisverwaltung wurde um Hilfe gebeten.

Die vielen Maßnahmen - wie etwa die Kompensationsgeschäfte Grevener Unternehmer - sollen hier nicht näher beschrieben werden. In einer Serie von Kleinkonferenzen bemühte sich der Hilfsausschuß, Vertreter der Parteien, Fabrikanten, Handwerker, des Landwirtschaftlichen Ortsvereins, des Einzelhandels und schließlich der Betriebsräte an einen runden Tisch zu bekommen. Von den Kanzeln aus riefen Pfarrer zur Hilfsbereit-

${ }^{85}$ Notiz des Grevener Wohlfahrtsamts vom 14. 5. 1946; StaG, 4-51-40 (1946/50).

${ }^{86}$ Dreßler/Galen/Spieker, Greven 1918-1950, Bd. 2, S. 241.

87 Westfälische Nachrichten, 13. 8. 1947, zitiert nach StaM, C 11 106/328. In einem Brief des Hilfsausschusses vom 30.5. 1947 an das Wirtschaftsministerium hieß es, "daß nicht nur ihre Einrichtungsgegenstände und Möbel restlos verschwunden sind, sondern, daß dazu auch noch ihre Wohnhäuser derart zerstört wurden, daß sich ein großer Teil nur noch in einem rohbaumäßigen Zustand befindet“; vgl. StaG, 1-70-34/2: Hilfsausschuß Nordviertel. 1948-1956. 
schaft auf, Bauern schlugen kostenlos Holz für die Notleidenden, Möbelsammlungen wurden initiiert. Wer im Dorf einen Neu- oder Anbau plante, wurde unter moralischen Druck gesetzt, seine Bautätigkeiten ruhen zu lassen, damit alle Maurer und sonstigen Bauhandwerker im Nordviertel, also in den Häusern der ehemaligen Evakuierten, zum Einsatz kämen ${ }^{88}$. So leistungsstark sich das Netz gegenseitiger Hilfe auch erwies, Unzufriedenheit trat immer wieder zu Tage. Die Verantwortung dafür lud der Hilfsausschuß bei der politischen Leitung der Gemeinde ab; er selbst hielt sich zugute, daß ohne seine Arbeit „die Bevölkerung nicht ruhig geblieben ${ }^{489}$ wäre.

\subsection{Wachsende Unzufriedenheit der Vertriebenen}

Unterdessen kam im Sommer 1947 in einer Sitzung des Flüchtlingsausschusses einmal mehr die „tägliche Not der Vertriebenen“ zur Sprache, wobei als Ergebnis festgehalten wurde, "daß diese Not nicht allein mit gutem Willen und ohne großzügige öffentliche Hilfe beseitigt werden kann ${ }^{490}$. Die Ungeduld über die eigene Lage wuchs in den kommenden Monaten. Bemerkenswert an einem Tätigkeitsbericht des Flüchtlingsausschusses aus dem Dezember 1947 ist weniger die Klage über die Behandlung durch die einheimische Bevölkerung als der Vergleich mit der Not der alteingesessenen Grevener, die ihre Häuser für das DP-Lager hatten räumen müssen. „Bei aller Not der Geräumten“ sei "das Los der Ostvertriebenen das härtere“, so daß man, wie es hieß, „eine Hintansetzung" bei den Hilfsmaßnahmen keineswegs verstehen könne ${ }^{91}$.

Während sich diese Kritik noch in internen Arbeitspapieren für die Verwaltung artikulierte, hatte sich ein halbes Jahr später die Situation verschärft. Ein Teil der Vertriebenen, die im Flüchtlingsausschuß tätig waren, kündigten an, „ihre Ämter in öffentlicher Versammlung unter dem Ausdruck des Protestes niederzulegen". Die ständige Abwesenheit der Vertreter der Einheimischen im Flüchtlingsausschuß werteten sie als „den besten Beweis für die Interesselosigkeit“ der Dorfbewohner für die Nöte der Vertriebenen. Hinzu käme, daß „der Ostvertriebene in Greven Tag für Tag Zeuge umfassender Hilfsmaßnahmen für die Geräumten des Nordviertels ist“. Dort würden „in großzügigster Weise alle die Gegenstände zur Verfügung gestellt [...], die er selbst schon seit Jahren nicht mehr kennt“92.

Der in dem Schreiben gegebene Hinweis, der Ausschuß könne „den stärker werdenden radikalen Einflüssen" nicht länger entgegentreten, war indessen keine leere Rhetorik, die allein taktischen Zwecken diente. Der Vorsitzende des Flüchtlingsausschusses, der dieses Amt seit dessen Konstituierung innegehabt hatte, war aufgrund seiner Einstufung durch die Entnazifizierungskommission des aktiven und passiven Wahlrechts enthoben worden. Von Politikern auf Kreisebene war der entscheidende Anstoß dafür ausgegangen, so daß er die Ämter als Vorsitzender des Flüchtlingsausschusses sowie als Mitglied der Kreisausschüsse Wirtschaft, Wohnung und Wohlfahrt ruhen lassen mußte ${ }^{93}$. Für die

${ }^{88}$ Siehe StaG, 1-70-34/2: Hilfsausschuß Nordviertel. 1948-1956.

${ }^{89}$ Versammlung des Hilfsausschusses vom 13.7. 1947; StaG, 1-70-34/2: Hilfsausschuß Nordviertel. 1948-1956.

90 Protokoll der 10. Sitzung des Flüchtlingsausschusses am 20. 7. 1947; StaG, 4-50-13.

91 Flüchtlingsausschuß an das Amt Greven: „Kurzer Überblick über seine Tätigkeit“ vom 7. 12. 1947; StaG, 4-50-13.

92 Brief des Flüchtlingsausschusses vom 13. 6. 1948 an den Amstdirektor; STaG, 4-50-10 (1945/57).

${ }_{93} \mathrm{Vgl}$. Aktenvermerke vom 24.5. und 25. 5. 1948 sowie das Sitzungsprotokoll vom 2.6. 1948; StaM, C 11 106/328 (Kreiswohnungsausschuß). Ferner: Schreiben der Entnazifizierungskommission vom 11.6. 1948; vgl. StaG, 4-50-10 (1945/57). 
Mitglieder des Grevener Flüchtlingsausschusses mußte dieses umso desillusionierender wirken, als sie ihm einige Monate zuvor - in dem Wissen um seine Einstufung in die $\mathrm{Ka}$ tegorie III durch die Entnazifizierungskommission - ihr Vertrauen ausgesprochen hat$\operatorname{ten}^{94}$. Seine gesamte politische Brisanz gewann dieser Fall dadurch, daß einer der exponiertesten Sprecher des Hilfsausschusses in der NS-Zeit als Gemeindevorsteher fungiert hatte. Genauer: Er war derjenige, der im März 1933 zum ersten Gemeindevorsteher nach der „Machtergreifung“ der Nationalsozialisten gewählt worden war. In den letzten Kriegstagen hatte er zudem gemeinsam mit weiteren Grevener Honoratioren dem örtlichen Reichsluftschutzbund vorgestanden ${ }^{95}$. Trotz alledem wirkte er nun im Hilfsausschuß in vorderster Reihe mit und gelangte durch das Engagement in diesem Gremium wieder ins öffentliche Leben, wenngleich er keinerlei offizielle Ämter bekleidete. Nicht nur bei den radikalen Kräften unter den Vertriebenen dürfte dieser Umstand das ohnehin verbreitete Gefühl verstärkt haben, gegenüber den Einheimischen in allen Belangen benachteiligt zu sein ${ }^{96}$. Einige bekannt gewordene Einzelfälle, in denen Einheimische die Familien von Vertriebenen schlecht behandelt haben sollten, heizten naturgemäß die Stimmung zusätzlich an und beförderten ein Klima gegenseitigen Mißtrauens ${ }^{97}$.

Zur offenen Eskalation kam es, als im Herbst dem Flüchtlingsausschuß bekannt wurde, daß die Hilfsmaßnahmen für die „evakuierten“ Grevener nochmals gesteigert worden waren: Eine Erhöhung der Strompreise zugunsten der „Geräumten“ hatten die Vertriebenen ebenso mitzutragen, wie sie zahlreiche Überstunden in den Betrieben zugunsten der Arbeit des Hilfsausschusses zu leisten hatten ${ }^{98}$. Als die eingelegten Proteste wirkungslos verpufften, genügte ein vermeintlich geringfügiger Anlaß, um die Vertriebenen auf den Plan zu rufen. Denn als im Oktober im gesamten Ort tatsächlich kein einziger Kochherd mehr zu besorgen war, da die Hilfsgemeinschaft sie allesamt zugunsten der evakuierten Alteingesessenen aufgekauft hatte, formierten sie sich zu einer „Interessengemeinschaft der Ostvertriebenen“. Die ausdrückliche Feststellung, der Hilfsausschuß für das Nordviertel behindere die Arbeit des Flüchtlingsausschusses, verdeutlicht die aus Sicht der Vertriebenen gegebene Notwendigkeit, andere Formen der Interessenarti-

94 Sitzung des Flüchtlingsausschusses vom 4. 1. 1948; StaG, 4-50-13.

${ }^{95}$ Dreßler/Galen/Spieker, Greven 1918-1950, Bd. 1, S. 200; Bd. 2., S. $168 \mathrm{ff} ., 176,200,215,243 \mathrm{ff}$.; siehe auch die Kritik, die dem ehemaligen Gemeindevorsteher in der Presse entgegengebracht wurde, als er offenbar das „Gespenst des Kommunismus" beschwor, um weitere Hilfsmaßnahmen gegen eine Verelendung der Bevölkerung zu mobilisieren. Er habe anscheinend Angst, so das „Volks-Echo“ in seiner Ausgabe vom 13. 3. 1948, „daß die leidgeprüften Einwohner Grevens einmal über die Ursachen ihres Unglücks nachsinnen könnten und und dann möglicherweise sich auch mit seiner eigenen Person befassen müßten, war er doch als ,Zeitfreiwilliger im Ruhrkampf‘ zumindest Handlanger jener Kräfte, die wenige Jahre später Deutschland in ein Meer von Blut und Tränen verwandelt haben“; vgl. StaM, C 11 106/328 (Flüchtlingskontrollausschuß).

96 Im Protokoll der Sitzung des Flüchtlingsausschusses am 8. 8. 1948 ist denn auch - nach der inzwischen erfolgten politischen Entlastung des Vorsitzenden - vermerkt: „In einer kurzen Ausführung zur Entnazifizierung stellte der Vorsitzende die Frage der Entnazifizierung hinsichtlich verschiedener Mißstände bei der Einstufung zur Debatte." Vgl. StaG, 4 50-13.

97 So geißelte der Flüchtlingsausschuß in seiner Sitzung vom 14.3. 1948 "das oftmals geradezu sträfliche unsoziale Verhalten einiger Hausbesitzer“, das eine "durchgreifende Unterstützung der maßgebenden Behörden“ erfordere, um die Wohnungssituation erträglicher zu gestalten; vgl. StaG, 4-50-13.

98 Sitzung des Flüchtlingsausschusses am 10. 10. 1948; vgl. StaG 4-50-13; siehe auch das Schreiben des Flüchtlingsausschusses vom 25. 9. 1948 an den Amtsdirektor; StaG, 4-50-10 (1945/57); zudem StaG, 1-70-34/2. 
kulation zu suchen. Nur auf diesem Weg, so glaubten sie, waren größere soziale und politische Teilhaberechte zu erlangen.

Obgleich die Gründung von Flüchtlings- und Vertriebenengruppen nach der Aufhebung des Koalitionsverbotes in der britischen Zone im Trend der Zeit lag, sind in Greven bei der Gründung der „Interessengemeinschaft der Ostvertriebenen“ exogene Faktoren als nachrangig einzustufen. Naturgemäß bargen derartige Initiativen und Versuche der Gestaltung der eigenen Integration Gefahren und Chancen. Neben der Möglichkeit, den Integrationsprozeß der betroffenen Klientel zu beschleunigen, bestand die Gefahr, „als Zeitverlangsamer zu wirken, weil die Verbandsmitglieder - in traditionellen Denkmustern verhaftet und Gruppenzwängen unterworfen - sich nach außen abschotten und sich somit von der Außengesellschaft eher absetzen" konnten ${ }^{99}$. Allgemein werden diese Gefahren von der Forschung eher als gering eingeschätzt, zumal auch die Flüchtlingsverbände „der Dynamik des Eingliederungsprozesses“ unterlagen ${ }^{100}$.

Auch der Bürgermeister von Greven sah keinerlei Grund zur Änderung seiner Politik. Priorität hatte für ihn auch weiterhin die Hilfe für die Nordviertel-Bewohner: „Bezüglich der Hilfsaktion des Hilfsausschusses für die Geräumten des Nordviertels möchte ich empfehlen, zunächst ihre Solidarität nicht zurückzustellen. Auch das Flüchtlingsproblem wird einer gerechteren Lösung zugeführt werden. " ${ }^{101}$ Dieser Lösung glaubten die Grevener Lokalpolitiker jedoch erst dann näherkommen zu können, sobald das DP-Lager vollends aufgelöst wäre. So führte ein Bericht für das Kreisflüchtlingsamt aus dem Dezember 1948 aus: „Wäre Wohnraum vorhanden, so könnte eine groß Zahl von Flüchtlingen in den hiesigen Textilbetrieben in Dauerstellung beschäftigt werden. “102 $\mathrm{Da}$ viele Vertriebene in den Bauerschaften untergebracht waren und keinerlei Fahrtverbindungen zum Dorf existierten, waren diese weiterhin „auf die Arbeit als landwirtschaftliche Helfer bei den Bauern gegen geringes Entgelt angewiesen“. Ein zufriedenstellender Zustand war dieses für die Grevener Verwaltung ebenfalls nicht, da sich die Zahl der hilfsbedürftigen Familien von 40 im April 1947 auf 150 im Dezember 1948 erhöht hatte, was wiederum die Gemeindekasse zunehmend belastete. Wirksame Maßnahmen wurden allerdings von der Verwaltung nicht ergriffen, so daß sich die britische Besatzungsmacht zu scharfer Kritik veranlaßt sah. Zahlreiche Menschen im Kreis würden unter absolut unzureichenden Bedingungen in Greven und Umgebung leben, vermerkten sie im Monatsbericht vom Oktober 1948. „The authorities have found a very convenient scapegoat in the presence of the two D. P. Camps in the Kreis, throw up their hands in despair and say nothing can be done until these camps are moved. This is, of course, not so. "103 Sieht man davon ab, näher nach der Berechtigung dieser Kritik zu fragen, so liefert diese Notiz jedoch ein starkes Indiz dafür, mit welchen Eigengesetzlichkeiten und Widerständigkeiten die auf höherer politischer und verwaltungstechnischer Ebene oder von den Besat-

99 Messerschmidt, Aufnahme und Integration, S. 9; umfassend zur Aufhebung des Koalitionsverbotes am 24. 6. 1948 siehe Steinert, Vertriebenenverbände, S. 57 ff., 61.

100 Frantzioch, Die Vertriebenen, S. 143; Messerschmidt, Aufnahme und Integration, S. 9; vor allem: Erker, Zeitgeschichte, S. 222, der die Vertriebenenintegration im Zusammenhang mit zentralen sozialen und gesellschaftlichen Nachkriegsprozessen in Verbindung bringt.

101 Schreiben von Bürgermeister Berlage am 28. 10. 1948; StaG, 4-50-10 (1945/57).

102 StaG, 4-50-10 (1945/57).

103 Bericht vom Oktober 1948; vgl. PRO, FO 1013/546. Monthly Reports KRO, LK Münster Godrich P. S., Aug. 1948 - Aug. 1949. Dem Grevener Stadtarchivar, Christoph Spieker, bin ich zu Dank verpflichtet, mir diese Akten zur Verfügung gestellt zu haben. 
zungsmächten ausgearbeiteten Konzepte konfrontiert waren. Diese Kluft zwischen allgemeinen Direktiven und den Gegebenheiten „vor Ort" bestand in der deutschen Nachkriegsgesellschaft allenthalben, also in der Ostzone wie in den Westzonen, und akzentuiert nachdrücklich die Grenzen der Ordnungs- und Konstruktionspolitik ${ }^{104}$. Zugleich belegt das Beispiel Greven, für welche Gruppen die dörfliche Gemeinschaft aus eigener Initiative in nicht unerheblichem Umfang Hilfe und Unterstützung mobilisieren konnte. Die Vertriebenen gehörten in der Regel zu jenen Personengruppen, die auf ein derartiges Netzwerk nicht zurückgreifen konnten. Um die Brücke zur Situation in Ludwigslust zu schlagen, sei angemerkt, daß sich vor diesem Hintergrund die Starthilfen, die die Kommunisten für die „antifaschistischen Umsiedler“ aus dem Sudetenland bereithielten, ausgesprochen bescheiden ausfielen.

\section{Grenzen der Konstruktionspolitik}

Das Schlagwort von den "Grenzen der Konstruktionspolitik“105 in der SBZ/DDR verweist auf eine vorhandene und von der Forschung noch näher zu untersuchende Kontinuität gesellschaftlicher Strukturen und Beziehungen sowie auf das allgemeine Chaos der „Zusammenbruchsgesellschaft“. Den Bemühungen, das ostdeutsche Nachkriegsdeutschland unter umfassende Kontrolle zu bringen, stand die chaotische Lage mithin entgegen ${ }^{106}$; zugleich aber erleichterte diese Ausgangssituation die Bemühungen des Machterwerbs, zumal sich die gesellschaftlichen Strukturen im Fluß befanden und erst noch Stabilität gewinnen mußten. Diese Instabilität versuchte die kommunistische Partei mit der Implantierung von „antifaschistischen Umsiedlern“ in örtliche Machtpositionen auszunutzen. Rasch jedoch wurde in vielen Orten wie in Ludwigslust deutlich, daß die politisch-dekretierte Integration vom Scheitern bedroht war oder zumindest auf enorme Hemmnisse traf. Die „antifaschistischen Umsiedler" hatten sich an die bestehenden dörflichen Milieus in Mecklenburg-Vorpommern sowie an die Eigenheiten der noch keineswegs homogenen kommunistischen Partei stärker anzupassen, als ihnen lieb war und als es nach den Vorgaben der Parteileitung zu erwarten stand. Die tagtägliche Praxis der Besatzungsmacht - von Norman Naimark als Bestandteil des ostdeutschen Nachkriegschaos beschrieben ${ }^{107}$ - trug überdies nur wenig dazu bei, die Situation dieser Gruppe zu verbessern.

Zieht man die Stimmungsberichte der Informationsabteilungen der Landes- und Provinzialregierungen heran, so offenbaren sich bei aller notwendigen Quellenkritik, mit der man ihnen zu begegnen hat, die Grenzen der Konstruktionspolitik bei der Aufnahme und Integration der Vertriebenenmassen. Am eindringlichsten lassen sich die Grenzen am Beispiel der „antifaschistischen Umsiedler“ aufzeigen, da ihnen trotz aller Privilegierung von seiten der zuständigen Verwaltungs- und Parteistellen letztlich durch die Aufnahmegesellschaft ein ähnlich niedriger sozioökonomischer Status zugewiesen wurde wie der Masse der Vertriebenen. Ausnahmen mochte es bei der Ansiedlung ganzer Hand-

104 Siehe allgemein: Kleßmann, Doppelte Staatsgründung, S. $71 \mathrm{f}$.

105 Bauerkämper, Führungsgruppen auf dem Lande, S. 89.

106 So die Position von Bessel/Jessen, Grenzen der Diktatur, S. 10. Die Autoren übersehen freilich dic Ambivalenz des Nachkriegschaos in Hinblick auf die Chancen des angestrebten umfassenden Machterwerbs.

107 Naimark, The Russians, S. 9 ff., 24. 
werkergenossenschaften ${ }^{108}$ geben, von denen man sich wirtschaftlichen Nutzen versprach. An den grundsätzlichen Problemen bei der politisch-dekretierten Integration der kommunistischen Funktionäre ändert dieses nichts. Kein Zufall ist es, daß sich die Konflikte an der knappen Ressource Wohnraum entzündeten. Als Ursache ist neben den politisch-kulturellen Unterschieden und den hochgesteckten Erwartungen der „antifaschistischen Umsiedler" vor allem die Begrenzung des politisch-ideologischen Herrschaftswillens durch lokale Eigenständigkeiten in der kleinstädtischen Gesellschaft zu sehen. Selbst die Genossen vor Ort konnten und wollten die Eingliederung der Neuankömmlinge nicht mit dem Nachdruck betreiben und diesen die weitreichenden Anrechte verschaffen, wie es "von oben“ gewünscht war, wollten sie nicht die eigene Macht in ihrer sozialen Umgebung aufs Spiel setzen. Mit dem eigenen Selbstverständnis wäre ein derartiges Vorgehen ohnehin kaum zu vereinbaren gewesen. Selbst die SED in Mecklenburg - einem Land mit einem Vertriebenenanteil an der Bevölkerung von nahezu fünfzig Prozent - verstand sich niemals als Flüchtlingspartei. Für sie blieb die Integration der Vertriebenen ein eher nachrangiges Problem, das nach Auffassung der SED in der Lösung der zahlreichen sozialen und gesellschaftspolitischen Nachkriegsprobleme aufgehen werde ${ }^{109}$.

Die Sperrigkeit des Problems, die Vertriebenen wohnlich unterzubringen, sowie die politische Brisanz dieser Frage wurde in Ludwigslust im November 1946 nochmals in aller Deutlichkeit aufgezeigt, als das Umsiedlerlager für einen größeren Kindertransport in Richtung Westen vollständig geräumt werden mußte. Die Aktion der Umsiedlerbehörden zur Wohnraumbeschaffung ist insofern bemerkenswert, als sie Kreise zog, die weit über Ludwigslust und sogar über Mecklenburg hinausreichten. Unter der Regie des ZVU-Sonderbeauftragten Arthur Vogt sowie des ohnehin nicht zimperlichen Leiters des Landesumsiedleramtes in Schwerin waren zahlreiche Wohnungen im Ort überprüft worden - mit dem Resultat, innerhalb von drei Tagen 57 Wohnungen ausfindig gemacht $\mathrm{zu}$ haben, die für die Unterbringung von rund 150 Erwachsenen und 39 Kindern ausreichten $^{110}$. Für ZVU-Präsident Engel war das Ergebnis der Aktion ein willkommener Grund, in einem Zeitungsartikel das Fehlen an "gutem Willen und der nötigen Energie“ bei den örtlichen Behörden anzuprangern und die Bedeutung der wohnlichen Unterbringung zu betonen. Erst wenn sie eine eigene Wohnung erhalten hätten, auch "wenn sie noch so klein ist", könnten die „Umsiedler" sich „zu Hause fühlen“ und „Wurzeln schlagen"111.

Als besonders krassen Einzelfall schilderten die Umsiedlerbehörden die Zustände in einer Villa eines Amtsleiters der Ludwigsluster Stadtverwaltung, in der sechs Personen auf 14 Räumen aufgeteilt eine Wohnfläche von 200 Quadratmetern benutzten. Zum Vergleich: Im Kreis Ludwigslust standen ansonsten jeder Person sechs Quadratmeter zur Verfügung ${ }^{112}$, womit der Kreis sich im Landesdurchschnitt noch sehen lassen konnte. Die Vertreter der Umsiedlerbehörden wiesen das Wohnungsamt an, in dieser Villa zwei Wohnungen für „antifaschistische Umsiedlerfamilien“ einzurichten. Wohnraum für An-

${ }^{108}$ Etwa die Studie von Kaltenborn, Umsiedlergenossenschaften, S. $178 \mathrm{ff}$.

${ }^{109}$ Dezidiert vertrat diese Auffassung der einflußreiche mecklenburgische SPD/SED-Politiker und langjährige Landtagspräsident Carl Moltmann.

$110 \mathrm{BAB}, \mathrm{DO} 1 / 10 / 40, \mathrm{Bl} .268$.

111 BAB, DO $1 / 10 / 4$, Bl. 69.

$112 \mathrm{BAB}, \mathrm{DO} 1 / 10 / 40, \mathrm{Bl} .340-344$. 
gehörige dieser Gruppe wurde gegen Ende des Jahres 1946 nicht mehr dadurch geschaffen, daß man zum „maßnahmenstaatlichen“ Mittel der Zwangsräumungen gegriffen hätte. Die Privilegierung der „antifaschistischen Umsiedler“ erschöpfte sich mittlerweile darin, daß sie lediglich an der Spitze der Liste standen, auf der Interessenten für freiwerdenden Wohnraum verzeichnet waren. Für den Besitzer der Villa war die zwangsweise Einquartierung Grund genug, sich beim Landeswohnungsamt zu beschweren ${ }^{113}$, womit er den Stein ins Rollen brachte.

Denn während die ZVU das unkonventionelle Vorpreschen der Umsiedlerbehörden als ein Vorgehen lobte, das mit der "nötigen Energie“ betrieben werde, beklagten das Wohnungsamt Ludwigslust, das mecklenburgische Landeswohnungsamt sowie die Deutsche Verwaltung für Arbeit und Sozialfürsorge (DVAS) in Berlin die Mißachtung ihrer eigenen Kompetenzbereiche. So prangerte die Vizepräsidentin der DVAS, Jenny Matern (SED), in einem Brief an die ZVU die Tendenz der mecklenburgischen Umsiedlerbehörden an, ihre Kompetenzen zu überschreiten ,und Wohnungspolitik auf eigene Faust zu betreiben "114. Matern interpretierte das Ludwigsluster Beispiel als einen Beleg für das fortwährende Bestreben der Umsiedlerbehörde, das Landeswohnungsamt planmäßig abzuschaffen. Dabei nahm sie ausdrücklich Bezug auf einen - freilich wenig erfolgreichen Antrag der Umsiedlerabteilung in Schwerin aus dem Frühherbst 1946 beim damaligen 1. Vizepräsidenten der Landesverwaltung, Hans Warnke, ihr das Landeswohnungsamt zu unterstellen. Sie prophezeite, daß dieser Weg nicht der geeignete sei, „größere Erfolge zu erzielen und die in Mecklenburg bestehenden besonderen Schwierigkeiten bei der Wohnraumbeschaffung zu überwinden "115.

Bemerkenswert erscheint, daß sich die Wogen der Empörung ein Jahr später noch nicht geglättet hatten. Als die SED das administrative Ende der ZVU einleitete, holte sie die Stellungnahmen derjenigen Verwaltungen ein, die mit der Umsiedlerverwaltung zusammenarbeiteten. Von seiten der DVAS kommentierte man den Auflösungsbeschluß mit unverhohlenem Wohlwollen. „Dadurch würde auch der Dualismus verschwinden, der mit der zunehmenden sozialpolitischen Tätigkeit der Umsiedlerverwaltung zu Störungen zwischen der Sozialfürsorge und Wohnungswesen sowie Umsiedlerverwaltung in Mecklenburg führte" ${ }^{116}$, heißt es in der Stellungnahme von Jenny Matern, die somit als Nachklang auf die Wohnungsaktion in Ludwigslust im November 1946 sowie auf eine vergleichbare Aktion in Schwerin im September 1947 zu verstehen ist. Sie fiel nicht nur deshalb so deutlich aus, weil ureigene Kompetenzen der Verwaltung berührt waren. Hinzu kam die zu weiten Teilen noch katastrophale Lebenssituation der Vertriebenen in Mecklenburg, die auch die Umsiedlerbehörden nicht leugnen konnten.

Gewiß gibt diese Stellungnahme nicht die Position der SED wieder. Aber man wird nicht fehlgehen in der Annahme, daß die Probleme vor Ort sich als so sperrig erwiesen und von den zuständigen Verwaltungen nicht in gewünschter Weise in den Griff bekommen wurden, so daß sie als eine wichtige Ursache für den abrupten Kurswechsel in der „Umsiedlerpolitik“ anzusehen sind, den die SED als Hegemonialpartei der SBZ im Frühjahr 1948 vollzog.

113 Vgl. MLHA, IV/L/2/6/331, Bl. 129.

114 DVAS, Jenny Matern, 13. 2. 1947, an die ZVU; BAB, DO 1/10/67, Bl. 136.

115 BAB, DO 1/10/67, Bl. 136.

116 DVAS, Jenny Matern, 2. 2. 1948, an das ZS der SED. Betr. Stellungnahme zu dem Schreiben vom 21. 1. 1948 (Auflösung Umsiedlerverwaltung). SAPMO, DY30/IV2/2.027/34, Bl. 174. 


\section{Steffi Kaltenborn}

\section{Wohn- und Lebensverhältnisse von Vertriebenen 1948 in Thüringen}

Als die Alliierten am 2. August 1945 in Potsdam endgültig den Beschluß zur sogenannten „humanen Überführung“ der deutschen Bevölkerung aus den ehemaligen Ostgebieten, dem Sudetenland und den Staaten Ost- und Südosteuropas nach Deutschland ${ }^{1} \mathrm{faßten}$, waren Flucht, Vertreibung und der Zwang zur Suche nach einer neuen Heimat für Millionen Menschen bereits grausame Realität. Allein das Territorium der SBZ beherbergte zu diesem Zeitpunkt ca. 1,5 Millionen Menschen, für die es nun kein Zurück mehr gab². Obwohl spätestens seit den Verhandlungen in Teheran und Jalta die Gewißheit bestand, daß diese Vertriebenen in den nach dem Krieg bei Deutschland verbliebenen Territorien aufgenommen werden mußten ${ }^{3}$, besaß die sowjetische Siegermacht zunächst kein tragfähiges Konzept zu ihrer Integration ${ }^{4}$. Erst nachdem die Lage insbesondere in den unmittelbar an die Vertreibungsgebiete grenzenden Städten und Landkreisen der SBZ im Sommer 1945 einem kaum überschaubaren Chaos glich, entwickelte die SMAD schrittweise Vorstellungen, die zugleich zu verbindlichen Handlungsanweisungen für die zonalen Parteien, Organisationen und Behörden wurden. Im Mittelpunkt ihres Integrationskonzeptes stand neben der politisch-ideologischen Einflußnahme und Umerziehung der Vertriebenen, der völligen rechtlichen Gleichstellung mit der Wohnbevölkerung, dem kurzfristigen Einfügen der Erwerbsfähigen in den Arbeitsprozeß sowie der Gewährung sozialer Unterstützung für Alte, Versehrte und Nichterwerbsfähige die Versorgung der ankommenden Menschen mit Wohnraum. Damit wurden - abgesehen von der Überbetonung politischer Fragen - in der SBZ die gleichen Prioritäten gesetzt wie im Westen Deutschlands ${ }^{6}$. Für alle Territorien stellte sich unmittelbar mit der Ankunft der Flüchtlingstrecks und der ersten Vertriebenen die Wohnraumproblematik als das im Augenblick drängendste Problem dar, mit dem zunächst die betroffenen Kommunen konfrontiert wurden. Ställe, Scheunen, Säle und Schulen boten den Ankommenden oft erste Unterkunft. Nachdem klar geworden war, daß diese Menschen würden bleiben müssen, versuchten die kommunalen Behörden mit Hilfe von "Ortsgesetzen“, des größten Chaos Herr zu werden ${ }^{7}$. Eine einheitliche Handhabung in allen Teilen Restdeutschlands wurde erst mit dem Gesetz Nr. 18 des Alliierten Kontrollrates vom März 1946 vorbereitet ${ }^{8}$. Für das Ter-

1 Vgl. Die Potsdamer (Berliner) Konferenz, S. 413.

2 Vgl. Wille, Zu einigen Fragen, S. 18.

3 Vgl. u. a. de Zayas, Anmerkungen, S. $112 \mathrm{ff}$.

+ Vgl. Hoffmann / Wille / Meinicke, Flüchtlinge, S. 12.

${ }^{5}$ Vgl. Wille, Die Vertriebenen, S. $121 \mathrm{ff}$.

6 Wille, $\mathrm{Zu}$ einigen Fragen, S. $24 \mathrm{f}$.

7 Ebenda, S. 26.

${ }^{8}$ Amtsblatt des Kontrollrates in Deutschland, S. $117 \mathrm{ff}$.; vgl. dazu auch: von Plato / Meinicke, Alte Heimat - neue Zeit, S. $49 \mathrm{f}$. 
ritorium der SBZ sah die am 27. Juli 1946 von der Deutschen Verwaltung für Arbeit und Sozialfürsorge mit Zustimmung der SMAD erlassene Durchführungsverordnung die Einrichtung von Wohnungsämtern und -ausschüssen vor, die eine gerechte Verteilung des Wohnraumes steuern sollten'. $\mathrm{Da}$ zu diesem Zeitpunkt an Wohnungsneubau nicht zu denken war, konnte diese "gerechte Verteilung" nur in der Einweisung Vertriebener in die Wohnungen der einheimischen Bevölkerung bestehen. Aus den massiven Eingriffen in die Privatsphäre der betroffenen Menschen, aus der gemeinsamen Nutzung von Küche, Toilette, Waschgelegenheit und Abstellkammern, oft auch aus der völlig unmöglichen Trennung der Haushalte Einheimischer und Zugezogener resultierten überall in Deutschland Zwistigkeiten, die die spätere Integration der Vertriebenen verzögerten ${ }^{10}$. Trotz dieser gemeinsamen Schwierigkeiten und der ein Jahr nach Kriegsende vorliegenden einheitlichen Richtlinien zur Einweisung der Vertriebenen in Privatquartiere unterschied sich deren Lebenssituation - resultierend aus zahlreichen Besonderheiten in den Ländern, Kreisen, Städten und Gemeinden - in der Folgezeit teilweise erheblich.

Charakteristisch für Thüringen war in erster Linie die von der in weiten Teilen bergigen Landschaft geprägte, vorrangig durch kleinere und mittlere Betriebe bestimmte wirtschaftliche Struktur. Die wenigen größeren Betriebe in Jena, Nordhausen und im Raum Altenburg hatten zudem durch Kriegseinwirkungen, die Mitnahme von Ausrüstungen, Patenten und Produktionsunterlagen beim Abzug der amerikanischen Truppen sowie durch Demontagen und Reparationsforderungen der sowjetischen Besatzungsmacht gelitten. Die natürlichen Voraussetzungen insbesondere im Süden und Westen des Landes beschränkten zudem die landwirtschaftliche Nutzfläche. Schon in der Vorkriegszeit war Thüringen nur in der Lage gewesen, den Eigenbedarf an landwirtschaftlichen Erzeugnissen zu 75 bis 90 Prozent zu decken. Das Eichsfeld und der Thüringer Wald galten seit jeher als Notstandsgebiete ${ }^{11}$.

Diesen für die Aufnahme Hunderttausender Menschen wenig vorteilhaften Bedingungen standen die im Vergleich mit anderen Territorien der SBZ geringeren Kriegszerstörungen gegenüber. Während durch Bombenangriffe 31000 Wohnungen vor allem in Nordhausen, Jena, Erfurt und Gera, aber auch in kleineren Städten wie Meuselwitz und Creuzburg, vernichtet worden waren ${ }^{12}$, berührten die eigentlichen Kriegshandlungen das Territorium Thüringens kaum. Somit verfügte das Land im Jahr 1945 noch über 98 Prozent der 1939 vorhandenen Wohnfläche und damit - verglichen mit den im Zonenmaßstab erhaltenen 68 Prozent - über einen entscheidenden Vorteil gegenüber den anderen Ländern und Provinzen ${ }^{13}$.

Infolge der mit dem Krieg verbundenen Veränderungen der natürlichen Bevölkerungsbewegungen sank die Zahl der einheimischen Thüringer Bevölkerung im gleichen Zeitraum von ca. 2,4 Millionen ${ }^{14}$ auf 2,2 Millionen ${ }^{15}$. Diese Bevölkerungsverluste von ca.

9 Plato / Meinicke, Alte Heimat - Neue Zeit, S. 50; Wille, Zu einigen Fragen, S. 26.

10 Vgl. hierzu u. a. Christopeit, Herkunft, S. 97 ff.; Frantzioch, Die Vertriebenen, S. 118 ff.

11 ThHStA, Ld. Thür., MdI, Nr. 3672, Bl. 181.

${ }^{12}$ Vgl. Barthel, Ausgangsbedingungen, S. 41.

13 Vgl. Rusche, Eingliederung, S. 135.

14 ThHStA, Ld. Thür., MdI, Nr. 3798, Bl. 11. Infolge von Verschiebungen der Landesgrenze wurde die genannte Zahl aus der Summe der im Jahr 1939 in den 1946 zu Thüringen gehörenden Kreisen lebenden Menschen ermittelt.

15 ThHStA, Ld. Thür., MdI, Nr. 3663, Bl. 30. Da auch hierfür keine offizielle Gesamtzahl vorliegt, wurde zu deren Ermittlung von der im Rahmen der Volkszählung von 1946 angegebenen Ge- 
200000 Menschen wurden durch das Hereinströmen der Flüchtlinge und Vertriebenen mehr als ausgeglichen. Bereits Ende August 1945 lebten in Thüringen 203767 „Umsiedler ${ }^{16}$. In den folgenden Wochen und Monaten stieg ihre Zahl sprunghaft an und betrug im Dezember $461436^{17}$. Dazu kamen in den Jahren 1946/47 im Rahmen des "organisierten Transfers" weitere Vertriebene. Erstmals trafen am 12. Juni 19461200 Personen aus Reichenberg/Sudetenland im Übernahmelager Gera ein. Diesem Transport folgten bis zum Oktober 1946 weitere 96 allgemeine und 15 Antifa-Transporte aus der CSR mit ca. 120000 Personen sowie unmittelbar daran anschließend 90 Transporte mit 138000 Menschen aus den an Polen abgetretenen ehemaligen deutschen Ostgebieten, 17 Transporte mit Zivilinternierten aus der UdSSR und 10 Transporte mit Menschen aus dem nördlichen Ostpreußen ${ }^{18}$. Der weitaus größte Teil der 1948 in Thüringen lebenden ca. 670000 Vertriebenen stammte aus Schlesien, dem Sudetenland und Ostpreußen ${ }^{19}$. Diese Menschen verteilten sich in unterschiedlichem Maße auf die Städte und Kreise des Landes. Auffallend ist ihr geringer Anteil an der Bevölkerung der Städte. Lebten Ende 1947 2,3 Prozent der Einheimischen in den kreisfreien Städten Thüringens und 51,2 Prozent in den Städten der Landkreise, so fanden nur 1,9 bzw. 42 Prozent der Vertriebenen dort eine Unterkunft, das heißt weit mehr als die Hälfte aller Vertriebenen in Thüringen lebten in Dörfern bzw. kleineren Landgemeinden ${ }^{20}$. Diese ungleichmäßige, den Verstädterungsprozeß der zurückliegenden Jahrzehnte zunächst umkehrende Tendenz betraf alle Länder und Besatzungszonen Deutschlands und resultierte in erster Linie aus dem unkontrollierten Einströmen der Flüchtlingstrecks am Ende des Krieges, die sich vorrangig dort eine Unterkunft suchten, wo die Ernährung einigermaßen gesichert war. Hinzu kam die Praxis der drei Siegermächte, die im Rahmen erster Lenkungsversuche des Vertriebenenstromes ebenfalls vorrangig den Zerstörungsgrad der Städte und die bessere Versorgungslage auf dem Lande, dagegen jedoch weder vorhandene Arbeitsmöglichkeiten noch die Nutzbarkeit des Wohnraumes berücksichtigten ${ }^{21}$. Aus den gleichen Gründen differierte der Anteil der Vertriebenen an der Bevölkerung der Landkreise teilweise erheblich, wie Tabelle Nr. 1 verdeutlicht.

Auffallend ist der hohe Anteil Vertriebener an der Bevölkerung der nördlichen und mittleren Kreise Thüringens, eine Tendenz, die sich bereits mit den ersten Erhebungen abzeichnete und die offensichtlich auf der günstigen Ernährungsbasis in den Regionen mit mittleren und guten Böden beruhte. In den nordöstlichen Kreisen Altenburg, Gera, Stadtroda ${ }^{22}$ und Weimar bot die vorhandene Industrie zudem günstige Voraussetzungen für die spätere Eingliederung der hier aufgenommenen Vertriebenen in den Arbeitspro-

samteinwohnerzahl die der Evakuierten und Umsiedler abgezogen. Eventuelle Zuzüge aus privaten oder anderen Gründen müssen unberücksichtigt bleiben.

16 ThHStA, Ld. Thür., MdI, Nr. 3944, Bl. 44; Die "Umsiedler“ wurden in der vorliegenden Statistik getrennt von „sonstigen Ostflüchtlingen“ und „aus dem Westen Evakuierten“ aufgeführt. Trotz Beachtung der in den ersten Monaten oft unklaren Zuordnung in die einzelnen Bevölkerungsgruppen kann davon ausgegangen werden, daß hier unter "Umsiedler" tatsächlich die von der Vertreibung betroffenen Menschen erfaßt wurden.

17 ThHStA, Ld. Thür., MdI, Nr. 3944, Bl. 45.

18 Ebenda, Bl. 46.

19 Ebenda, Nr. 3943, Bl. 37.

20 Ebenda, Nr. 3664, Bl. 33.

${ }^{21}$ Vgl. u. a. Frantzioch, Die Vertriebenen, S. 99; Rusche, Eingliederung, S. 133; Hoffmann / Wille / Meinicke, Flüchtlinge, S. 20; Plato / Meinicke, Alte Heimat - Neue Zeit, S. 46.

22 Das Territorium des Landkreises Stadtroda umschließt die Stadt Jena. 
Tabelle 1: Anteil der Vertriebenen an der Bevölkerung ausgewählter Kreise in Thüringen (Stand 31. 12. 1948) $)^{23}$

\begin{tabular}{|l|c|c|c|}
\hline Kreis & $\begin{array}{c}\text { Gesamt- } \\
\text { bevölkerung }\end{array}$ & Vertriebene & $\begin{array}{c}\text { Anteil der Vertriebenen } \\
\text { in Prozent }\end{array}$ \\
\hline kreisfreie Städte & 34499 & & \\
Apolda & 30318 & 7718 & 22,3 \\
Arnstadt & 80980 & 7125 & 23,5 \\
Jena & 33260 & 10801 & 13,3 \\
Nordhausen & & 1299 & 3,9 \\
Landkreise & 57322 & & \\
Langensalza & 106208 & 17664 & 36,8 \\
Sondershausen & 130942 & 32378 & 30,5 \\
Gera & 122653 & 39529 & 30,0 \\
Stadtroda & 138874 & 35050 & 28,6 \\
Weimar & 116993 & 39589 & 28,5 \\
Altenburg & 58224 & 30870 & 26,4 \\
Schmalkalden & 91630 & 10384 & 17,9 \\
Worbis & 86451 & 16305 & 17,8 \\
Suhl & 85880 & 11861 & 13,7 \\
Sonneberg & 2988288 & 7601 & 8,8 \\
\hline Land Thüringen & & 685913 & 22,3 \\
\hline
\end{tabular}

zeß. Sie trafen somit auf wesentlich günstigere Integrationsbedingungen als die in überwiegend landwirtschaftlich geprägten Gebieten - beispielsweise in den nordwestlichen Thüringer Kreisen Sondershausen und Langensalza - Aufgenommenen, für die die Versorgungsmöglichkeiten zwar oft zufriedenstellend waren, die Suche nach einer Arbeit aufgrund der großen Entfernung vom Wohnort jedoch meist erfolglos blieb.

Auf noch ungünstigere Bedingungen trafen die in den Kreisen des östlichen Thüringer Waldes - Schmalkalden, Suhl und Sonneberg - und des Eichsfeldes - Teile des Landkreises Worbis - eingewiesenen Vertriebenen. Aufgrund der schwierigen Versorgungslage hatten hier von Anfang an weniger Menschen Zuflucht gesucht als in anderen Thüringer Regionen. Zusätzlich erschwerend sollte sich später der große Mangel an Arbeitsplätzen in der dort vorherrschenden Klein- und Heimindustrie auswirken.

Die Unterschiede im Anteil der Vertriebenen an der Bevölkerung der Städte und Landkreise beeinflußten neben dem - wie bereits erwähnt für Thüringen nur bedingt relevanten - Zerstörungsgrad in entscheidendem Maße die Größe des für ihre Aufnahme verfügbaren Wohnraumes. Insgesamt hatte sich die für jeden Einwohner des Landes durchschnittlich zur Verfügung stehende Wohnfläche von $18 \mathrm{~m}^{2}$ im Jahr 1939 über $11,7 \mathrm{~m}^{2}$ unmittelbar nach Kriegsende ${ }^{24}$ und $10 \mathrm{~m}^{2}$ im Oktober $1946^{25}$ auf $8,6 \mathrm{~m}^{2}$ Ende $1948^{26}$ verringert. Jedoch auch hier wiesen die einzelnen Regionen des Landes zum Teil erhebliche Differenzen sowohl in bezug auf die insgesamt vorhandene Fläche als auch hinsichtlich ihrer Zuteilung an Vertriebene auf.

${ }^{23}$ ThHStA, Ld. Thür., MinPräs., Büro des MinPräs., Nr. 444/1, Bl. 23.

${ }^{24}$ Rusche, Eingliederung, S. 135.

25 Thüringer Volk, Landeszeitung der Sozialistischen Einheitspartei Deutschlands, Weimar, 17. 10. 1946.

${ }^{26}$ ThHStA, Ld. Thür., MinPräs., Büro des MinPräs., Nr. 444/1, Bl. 99. 
Tabelle 2: Verfügbarer Wohnraum in ausgewählten Thüringer Kreisen (Stand 31. 12. 1948) ${ }^{27}$

\begin{tabular}{|l|c|c|c|}
\hline \multirow{2}{*}{ Kreis } & \multicolumn{3}{|c|}{ vorhandener Wohnraum in $\mathrm{m}^{2}$ je Kopf } \\
\cline { 2 - 4 } & insgesamt & $\begin{array}{c}\text { für Einheimische } \\
\text { und Evakuierte }\end{array}$ & für Vertriebene \\
\hline Stadtkreise & & & \\
Gotha & 10,7 & 11,2 & 9,0 \\
Grciz & 10,0 & 10,8 & 7,9 \\
Mühlhausen & 9,9 & 10,2 & 7,9 \\
Weimar & 7,8 & 7,8 & 7,8 \\
Apolda & 7,6 & 7,7 & 7,2 \\
Landkreise & & & \\
Suhl & 9,8 & 9,7 & 9,8 \\
Altenburg & 9,7 & 9,9 & 7,4 \\
Schmalkalden & 9,5 & 9,4 & 9,9 \\
Hildburghausen & 9,4 & 10,1 & 6,2 \\
Gotha & 8,4 & 9,1 & 6,3 \\
Weimar & 7,8 & 8,1 & 7,2 \\
Stadtroda & 7,8 & 8,2 & 6,8 \\
Gera & 7,6 & 8,7 & 6,5 \\
Eisenach & 6,9 & 6,7 & 7,8 \\
Sondershausen & 6,8 & 7,0 & 6,5 \\
\hline Land Thüringen & 8,6 & 8,8 & 7,6 \\
\hline
\end{tabular}

Ein Vergleich der Angaben in beiden Tabellen zeigt deutlich die Abhängigkeit der verfügbaren Wohnfläche von der Zahl der aufgenommenen Vertriebenen. Insbesondere in den Landkreisen Sondershausen, Weimar, Stadtroda und Gera verringerte der große Menschenzustrom den pro Kopf vorhandenen Wohnraum offensichtlich deutlich, während in den Stadtkreisen eine gegenteilige Tendenz zu beobachten ist. Im Norden Thüringens hebt sich lediglich der Kreis Altenburg von den benachbarten Regionen ab. Für den Kreis, der sowohl industriell als auch landwirtschaftlich zu den am weitesten entwickelten des Landes zählte, wirkte sich der im Gegensatz zu den ähnlich strukturierten Nachbarkreisen geringere Zuzug offensichtlich besonders günstig aus. Die starke Benachteiligung der Vertriebenen gegenüber der einheimischen Bevölkerung hinsichtlich der Größe des verfügbaren Wohnraumes konnte zudem dadurch ausgeglichen werden, daß die durchschnittlich verfügbaren $7,4 \mathrm{~m}^{2}$ je Person nicht weit unter dem Landesdurchschnitt lagen.

Für einen Zusammenhang zwischen der Zahl der aufgenommenen Vertriebenen und vorhandener Wohnfläche spricht auch der vergleichsweise große nutzbare Wohnraum in den vom Menschenzustrom der Nachkriegsjahre weniger betroffenen Kreisen Suhl, Schmalkalden und Hildburghausen. Dagegen blieb die Wohnfläche in anderen Kreisen des Thüringer Waldes - wie zum Beispiel Sonneberg - trotz des geringen Bevölkerungs-

27 Ebenda.

${ }^{28}$ Bei einem Anteil von 3,1\% an der Gesamtbevölkerung kann die Zahl der Evakuierten, die 1945 entscheidend zur Verknappung der Wohnfläche beigetragen hatte, für das Jahr 1948 außer acht gelassen werden. Lediglich in der Stadt Greiz muß davon ausgegangen werden, daß zu diesem Zeitpunkt bei einem Bevölkerungsanteil dieser Menschengruppe von 7,8\% der Wohnraum für dic Vertriebenen auch weiterhin aufgrund der Unterbringung Evakuierter eingeschränkt blieb. Vgl. ThHStA, Ld. Thür., MinPräs., Büro des MinPräs., Nr. 444/1, Bl. 23. 
zuwachses eng begrenzt. Das lag vor allem in der überwiegend von einfachen Einfamilien-Fachwerkhäusern mit äußerst beengten Unterkunftsmöglichkeiten geprägten baulichen Struktur der Berggemeinden begründet. Mittelalterliche Fachwerkbauten, die in den wenigen kleinen Städten dominierten, verfügten ebenfalls nur über eine begrenzte Aufnahmefähigkeit ${ }^{29}$.

$\mathrm{Zu}$ einer weiteren Wohnraumverknappung insbesondere in den Kreisen des Thüringer Waldes trugen die sich seit 1947 verstärkenden Bemühungen um das Untersagen der Einweisung Vertriebener in Heilbäder be ${ }^{30}$. Diese Forderungen sind angesichts der Tatsache, daß allein in den zehn Thüringer Heilbädern ca. 25 Prozent der Einwohner Vertriebene waren, die meist in ursprünglich Kurzwecken vorbehaltenen Unterkünften und Einrichtungen lebten, durchaus verständlich. Die verlangte Ausweisung der ca. $16000^{31}$ betroffenen Menschen konnte jedoch als Lösung - zumindest zunächst - nicht in Betracht gezogen werden, zumal man davon ausgehen mußte, daß sich die ca. 30 Kurorte im Land derartigen Aktionen anschließen würden. Es zeichnete sich jedoch spätestens seit 1947 $a b$, daß die dauerhafte Unterbringung einer größeren Zahl Vertriebener weder in Heilbädern noch in Kurorten möglich sein würde ${ }^{32}$.

Unmittelbare Auswirkungen auf die Verringerung des Wohnraumbestandes hatten auch die von den Siegermächten getroffenen Festlegungen für die zeitweilige Besetzung Deutschlands. Zum einen wurden in allen Kreisen Unterkunftsmöglichkeiten für die Angehörigen der Besatzungstruppen benötigt. So beherbergte die Gemeinde Gefell im Kreis Sonneberg bereits Ende August 1945 bei 370 Einwohnern neben ca. 200 Evakuierten ebenso viele Angehörige der Roten Armee ${ }^{33}$. Thüringen verfügte zudem über eine relativ lange Demarkationslinie zur amerikanischen und britischen Besatzungszone. Spätestens seit 1946 sperrte die SMAD die unmittelbar daran gelegenen Gebiete für die Ansiedlung von Vertriebenen ${ }^{34}$. Hinzu kam eine weitere Wohnraumverknappung durch die Unterbringung der Polizei ${ }^{35}$. Allein Mühlhausen mußte zu diesem Zweck innerhalb kürzester Zeit 200 Wohnungen für insgesamt 750 Personen zur Verfügung stellen ${ }^{36}$. Noch stärker war der Kreis Eisenach von diesen Maßnahmen betroffen, da auf ihn fast die gesamte Grenze Thüringens zu Hessen entfiel. Die statistische Angabe, wonach hier die Vertriebenen im Durchschnitt über $1,2 \mathrm{~m}^{2}$ mehr Wohnfläche verfügt haben sollen als die einheimische Bevölkerung, ist angesichts dieser Tatsache anzuzweifeln.

Trotz der aufgezeigten deutlichen Unterschiede in den Ausgangsbedingungen meldeten Ende 1947 nahezu alle Thüringer Kreise an das Landesamt für Neubürger, daß die

29 Ebenda, MdI, Nr. 3876, Bl. 104.

30 Vgl. u. a. ebenda, Nr. 3709, Bl. $364 \mathrm{ff}$.

${ }^{31}$ Mit dem Stand von Ende Februar 1948 lebten 16385 Vertriebene in den 10 Heilbädern. Vgl. ebenda, Nr. 3934, Bl. 424.

32 Im folgenden Jahr hatten die Bemühungen der betroffenen Gemeinden Erfolg. Mit dem „Gesetz über die Unterbringung Werktätiger in Heilbäder, Kur- und Erholungsorte“ vom 19. Mai 1949 wurde festgelegt: „Einrichtungen oder Unterbringungsmöglichkeiten, die Kurzwecken entfremdet worden sind, sind [...] ihrem früheren Zweck wieder zuzuführen. Das gilt insbesondere für Einrichtungen und Räume, die während des Krieges oder später stillgelegt oder mit Neubürgern belegt worden sind." Regierungsblatt für das Land Thüringen, Teil I: Gesetzsammlung, Nr. 7, Weimar 31. Mai 1949, S. 31.

33 ThHStA, Ld. Thür., MdI, Nr. 3934, Bl. 140.

${ }^{34}$ Ebenda, Bl. 76 RS.

35 Ebenda, MinPräs., Büro des MinPräs, Nr. 444/1, Bl. 71 f.

${ }^{36}$ Ebenda, MdI, Nr. 683, Bl. 21. 
Unterbringung der Vertriebenen fast ausschließlich in „beständigen Wohnungen“ erfolgt sei. Angeblich lebten zu diesem Zeitpunkt nur 2,3 Prozent der Vertriebenen in „zeitweiligen unzulänglichen Wohnungen" und 0,1 Prozent von ihnen besaßen keinen Wohnraum $^{37}$. Einen Anhaltspunkt dafür, welche Wohnungen als "beständig" betrachtet wurden, bieten die Forderungen des Leiters des Amtes für Neubürger, Kalinke, vom Dezember 1947, wonach für die wohnliche Unterbringung die folgenden Minimalanforderungen fixiert wurden: Die Heizbarkeit des genutzten Raumes, das Vorhandensein verglaster Fenster, dichter Türen, einer Kochgelegenheit sowie der notwendigen mobiliaren Ausstattung, d. h. eines Schrankes, eines Tisches sowie je Person eines Bettes und eines Stuh$\mathrm{les}^{38}$. Obwohl angesichts der günstigeren Situation im Land davon ausgegangen werden konnte, daß Thüringen weitaus weniger Schwierigkeiten bei der Unterbringung der Vertriebenen hatte als andere Länder der SBZ, ist es angesichts der auch hier zweifellos vorhandenen Notlage äußerst unwahrscheinlich, daß tatsächlich fast 99 Prozent der Unterkünfte von Vertriebenen im Land diesen Anforderungen gerecht wurden. Offensichtlich schenkte auch das Amt für Neubürger den aus den Kreisen gemeldeten statistischen Angaben wenig Glauben. Um sich selbst ein genaues Bild über die Lage zu verschaffen, führte das Amt in der Zeit vom 23. Juni bis 10. Dezember 1948 „Überprüfungen der Wohn- und Lebensverhältnisse der Alt- und Neubürger" durch. Diese bildeten letztendlich zugleich den Höhepunkt und Abschluß der Tätigkeit des Umsiedleramtes, da SMAD und SED bereits seit 1947 verstärkt auf die Auflösung der ZVU und aller speziell mit Vertriebenenfragen befaßten Behörden in den Ländern hingearbeitet hatten ${ }^{39}$, was unter anderem auch zur Auflösung des Thüringer Amtes für Neubürger am 1. April 1949 führte $^{40}$. Nach außen hin wurde versucht, die wahren Gründe für diese Politik zu verschleiern, indem man das sogenannte „Umsiedlerproblem“ für „gelöst" erklärte und im Rahmen von Umsiedlerwochen in der ersten Jahreshälfte 1948 in allen Ländern und Kreisen der SBZ die zweifellos vorhandenen Erfolge bei der Aufnahme und beginnenden Integration der Vertriebenen in den Mittelpunkt stellte. Gleichzeitig sollten damit die kaum weniger großen weiterhin bestehenden Probleme dieser Menschen - der noch immer gravierende Mangel an Wohnraum, Arbeitsplätzen, Kleidung und Mobiliar, die Benachteiligung gegenüber der einheimischen Bevölkerung in nahezu allen Lebensbereichen, die Sehnsucht nach der Heimat und das Nichtvergessenkönnen der brutalen Art und Weise der Ausweisungen - zunehmend verdrängt werden. Erfolgsbilanzen hinsichtlich der wohnlichen Unterbringung ließen sich offensichtlich am ehesten in Thüringen nachweisen. Die Kontrolle von insgesamt 5674 Haushalten - davon 3060 von Vertriebenen - in 238 der 2382 Städte und Gemeinden des Landes zeigten tatsächlich beachtliche Ergebnisse bei der menschenwürdigen Unterbringung. Trotzdem verdeutlichten Mißstände in nahezu allen Kreisen, daß die im Vorjahr gemeldeten statistischen Angaben nicht in jedem Fall der Realität entsprachen.

Relativ günstige Wohnbedingungen fanden die Vertriebenen den Kontrollergebnissen zufolge in einem Teil der Städte vor. So stellte die für die Überprüfung der Haushalte in Apolda zuständige Kommission fest, es sei „die Stadt Thüringens, in der das Neubürgerproblem als gelöst betrachtet werden kann. [.. . ] Die Überprüfung ergab, daß ein Unter-

${ }^{37}$ Ebenda, Nr. 3664, Bl. 139.

${ }^{38}$ Ebenda, Nr. 3726, Bl. 53.

39 Vgl. Wille, Zentralverwaltung, S. $51 \mathrm{ff}$.

40 ThHStA, Ld. Thür., MinPräs., Büro des MinPräs., Nr. 444/1, Bl. 2. 
schied zwischen Alt- und Neubürgern in vielen Fällen nicht mehr zu bemerken ist." In einer ehemaligen Fabrik konnten neue, ausnahmslos zur Abgabe an Vertriebene vorgesehene, Wohnungen fertiggestellt werden ${ }^{41}$. Als Ursache für die erfolgreiche Unterbringung wurde eine bereits früher stattgefundene Überprüfung der den Vertriebenen überlassenen Wohnräume durch Mitarbeiter des Wohnungsamtes und Stadtverordnete betrachtet. Selbst wenn man von der überzogenen Feststellung eines „bereits gelösten Neubürgerproblems" absieht, kann davon ausgegangen werden, daß in Apolda zumindest die Sicherung der Grundanforderungen an die Wohnraumversorgung gelungen war. Offensichtlich stellte dabei in der Stadt der relativ hohe Bevölkerungszuwachs von 24 Prozent gegenüber 1939 kein entscheidendes Hindernis dar ${ }^{42}$.

Ähnlich positive Einschätzungen traf das Amt für Neubürger auch für die Städte Altenburg, Greiz, Mühlhausen und - mit Abstrichen - Langensalza ${ }^{43}$. In Altenburg verfügten Vertriebenenhaushalte mit zwei Personen teilweise bereits über zwei Räume. Bei Familien mit mehr als vier Personen konnte die Vergabe von mindestens zwei Räumen garantiert werden ${ }^{44}$. Als besonders erwähnenswert betrachteten die Prüfer, daß in Mühlhausen „die Neubürger nicht in Hinterzimmer untergebracht, sondern gleichberechtigt mit den Altbürgern wohnen." ${ }^{* 45}$ Gleichzeitig fällt am Beispiel von Mühlhausen, Greiz und besonders Langensalza auf, daß selbst dort, wo im unmittelbaren Umfeld erhebliche Mißstände beobachtet werden mußten ${ }^{46}$, die Vertriebenen in den Städten der Landkreise eine einigermaßen menschenwürdige Unterkunft gefunden hatten.

Völlig anders zeigte sich die Situation in den von den Kriegszerstörungen besonders betroffenen größeren Städten. So konnte auch ein Bevölkerungsrückgang in Nordhausen um etwa ein Viertel ${ }^{47}$ den erheblichen Wohnraumverlust nicht ausgleichen. Einheimische und Vertriebene waren hier gezwungen, in oftmals nur notdürftig hergerichteten Baracken zu leben. Über die Bedingungen, denen die Menschen in derartigen Unterkünften ausgesetzt waren, geben die Berichte zur Situation einzelner Familien wie folgt Auskunft: „Umsiedlerfamilie P., Nordhausen, Baracke Freiherr v. Stein-Straße: Räumlich durchaus ausreichend bewohnt die 4 köpfige Umsiedlerfamilie 3 Räume in einer Baracke, die nicht winterfest ist. Die sehr ordentliche und saubere Familie hat den Wunsch, endlich, nach 3 Jahren eine Wohnung zu erhalten, da es bei Regenwetter furchtbar sei, in der Baracke, deren Dach schadhaft ist, zu wohnen. [. . .] Umsiedlerfamilie L., Nordhausen, Baracke Freiherr v. Stein-Straße: Die 12 Personen starke Familie, die gleichfalls in einer der undichten Baracken wohnen muß, ist dort sehr beengt untergebracht. In 2 Zimmern und dem Abstellraum von zusammen 30 qm Wohnraum sind nur 7 Schlafgelegenheiten vorhanden. Die Räume sind sehr unsauber, was bei der Beengtheit kaum anders sein kann. Das wenige Mobiliar ist schlecht. Die Verhältnisse dieser Familie müssen in Kürze geändert werden, da sonst die Gefahr besteht, daß sich ein Krankheitsherd ent-

41 Ebenda, Bl. 80 f.

42 Zu der Zahlenangabe vgl. ThHStA, Ld. Thür., MdI, Nr. 3798, Bl. 11 und ebenda, MinPräs., Büro des MinPräs., Nr. 444/1, Bl. 23. Apolda verzeichnete damit den höchsten Bevölkerungszuwachs aller kreisfreien Städte Thüringens.

${ }^{43}$ ThHStA, Ld. Thür., MinPräs., Büro des MinPräs., Nr. 444/1, Bl. 76; ebenda, MdI, Nr. 682, Bl. 68 ff. und Nr. 686, Bl. 44.

${ }^{44}$ Ebenda, MdI, Nr. 682, Bl. $68 \mathrm{ff}$.

45 ThHStA, Ld. Thür., MinPräs., Büro des MinPräs., Nr. 444/1, Bl. 76.

${ }^{46}$ Vgl. ebenda, MdI, Nr. 682, Bl. 2-18 und Bl. 86-125; Nr. 683, Bl. 15-49.

47 Vgl. ebenda, Nr. 3798, Bl. 11; MinPräs., Büro des MinPräs., Nr. 444/1, Bl. 23. 
wickelt. Die Einschaltung des Gesundheitsamtes ist dringendst erforderlich. ${ }^{48}$ Die statistische Angabe, wonach in Nordhausen eine ebenso große Wohnfläche je Einwohner wie im Landesdurchschnitt zur Verfügung gestanden haben soll, kann nur unter Zurechnung derartiger Unterkünfte entstanden sein.

Erhebliche Probleme bei der Unterbringung der Vertriebenen bestanden auch in anderen Städten wie zum Beispiel Jena, Erfurt und Weimar. Erschwerend wirkte sich in Weimar zusätzlich der Status als Landeshauptstadt aus, da zahlreiche Räume für die Einrichtung von Behörden und gleichzeitig Unterkünfte für die Abgeordneten während der Sitzungen des Landtages bereitgestellt werden mußten. Für Jena wiederum brachte der Charakter als Universitätsstadt zusätzliche Schwierigkeiten mit sich. Traditionell vermieteten die Einheimischen hier ihre ungenutzten Räume an Studenten. Nach Ansicht des Amtes für Neubürger wäre dabei jedoch eine planvollere Lenkung durchaus möglich gewesen. In zahlreichen Fällen empfahlen die Kommissionsmitglieder die Vergabe größerer Räume an die Familien der Vertriebenen, während deren bisher genutzte kleine Zimmer für die Bedürfnisse der Studenten ausreichen sollten ${ }^{49}$.

Weitaus differenzierter als in den Städten gestaltete sich die wohnliche Unterbringung der Vertriebenen in den Thüringer Landkreisen. Die guten Voraussetzungen in den industriell und landwirtschaftlich weit entwickelten nordöstlichen Kreisen wirkten sich auch auf die Vergabe von Wohnraum an die neu Hinzugezogenen aus. Vor allem im Kreis Altenburg war die Situation trotz aller Probleme bei weitem nicht mit der Notlage in anderen Kreisen des Landes - und schon gar nicht mit der im Norden und Osten der SBZ vergleichbar. Nach der Kontrolle der Wohn- und Lebensverhältnisse in sieben Gemeinden des Kreises wurde festgestellt, daß die Vertriebenen in zufriedenstellenden Verhältnissen mit guter wohnlicher Ausstattung lebten. Kleinere Mängel wurden unmittelbar nach der Überprüfung behoben ${ }^{50}$. Diese positive Einschätzung erfolgte im Kreis nahezu flächendeckend und unabhängig von der konkreten Wohnlage. Sie bezog sich sowohl auf Gemeinden wie Langenleuba-Niederhain, in denen sich aufgrund der vorhandenen großen Bauernhäuser die Einschränkungen für die einheimische Bevölkerung in Grenzen hielten, als auch auf die durch Kriegseinwirkungen zu 82 Prozent zerstörte Stadt Meuselwitz ${ }^{51}$. Selbst in der Gemeinde Flemmingen, in der die Zahl der Vertriebenen annähernd die der Einheimischen erreichte, blieb die Kritik des Weimarer Amtes auf den fehlenden Abstellraum bei einer Familie beschränkt ${ }^{52}$. Besonders hervorgehoben wurde das offensichtlich aus dem unter den gegebenen Bedingungen annähernd optimal gelösten Wohnraumproblem resultierende gute Verhältnis zwischen Einheimischen und Vertriebenen ${ }^{53}$.

Im Kreis Gera hatten ähnlich wie in Apolda bereits 1947 Überprüfungen der Wohnsituation bei den Familien Vertriebener von seiten der Kreisverwaltung stattgefunden, und auch hier führte das Amt für Neubürger seinen positiven Gesamteindruck vor allem auf diese Maßnahme zurück. Offensichtlich gelang nicht nur eine Erfassung bisher nicht ausgelasteter Räume - allein 70 in Neustadt und 72 in Triptis - sondern auch eine relativ

${ }^{48}$ Ebenda, MdI, Nr. 683, Bl. $62 \mathrm{f}$.

49 Ebenda, MinPräs., Büro des MinPräs, Nr. 444/1, Bl. 69.

so Ebenda, B1. 74.

${ }^{51}$ Ebenda, MdI, Nr. 682, Bl. $68 \mathrm{ff}$.

52 Ebenda, B1. 84.

53 Ebenda, Bl. 71 u. Bl. 84. 
gleichmäßige Belastung aller Gemeinden des Kreises mit Vertriebenen. Insgesamt wurden die Wohnverhältnisse in den überprüften Gemeinden als gut eingeschätzt und ausdrücklich darauf verwiesen, daß kaum Unterschiede zwischen Alt- und Neubürgerhaushalten erkennbar seien.

Auffallend ist in diesem Zusammenhang die völlig fehlende Übereinstimmung der erwähnten positiven Kontrollergebnisse mit den statistischen Angaben. Die Geraer Kreisverwaltung ging Ende 1948 bei 12 Prozent der Vertriebenen von einer unzureichenden Unterbringung aus ${ }^{54}$. Ursachen für diese Aussage, die der weitaus deutlicher verbreiteten Tendenz zur Beschönigung statistischer Angaben entgegenstand, lassen sich allenfalls vermuten. Es ist unwahrscheinlich, daß angesichts der allgemeinen Not die Kreisverwaltung in Gera an die Unterbringung der zugezogenen Menschen höhere Ansprüche stellte, als dies generell der Fall war. Unterstellt man eine bewußte Manipulation der Zahlen, so liegt die angesichts des geringen Zuzuges seit 1948 jedoch eher unwahrscheinliche Vermutung nahe, daß der Kreis wegen schlechter Unterbringungsmöglichkeiten eine weitere Zuweisung Vertriebener verhindern wollte. Anzunehmen ist jedoch, daß die Zahlen die tatsächliche Situation in einzelnen Gebieten des Kreises, die von den Kontrollen des Amtes für Neubürger nicht erfaßt wurden, widerspiegeln.

Gemeinsamkeiten hinsichtlich der Voraussetzungen für die wohnliche Unterbringung bestanden auch in den vorrangig durch eine hochentwickelte Landwirtschaft geprägten Kreisen Sondershausen und Langensalza, die zudem beide aufgrund des hohen Bevölkerungszuwachses nur über eine geringe Wohnfläche je Einwohner verfügten. Trotzdem zeigten sich zwischen den Einschätzungen des Amtes für Neubürger über die unmittelbar benachbarten Regionen deutliche Differenzen. Bis zum Jahr 1947 hatte sich das Amt mehrfach veranlaßt gesehen, auf die völlig unzureichende Unterbringung der Vertriebenen im Landkreis Sondershausen, die offensichtlich durch die im Landesmaßstab geringste Wohnfläche je Einwohner verursacht wurde, hinzuweisen. Ein Jahr später berichteten die zuständigen Kommissionen über eine deutliche Anhebung des Lebensniveaus, die auf eine verstärkte Kontrolltätigkeit seitens der Kreisverwaltung zurückzuführen sei ${ }^{55}$. Inwiefern eine Verbesserung der Wohnqualität bei $6,5 \mathrm{~m}^{2}$ Wohnfläche für jeden Vertriebenen erreichbar war, wurde in dem Bericht nicht erläutert. Die gleichzeitige Erwähnung von Streitigkeiten unter der einheimischen Bevölkerung, da die Verknappung aufgrund „reichlich vorhandenen Wohnraumes" nur einen Teil von deren Haushalten beträfe, ${ }^{56}$ läßt vielmehr vermuten, daß im Kreis Sondershausen im Rahmen der Kontrollen vorwiegend Dörfer mit einem geringen Vertriebenenanteil - bei insgesamt ungleichmäßiger Verteilung - erfaßt wurden. Die Lebenssituation der in andere Dörfer des Kreises eingewiesenen Menschen kann mit großer Wahrscheinlichkeit mit der im Nachbarkreis Langensalza verglichen werden. In den überprüften Gemeinden - insbesondere Großengottern und Ilefeld - trafen die Kommissionen auf derart erbarmungswürdige $\mathrm{Zu}$ stände, daß das Amt für Neubürger einschätzte, Langensalza dürfe „für sich das Recht in Anspruch nehmen," hinsichtlich der Vertriebenenbetreuung "der schlechteste Kreis in Thüringen zu sein. Auf der ganzen Linie ist in diesem zwar industriearmen, doch landwirtschaftlich sehr reichen Kreise für die Umsiedler sehr wenig getan worden. Ganz besonders haben die Großbauern sehr wenig Verständnis für die sozialen Verhält-

${ }^{54}$ Ebenda, MinPräs., Büro des MinPräs., Nr. 444/1, Bl. 99.

${ }^{55}$ Ebenda, Bl. $79 \mathrm{f}$.

${ }^{56}$ Ebenda. 
nisse der Neubürger. ${ }^{57}$ Besonders menschenunwürdig wurde die Unterbringung der Vertriebenen in Großengottern empfunden. Während alteingesessene Bauern den Vertriebenen Unterkünfte in den schlechtesten Zimmern ihrer Häuser zuwiesen, nutzten sie vollständig eingerichtete Wohnräume als „Wurst-“ oder „Abstellkammern“. So mußten vier erwachsene Vertriebene mit ihren vier Kindern in einem Zimmer mit Küche, das zudem einer Rußkammer glich und eine Fläche von nur $14 \mathrm{~m}^{2}$ umfaßte, leben, während der außerhalb des Ortes wohnende Eigentümer drei Räume im gleichen Haus als Abstellkammern beanspruchte ${ }^{58}$. Die ausgesprochen unmenschliche Unterbringung Vertriebener in einem Wohnviertel des Dorfes wurde wie folgt beschrieben: „Der Bau, Eigentum der Gemeinde Großengottern, kann in seinem jetzigen Zustand überhaupt nicht als Wohnraum angesehen werden. Er widerspricht den einfachsten Begriffen, der Möglichkeit über Unterbringung von Menschen. Stellt ein vollkommen verrustes, total verkommenes Gebäude dar, in dem nur Neubürger wohnen müssen. Erdgeschoß rechts wohnt Familie K., 2 Erw. und 7 Kinder in einem Raum. Die Mutter teilt das Bett mit 3 Kindern, die übrigen müssen gleichfalls als Haufen zusammen schlafen. Die Frau sagt aus, daß die Wohnungen vollkommen verwanzt sind, sie bald nicht mehr imstande ist, die Chemikalien zu kaufen und sich vor dem Ungeziefer auch nur einigermaßen zu schützen.

Weiters wohnt die Neubürgerfamilie H., 5 Personen in 2 kleinen ,Löchern'. Das eine mit einem Feldofen für einen Topf aufstellbar eingerichtet, der das ganze Haus verqualmt und das Leben der übrigen Bewohner untragbar macht. [. . . ] Das ganze Gebäude ist meines Erachtens nicht einmal für Großvieh benützbar [...] Das Trinkwasser muß aus einem ungefähr $6 \mathrm{~m}$ tiefen Brunnen entnommen werden, der nicht abgedeckt ist und mit allem Unrat versehen ist. ${ }^{\text {}} 59$

Ähnliche Mißstände wie in Großengottern mußten auch in anderen Gemeinden des Kreises registriert werden. In einem besonders mitleiderregenden Zustand befanden sich die Bewohner des Ilefelder Altenheimes, in dem nicht nur die hygienischen Verhältnisse als katastrophal betrachtet wurden, sondern zudem der begründete Verdacht bestand, daß die hier untergebrachten alten Menschen regelrecht dem Verhungern preisgegeben waren. Entsprechend harte Worte richtete der Leiter des Thüringer Amtes für Neubürger, Kalinke, im Rahmen der Abschlußbesprechung an alle Verantwortlichen. Seine Vorwürfe konnten mit Hinweisen auf die schwierige soziale Lage in dem industriearmen Kreis sowie auf die Tatsache, daß hier im Rahmen des Befehls Nr. 209 der SMAD besonders viel Wohnraum für Neubauern errichtet werden mußte, nur zum Teil entkräftet werden ${ }^{60}$.

Die Feststellung der Prüfungskommission, wonach im Kreis Langensalza vorrangig Bauern mit relativ großen Wirtschaften - und entsprechenden Wohnräumen - den Nöten der Vertriebenen wenig Verständnis entgegenbrachten, wurde auch bezüglich einzelner Dörfer in den Landkreisen Worbis und Weimar wiederholt ${ }^{61}$. Offensichtlich gelang es den Behörden in Dörfern mit über Jahrhunderte gewachsenen, von deutlichen Besitzunterschieden geprägten sozialen Strukturen besonders schwer, sich gegen letztere, aber auch gegen verwandtschaftliche und freundschaftliche Bindungen im notwendigen

57 Ebenda, Bl. 72.

${ }^{58}$ Ebenda, MdI, Nr. 682, Bl. 9 ff.

59 Ebenda, Bl. 12.

60 Ebenda, Bl. $2 \mathrm{ff}$.

${ }^{61}$ Ebenda, MinPräs., Büro des MinPräs., Nr. 444/1, Bl. 78 und Bl. 83. 
Maße durchzusetzen. Auf wesentlich mehr Durchsetzungsvermögen der Behörden, aber auch eine offensichtlich größere Hilfsbereitschaft der Einheimischen trafen die Vertriebenen hingegen in den traditionell ärmsten Regionen des Landes. So wurden ihre Lebensverhältnisse im Kreis Sonneberg als gut eingeschätzt. Ausdrücklich verwies die Kommission auf das Vorhandensein von genügend Wohnraum in einem Teil der Gemeinden sowie auf die geringe Anzahl Vertriebener ${ }^{62}$. Von dieser günstigen Situation profitierten besonders die 478 in Steinach eingewiesenen Menschen, deren Anteil an der Gesamtbevölkerung lediglich 5,6 Prozent betrug. Trotz schlechter baulicher Voraussetzungen gelang in der Stadt eine planvolle Wohnraumverteilung ${ }^{63}$. Nachteilig wirkte sich jedoch die schlechte Ernährungslage aus, die angesichts der bis ins Stadtinnere reichenden Felsen auch nicht durch die Vergabe von Gartenland ausgeglichen werden konnte ${ }^{64}$.

Ähnlich positiv wurde die Arbeit der zuständigen Behörden im ebenfalls im Thüringer Wald gelegenen Kreis Meiningen eingeschätzt. Ein Pressebericht hob besonders die Arbeit des Bürgermeisters in Wölfershausen hervor, der sich persönlich auffallend für die Vertriebenen engagierte und von erst vor wenigen Tagen aus Polen Angekommenen als „ihr Freund“ bezeichnet wurde, der dafür gesorgt hätte, daß ihnen bereits unmittelbar nach der Ankunft mit reichlichem Mobiliar ausgestattete Wohnungen zur Verfügung gestellt wurden ${ }^{65}$. Aus den Überprüfungsergebnissen des Kreises Meiningen geht hervor, daß sich die zuständigen Behörden trotz des äußerst beengten Wohnraumes offensichtlich vielfach erfolgreich um eine menschenwürdige, wenn auch nicht als dauerhaft zu betrachtende Unterkunft für die Vertriebenen bemühten ${ }^{66}$.

Unabhängig von den gezeigten regionalen Unterschieden verwiesen die Kommissionen auf bestimmte Probleme, die offensichtlich in nahezu allen Kreisen Thüringens auch bei größtmöglichem Einsatz nur schwer lösbar waren. So gelang es einem Teil der Wohnraumbesitzer, sich gegen die Beschlagnahme von Zimmern in ihren 4-, 5oder 6-Raumwohnungen mit Hilfe von Einsprüchen an übergeordnete Dienststellen erfolgreich zu wehren. Insbesondere die Hauptabteilung Bau- und Wohnungswesen im Thüringer Ministerium für Arbeit und Soziales traf mehrfach derartige schwer nachvollziehbare Entscheidungen ${ }^{67}$. Streitigkeiten zwischen den Parteien, so zum Beispiel zwischen SED und CDU über die Notwendigkeit der Nutzung der Arbeitszimmer von Pfarrern als Wohnraum im Kreis Mühlhausen ${ }^{68}$, trugen ebenfalls nicht zur ausreichenden Berücksichtigung der Interessen Vertriebener bei. Das Beispiel Erfurts verdeutlichte letztendlich grundlegende Schwierigkeiten zahlreicher Städte und Kreise. Hier blieb das Vertreten der Belange der Vertriebenen auf einen eng begrenzten Personenkreis be-

${ }_{62}^{62}$ Ebenda, MdI, Nr. 684, Bl. 9 und Nr. 686, Bl. 5.

63 Ebenda, MinPräs., Büro des MinPräs, Nr. 444/1, Bl. 79.

${ }^{64}$ Ebenda, MdI, Nr. 684, Bl. 16; mit dem „Gesetz über die Verteilung von Gartenland an Neubürger" vom 30. Januar 1947, das die Vergabe von nach Möglichkeit 100 bis $300 \mathrm{~m}^{2}$ Land an die Familien Vertriebener vorsah, gelang in zahlreichen Territorien des Landes tatsächlich eine Verbesserung der Ernährungsbasis, was zahlreiche Berichte zu den Kontrollen im zweiten Halbjahr 1948 belegen. Andererseits wurden auch hier zum Teil ungerechtfertigte Unterschiede zwischen den Kreisen kritisiert; zum Gesetz vgl.: Regierungsblatt für das Land Thüringen, a. a. O. ., 14. März 1947, S. 27; zu Ergebnissen bei der Vergabe von Gartenland vgl. ThHStA, Ld. Thür., MdI, Nr. 682, Nr. 683 und Nr. 684.

${ }_{65}$ Ebenda, Nr. 686, Bl. 51.

66 Ebenda, Nr. 683, Bl. $124 \mathrm{ff}$.

67 Ebenda, MinPräs., Büro des MinPräs, Nr. 444/1, Bl. 84.

${ }^{68}$ Ebenda, Bl. 77 und MdI, Nr. 683, Bl. $15 \mathrm{ff}$. 
schränkt. Aufgrund mangelnder Zusammenarbeit zwischen allen betroffenen Dienststellen wurde das sogenannte „Neubürgerproblem“ zu einer Ressortfrage abgestuft ${ }^{69}$. Zudem mangelte es vor allem in kleineren Städten und Landgemeinden Thüringens am systematischen Aufbau unentbehrlicher Dienststellen. So fehlte in Triebes/Kreis Gera sogar ein hauptamtlicher Mitarbeiter des Wohnungsamtes. Ohne das Vorhandensein übersichtlicher Wohnungskarteien - beispielsweise in den Landkreisen Greiz, Mühlhausen und Gotha - blieb die Einweisung der Vertriebenen in bewohnbare Räume oft dem Zufall überlassen ${ }^{70}$.

Bei aller Kritik an der Arbeitsweise einzelner Verantwortlicher wurde nicht übersehen, daß auch ein Teil der Vertriebenen nicht im Rahmen der vorhandenen Möglichkeiten zu einer Verbesserung seiner Lebensverhältnisse beitrug. So ergab die Überprüfung von zwei im gleichen Haus untergebrachten Familien in Gotha folgendes Bild: Die betreffenden Wohnräume boten äußerlich ein erschreckend verwohntes Bild. Während sich in einem Fall die Familie offensichtlich bemühte, sie trotzdem „ordentlich und sauber zu halten und ihnen eine wohnliche Note zu geben", wirkte der von der anderen Familie bewohnte Raum durch die unordentliche Haushaltführung noch abstoßender. Die Vertriebene selbst bat um Verständnis dafür, „daß ihr in diesem Raum alle Lust zu einer ordentlichen Haushaltführung verloren gegangen ist. ${ }^{"}{ }^{1}$ In einigen Fällen mußte zudem festgestellt werden, daß völlig überzogene, an den Lebensverhältnissen in der Heimat orientierte Ansprüche Vertriebener wenig zu einer Verbesserung des Verhältnisses zu Einheimischen und Behörden beitrugen ${ }^{72}$.

Unabhängig von der Qualität der Unterbringung stellten teilweise kaum bezahlbare Mieten für zahlreiche Vertriebene ein großes Problem dar. Waren sie vor der Währungsreform vom Juni 1948 oft in der Lage, einen höheren Betrag zu zahlen, so konnten die hierzu benötigten Mittel seither in vielen Fällen nicht mehr aufgebracht werden ${ }^{73}$. Hinzu kam die Tatsache, daß ein Teil der Einheimischen offensichtlich die Not der Heimatlosen zum eigenen Vorteil nutzte. So verlangte ein Wohnungsinhaber in Meiningen, dessen dreiköpfige Familie selbst drei Zimmer und Küche nutzte, von den in jeweils einem Zimmer untergebrachten Vertriebenen (eine bzw. zwei Personen) je 25,- M Miete, während er selbst für die gesamte Wohnung 75,- M zahlte ${ }^{74}$. In Langensalza entrichtete ein Ehepaar aus Breslau bereits seit Jahren 20,- M Miete für ein Zimmer, während für die gesamte, aus drei Zimmern und Küche bestehende, Wohnung lediglich 28,- $\mathrm{M}$ aufgebracht werden mußten. In einzelnen Fällen wurden derartige Probleme schnell und unbürokratisch unmittelbar im Rahmen der Kontrollen abgestellt. So genügte ein Hinweis an die Vermieterin, um die Belastung für das erwähnte Breslauer Ehepaar um 5,- M zu sen$k{ }^{75}$. Ähnliche Fälle wurden aus Gemeinden in verschiedenen Kreisen, so z. B. aus Remstädt/Kreis Gotha gemeldet ${ }^{76}$. Andere Kommissionen forderten in besonders ungerechten Fällen eine Prüfung durch die Mietpreisüberwachungsstelle ${ }^{77}$.

${ }^{69}$ Ebenda, MinPräs., Büro des MinPräs, Nr. 444/1, Bl. 81.

${ }^{70}$ Ebenda, MdI, Nr. 686, Bl. 44 und Nr. 682, Bl. 22.

71 Ebenda, Nr. 682, Bl. 35.

72 Ebenda, Bl. 3.

73 Vgl. z. B. ebenda, Bl. $20 \mathrm{ff}$.

74 Ebenda, Nr. 683, Bl. 124.

75 Ebenda, Nr. 682, Bl. 8.

76 Ebenda, Bl. 39.

77 Ebenda, Nr. 684, Bl. 8. 
Nahezu flächendeckend zeigte sich der völlig unzureichende Ausstattungsgrad der Wohnräume mit dem lebensnotwendigsten Mobiliar und Hausrat. Die Grundlage für die diesbezüglichen Einschätzungen der Überprüfungskommissionen bildete die Umsetzung des am 27. November 1946 verabschiedeten Gesetzes „über die Versorgung von Neubürgern und Bombengeschädigten mit Hausrat." In ihm wurden alle Thüringer verpflichtet, unverzüglich ein Inventarverzeichnis über nicht nachweislich für den eigenen Bedarf benötigte Möbel und Hausratsgegenstände aufzustellen und diese Vertriebenen und Bombengeschädigten - meist leihweise - zu überlassen ${ }^{78}$. Tausende Einheimische verzichteten freiwillig auf ganze Zimmereinrichtungen, einzelne Möbelstücke, Öfen, Federbetten usw. . Beispielsweise konnte in Arnstadt und im Kreis Stadtroda in den Haushalten Vertriebener eine gute Versorgung mit Möbeln und Hausrat registriert werden. Neben der bloßen Sammlung verwiesen zahlreiche Kreise auf vielfältige andere Aktionen im Interesse der Ärmsten der Armen. So legte die Stadtverwaltung Arnstadt besonderen Wert auf die Beschaffung von Kochherden, um immer wiederkehrende Streitigkeiten bei der Benutzung gemeinsamer Küchen zu verringern ${ }^{79}$. In Altenburg erhielten Vertriebene bereits seit über zwei Jahren die Möglichkeit, sich einfache Möbel selbst herzustellen bzw. Umarbeiten vorzunehmen. An den Wochenenden wurde ihnen dazu Werkzeug und soweit vorhanden Material zur Verfügung gestellt ${ }^{80}$. In der Werkstatt der „Neubürger Tischlergemeinschaft" hatten mehrere Vertriebene zudem ein neues Arbeitsverhältnis gefunden $^{81}$. Trotz zahlreicher positiver Beispiele gab es Städte wie Jena bzw. Gemeinden, insbesondere im Kreis Schmalkalden, in denen der Mangel an Möbeln und Hausrat bei den Vertriebenen erheblich blieb, während die dringend benötigten Gegenstände bei Einheimischen ungenutzt herumstanden ${ }^{82}$. Sammlungen bei den Einheimischen, die im Rahmen zahlreicher derartiger Aktionen bereits in der NS-Zeit einen Teil ihres Eigentums zur Verfügung gestellt hatten, blieben immer erfolgloser. Auch die Herstellung neuer Möbel brachte - falls sie überhaupt möglich war - oft nicht den gewünschten Erfolg. Der im Kreis Meiningen geforderte Preis von 850,- M für ein Schlafzimmer konnte von den Vertriebenen unmöglich aufgebracht werden ${ }^{83}$. Letztendlich gelang es angesichts des allgemeinen Mangels nur, die größte Not zu mildern.

Trotz aller Probleme wurde im Rahmen der Überprüfungen der Lebensverhältnisse erreicht, daß einzelne Wohnungsinhaber bestimmte, von ihnen zumindest zeitweise nicht dringend benötigte Gegenstände den in ihren Wohnungen Eingewiesenen übergaben ${ }^{84}$. Offensichtlich erwies es sich in diesem Zusammenhang zumindest in Dörfern als günstig, daß vorrangig ortsfremde Personen in den Kommissionen tätig waren, die bei der Beschlagnahme von Gegenständen keine Rücksicht auf verwandtschaftliche und freundschaftliche Bindungen oder die soziale Stellung des Betroffenen nahmen.

Das Amt für Neubürger verwies in seinem Abschlußbericht zur Gesamtsituation in Thüringen darauf, daß die Überprüfung der Wohnraumsituation in vielen Fällen ein durchaus positives Bild gezeigt habe. Diese Feststellung unterstrich auch der Vertreter der Zentralverwaltung für deutsche Umsiedler, Kolander, der an den Kontrollen in ein-

${ }^{78}$ Regierungsblatt für das Land Thüringen, a. a. O. ., 28. Dezember 1946, S. 156.

79 ThHStA, Ld. Thür., MinPräs., Büro des MinPräs, Nr. 444/1, Bl. 70.

${ }^{80}$ Thüringer Volk, a. a. 0. ., 7. 9. 1946.

81 ThHStA, Ld. Thür., MdI, Nr. 682, Bl. 69.

82 Thüringer Volk, a. a. O. ., 8. 9. 1946.

83 ThHStA, Ld. Thür., MdI, Nr. 686, Bl. $51 \mathrm{f}$.

${ }^{84} \mathrm{Vgl}$. u. a. ebenda, Nr. 684, Bl. 12. 
zelnen Kreisen teilnahm. Während er betonte, daß sich die Fürsorge für die Vertriebenen in Thüringen positiv von der in den übrigen Ländern und Provinzen der SBZ abhob, verwies er jedoch gleichzeitig auf die in diesem Territorium ungleich günstigeren Ausgangsbedingungen ${ }^{85}$. Gleichzeitig darf nicht übersehen werden, daß es sich auch bei sogenannten "dauerhaften Wohnungen“ in der Regel um Unterkünfte in den Wohnungen Einheimischer mit allen daraus resultierenden Problemen des Zusammenlebens handelte. Außerdem mußten noch zahlreiche Vertriebene in - auch angesichts niedriger Ansprüche unbefriedigenden Verhältnissen leben. Zur Behebung vorhandener Mißstände wurde insbesondere auf die konsequente Umsetzung des Wohnungsgesetzes des Alliierten Kontrollrats verwiesen. Desweiteren sollten die zuständigen Behörden in den Kreisen, Städten und Gemeinden deutlicher prüfen, wo Wohnräume noch für gewerbliche Zwecke genutzt wurden bzw. ob ein Umzug von Behörden aus Wohnräumen in Baracken möglich wäre ${ }^{86}$. Die Vergabe wirklich menschenwürdigen Wohnraumes an Vertriebene - einschließlich eines erträglichen Ausstattungsgrades mit Mobiliar und Hausrat - konnte in Thüringen wie in allen Territorien der SBZ auch in den fünfziger Jahren noch nicht zur Zufriedenheit gelöst werden.

${ }^{85}$ Ebenda, Nr. 682, Bl. 23 f.

${ }^{86}$ Ebenda, MinPräs., Büro des MinPräs, Nr. 444/1, Bl. 84. 